PEABODY MUSEUM OF NATURAL HISTORY

YALE UNIVERSITY

BULLETIN 24

Comparative Feeding Ecology of Sea Birds of a Tropical Oceanic Island

BY

N. PHILIP ASHMOLE AND MYRTLE J. ASHMOLE

Peabody Museum of Natural History and Department of Biology, Yale University 
Bulletins published by the Peabody Museum of Natural History, Yale University, are based on research carried out under the auspices of the Museum. The issues are numbered consecutively as independent monographs and appear at irregular intervals. Shorter papers are published at frequent intervals in the Peabody Museum Postilla series.

Publications Committee: A. Lee McAlester, Chairman Theodore Delevoryas

Willard D. Hartman

Elwyn L. Simons

Keith S. Thomson

Alfred W. Crompton, ex officio

EDITOR: Jeanne E. Remington

Asst. EdrTor: Nancy A. Ahlstrom

Communications concerning purchase or exchange of publications should be addressed to the Publications Office, Peabody Museum of Natural History, Yale University, New Haven, Connecticut 06520, U.S.A. 


\section{CONTENTS}

LIST of FigURES $\ldots \ldots \ldots \ldots \ldots \ldots \ldots \ldots \ldots \ldots \ldots \ldots \ldots \ldots \ldots \ldots \ldots \ldots$, iv

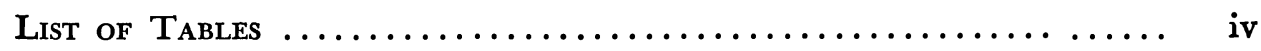

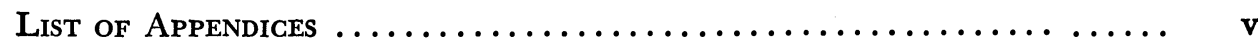

Abstracts (English, German, Russtan) $\ldots \ldots \ldots \ldots \ldots \ldots \ldots \ldots \ldots$. 1

1. INTRODUCTION

Outline of the investigation $\ldots \ldots \ldots \ldots \ldots \ldots \ldots \ldots \ldots \ldots \ldots, \quad 5$

Christmas Island and its sea bird populations ............. 8

2. Techniques

Collection of samples $\ldots \ldots \ldots \ldots \ldots \ldots \ldots \ldots \ldots \ldots \ldots \ldots, 11$

Laboratory treatment $\ldots \ldots \ldots \ldots \ldots \ldots \ldots \ldots \ldots \ldots \ldots \ldots, 11$

Methods of analysis $\ldots \ldots \ldots \ldots \ldots \ldots \ldots \ldots \ldots \ldots \ldots \ldots \ldots, 12$

3. Species Accounts

Phaethon rubricauda Red-tailed Tropic-bird ............... 19

Puffinus nativitatis Christmas Island Shearwater ............. 27

Pterodroma alba Phoenix Petrel ....................... 30

Sterna fuscata Sooty Tern .......................... 33

Anous stolidus Brown Noddy ......................... 34

Gygis alba White Tern ............................... 36

Anous tenuirostris Black Noddy ...................... $\quad 39$

Procelsterna cerulea Blue-grey Noddy .................. 41

4. Comparison and Summary of the Diets of the Birds

Proportions of fish, squid, and other items ............... 44

Size of food items ................................ 47

Representation of different kinds of fish and squid ........... 49

5. Food of Surface-caught Yellowfin Tuna $\ldots \ldots \ldots \ldots \ldots \ldots \ldots, 52$

6. The Birds in Their Marine Environment

The environment, and the availability of food $\ldots \ldots \ldots \ldots \ldots \ldots . \quad 55$

Feeding zones, and adaptations for feeding far from the colony .... 61

Feeding methods, and associated structural adaptations ......... 70

7. Seasonal Considerations

Seasonal variation in the environment $\ldots \ldots \ldots \ldots \ldots \ldots \ldots \ldots . .62$

Seasonal variation in the food of the birds $\ldots \ldots \ldots \ldots \ldots \ldots \ldots . .63$

Seasonal variation in breeding activities $\ldots \ldots \ldots \ldots \ldots \ldots \ldots \ldots . \quad 89$

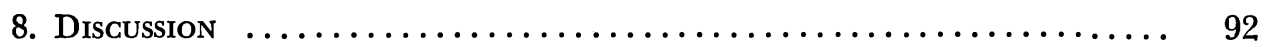

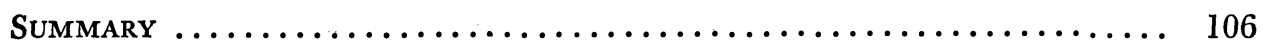

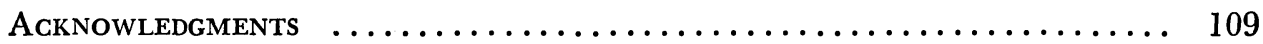

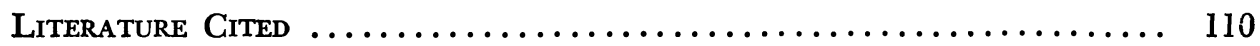




\section{LIST OF FIGURES}

1. Breeding activity among eight species of sea birds on Cook Island and Motu Tabu (both in the lagoon of Christmas Island), based on observations made during the series of visits by N. P. A. in 1963 and 1964,

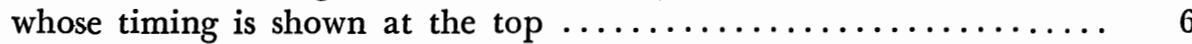

2. Major features of the Central Equatorial Pacific Ocean ......... 8

3. Percentage composition of samples from eight species of sea birds and from surface-caught Yellowfin Tuna ................... 14

4. Size-frequency distribution of fish and squid in the diets of the birds... 22

5. Important fish families in the diets of the birds $\ldots \ldots \ldots \ldots \ldots \ldots .26$

6. Bills of the sea birds studied on Christmas Island: natural size photographs of specimens preserved in alcohol ............... 70

7. Feeding methods employed by the sea birds studied ........... 71

8. Seasonal variation in the proportions (by volume) of the major food

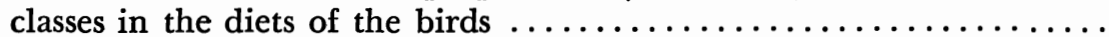

9. Seasonal variation in the size of the fish and squid in the diets of four

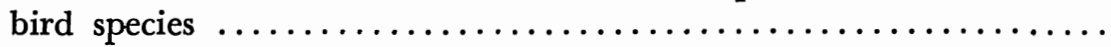

10. Seasonal variation in the representation (by number) of some important fish families in the diets of Sterna fuscata, Gygis alba, and Anous

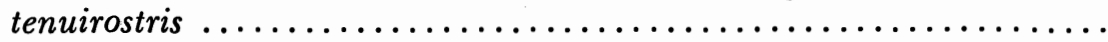

11. Two views of a dense flock of Anous tenuirostris feeding over a tuna school close to the western end of Christmas Island

\section{LIST OF TABLES}

1. The sea bird populations of Christmas Island $\ldots \ldots \ldots \ldots \ldots \ldots$

2. Food samples from sea birds on Christmas Island: general information and condition of samples $\ldots \ldots \ldots \ldots \ldots \ldots \ldots \ldots \ldots \ldots \ldots \ldots \ldots$

3. Percentage composition of food samples from the bird species ...... 20

4. Volumes of food items in samples from the bird species . . . . . . . . 24

5. Length of fish and squid in the diets of the birds: cumulative percentages 28

6. Invertebrates other than cephalopods in the diets of Pterodroma alba

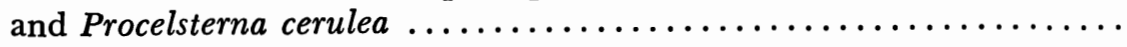

7. Length of incubation shifts of some sea birds on Christmas Island, and percentages of identified fish in their diets belonging to primarily reef-

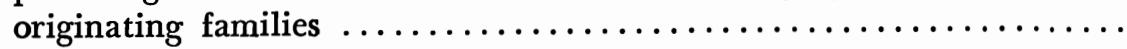

8. Mean dimensions of some Christmas Island sea birds ............

9. Frequency of occurrence of fish and squid obtained from Gygis alba adults at different times of day $\ldots \ldots \ldots \ldots \ldots \ldots \ldots \ldots \ldots \ldots \ldots \ldots \ldots \ldots \ldots \ldots$ 


\section{LIST OF APPENDICES}

1. Composition of food samples: basic data $\ldots \ldots \ldots \ldots \ldots \ldots \ldots \ldots, 117$

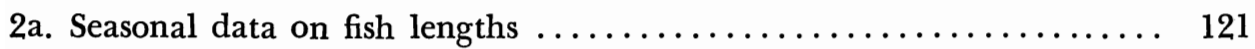

2b. Seasonal data on squid mantle lengths $\ldots \ldots \ldots \ldots \ldots \ldots \ldots \ldots . \ldots \ldots$

3. Fish families in the diets of the birds: number of fish identified in each

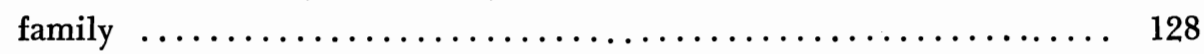

4. Cephalopods in the diets of the birds $\ldots \ldots \ldots \ldots \ldots \ldots \ldots \ldots \ldots, 130$

5. Details of the stomach contents of 191 Yellowfin Tuna (Neothunnus macropterus), caught by surface-trolling within 10 miles of Christmas, Jarvis, Washington and Fanning Islands (Line Islands) $\ldots \ldots \ldots \ldots, 131$ 

Comparative feeding ecology of sea birds of a tropical oceanic island

\author{
by N. Philip Ashmole and Myrtle J. Ashmole
}

\begin{abstract}
In 1963 and 1964, 800 food samples, regurgitated or dropped by captured birds, were collected on Christmas Island (Pacific Ocean) from Phaethon rubricauda, Puffinus nativitatis, Pterodroma alba, Sterna fuscata, Anous stolidus, Gygis alba, Anous tenuirostris and Procelsterna cerulea. Food items were counted, measured, and identified as far as possible. The diets are analysed by number, by volume, and by frequency of occurrence of the different food classes, and the size of the prey taken by the different birds is compared. Fish (from many families, but especially Exocoetidae) and squid (mainly Ommastrephidae) formed the bulk of the food; fish were especially important in $A$. tenuirostris and Pr. cerulea, and squid in Pt. alba and P. nativitatis. Pt. alba and $P r$. cerulea took many invertebrates other than squid, including insects (Halobates) and crustaceans. Although the large birds in general took much larger prey than the small ones, the petrels $P$. nativitatis and Pt. alba took fewer large fish than the smaller terns S. fuscata and A. stolidus. The diet of surface-caught Yellowfin Tuna (Neothunnus macropterus) differed from that of the birds in that fewer squid but more other invertebrates were eaten, while the representation of the various fish families was very different.

The oceanography of the Central Equatorial Pacific is considered in relation to the distribution of surface-feeding tunas, which drive their prey to the surface and so make it available to birds. Concentrations of plankton and nekton at "fronts" may have important effects on the distribution of tunas and of birds. Seasonal variation in the environment is slight, and only $\boldsymbol{A}$. tenuirostris showed striking differences in its diet at different seasons. Some of the birds feed close inshore, but others range far from land even when breeding, and have various adaptations for this, including long incubation shifts, infrequent feeding of the young, and in Pt. alba, secretion of stomach oil. Only Ph. rubricauda and $P$. nativitatis can catch prey appreciably below the surface; all the other species feed mainly by "Dipping" or "Plunging to surface," but their feeding methods differ in detail.

Numbers of most of the species were probably limited originally by competition for available food. Among the birds which are not closely related, reduction of interspecific competition to the level permitting coexistence depends mainly on differences in feeding methods, feeding zones and feeding times. Among the closely related species it depends more on differences in body size and in the other morphological characteristics determining the size of the prey.
\end{abstract}


Vergleichende Nahrungs-Oekologie bei Seevögeln einer

tropischen Ozeaninsel

von N. Philip Ashmole und Myrtle J. Ashmole

\section{ZUSAMMENFASSUNG}

1963 und 1964 wurden 800 Nahrungsproben, von gefangenen Vögeln entweder fallengelassen oder wiederausgestossen, von Phaethon rubricauda, Puffinus nativitatis, Pterodroma alba, Sterna fuscata, Anous stolidus, Gygis alba, Anous tenuirostris und Procelsterna cerulea auf Christmas Island (Pazifik) gesammelt. Die einzelnen Bestandteile der Nahrungsproben wurden so weit als möglich gezählt, gemessen und identifiziert. Die Art der aufgenommenen Nahrung wird zahlen- und volumenmässig und nach der Häufigkeit des Auftretens der verschiedenen Nahrungs-Klassen analysiert und die Grösse der Beute bei den verschiedenen Vögeln wird verglichen. Fisch (von vielen Familien, aber hauptsächlich Exocoetidae) und Tintenfisch (hauptsäschlich Ommastrephidae) machten den Hauptanteil der Nahrung aus. Fische waren besonders wichtig für $A$. tenuirostris und $P r$. cerulea, und Tintenfische für $P t$. alba und $P$. nativitatis. Pt. alba und Pr. cerulea nahmen viele Wirbellose ausser Tintenfisch an, einschliesslich Insekten (Halobates) und Krustentiere. Obwohl die grossen Vögel im allgemeinen eine viel grössere Beute brachten als die kleinen, nahmen die Sturmvögel $P$. nativitatis und $P$. alba weniger grosse Fische an als die kleineren Seeschwalben $S$. fuscata und $\boldsymbol{A}$. stolidus. Die Nahrung der an der Oberfläche gefangenen Gelbfinnigen Tuna (Neothunnus macropterus) unterschied sich von der der Vögel darin, dass weniger Tintenfische aber mehr andere Wirbellose aufgenommen wurden, während die verschiedenen Fischfamilien sehr unterschiedlich vertreten waren.

Die Ozeanographie des zentralen äquatorialen Pazifik wird in Hinblick auf die Verteilung der Tuna betrachtet, die an der Oberfläche Nahrung aufnehmen, ihre Beute an die Oberfläche treiben und so für die Vögel erreichbar machen. Konzentration von Plankton und Nekton bei "fronts" kann von grosser Wirkung auf die Verteilung von Tuna und von Vögeln sein. Jahreszeitliche Variation in der Umwelt ist gering und nur $\boldsymbol{A}$. tenuirostris zeigte zu verschiedenen Jahreszeiten auffällige Unterschiede in den Nahrungsgewohnheiten. Einige der Vögel nehmen Nahrung nahe der Küste auf, andere dagegen weit vom festen Land entfernt, sogar während des Brütens, und haben dafür verschiedene Anpassungsmöglichkeiten, einschliesslich langer Schichtwechsel beim Brüten, seltene Fütterung der Jungen, und, bei Pt. alba, Absonderung von Magenöl. Nur $P h$. rubricauda und $P$. nativitatis können Beute merklich unter der Oberfläche fangen. Alle die anderen Arten nehmen Nahrung hauptsächlich auf, indem sie nur bis zur Oberfläche niederstossen ("Dipping") oder sich fallen lassen ("Plunging to surface"), aber ihre Methoden differieren untereinander in Einzelheiten. 
Der Zahlen-Bestand dur meisten der Arten war wahrscheinlich ursprünglich beschränkt durch den Wettbewerb für erreichbare Nahrung. Unter den Vögeln, die nicht eng verwandt sind, hängt der Ausgleich des Nahrungs-Kampfes zwischen den Arten zur Koexistenz hauptsächlich ab von den Unterschieden bezüglich der Art, der Zone und der Zeit der Nahrungsaufnahme. Bei den eng miteinander verwandten Arten hängt der Ausgleich eher ab von Unterschieden in Körpergrösse und anderen morphologischen Eigentümlichkeiten, die die Grösse der Beute bestimmen.

\section{Сравнительная Экология Питания Морских Птиц на Тропическом 0кеанском 0строве}

\section{Н. Филип Ашмол и Мэртл Дж. Ашмол}

\section{ABCTPAKT}

800 образцов пищи, изрыганной или брошенной пойманными птицами, было собрано в 1963 и 1964 годах на Рождественском острове в Тихом океане от Phaethon rubricauda, Puffinus nativitatis, Pterodroma alba, Sterna fuscata, Anous stolidus, Gygis alba, Anous tenuirostris, Procelsterna cerulea. Единицы пищи были сосчитаны, смерены, и по возможности опознаны. Образ питания изучается по qислу, количеству, и чистоте повторения разных сортов пищи. Сравнивается величина добычи, взятая разными птицами. Рыба (многих родов, но особенно Exocoetidae) и каракатицы (главным образом Ommastrephidae) составляли больпую часть пищи. Рыба была особенно важной для $A$. tenuirostris и $P r$. cerulea a каракатицы для Pt. alba и $P$. nativitatis. Pt. alba и Pr. cerulea брали многих беспозвоночных помимо каракатиц, включая насекомых (Halobates) и ракообразных. Хотя большие птицы обыкновенно брали добычу бо́льшего размера, чем маленькие, вилохвостые качурки $P$. nativitatis и $P t$. alba брали меньшее количество больших рыб чем меньшие по размеру крачки $S$. fuscata и $A$. stolidus. Пища желтоплавникового тунща (Neothunnus macropterus) отличается от пищи птиц тем, что пожирается меньше каракатиц и больпе других бевповвоночных животных, а также тем, что роды пожираемых рыб совершенно другие.

0кеанографоия центрального экваториального Тихого океана была учтена в отношении к распределению тунща, питающегося у поверхности воды. Тунец гонит добычу к поверхности воды и таким образом предоставляет ее птицам. Концентрации планктона и нектона на «фронтах» может сильно повлиять на распределение тунца и птиц. Сезонные изменения незначительны, и только A. tenuirostris существенно меняет образ питания с сезона на сезон. Некоторые птицы питаются у берега, другие отлетают далеко от земли, будучи приспособленными к этому: длинные смены высиживания, редкий корм птенцов, и выделение желудочного масла (у Pt. alba). Только Ph. rubricauda и $P$. nativitatis добывают пищу на значительной глубине под поверхностью воды; все другие породы кормятся окунаясь или падая на поверхность, хотя методы кормления отличаются в деталях.

Численность большинства пород вероятно была ограничена соревнованием в добыче пищи. Среди птиц, не состоящих в близком родстве, понижение межвидовой конкуренции до уровня, позволяющего совместное существование, зависит главным образом от разницы в способах, раенах, и временах питания. Среди более родственных пород, более существенную роль играет разница в величине тела и те другие морфологические особенности, которые определяют величину добычи. 



\title{
COMPARATIVE FEEDING ECOLOGY OF SEA BIRDS OF A TROPICAL OGEANIC ISLAND ${ }^{1}$
}

\author{
by N. PHILIP ASHMOLE and MYRTLE J. ASHMOLE
}

\section{INTRODUCTION}

\section{OutLine OF THE INVESTIGATION}

This analysis of the food of sea birds on Christmas Island forms part of a study whose object was to describe and compare the sexual and molt cycles of various species of sea birds and to try to relate them to the feeding ecology of the different species.

In the course of routine work, several thousand birds were handled, and some individuals of all the species regurgitated (or dropped) food, which was collected and preserved. In addition, some catching was carried out with the prime objective of obtaining food samples. It is the analysis of the $800 \mathrm{food}$ samples obtained which forms the basis of this paper.

Samples were collected on eight fairly evenly spaced visits to the island between March 1963 and February 1964, with a single later visit in June 1964 (Fig. 1: the short visit at the end of November 1963 was treated as part of the preceding visit, while the January 1964 visit was interrupted for a few days in the middle of the month). It is thus possible to compare food obtained at different seasons, an obviously necessary preliminary to understanding the breeding regimes of the different species. It was unfortunately not practicable to sample directly the availability of food organisms in the area of Christmas Island during the course of the study. However, some relevant information is provided by the publications of the Pacific Oceanic Fishery Investigations (now the Biological Laboratory, Honolulu) of the Bureau of Commercial Fisheries, U.S. Fish and Wildlife Service.

Since samples were obtained from eight species, including all the most abundant of the smaller sea birds breeding on the island, the analysis represents an attempt to determine the degree of difference to be found in the food and feeding habits of the various members of a sea bird community typical of tropical oceanic islands. All the species feed in the surface layers of the sea, and it is clear that there are considerable possibilities for competition for food, both within and between species. Furthermore, in contrast with some other oceanic islands, Christmas Island appears to offer, for nearly all the species con-

1 Published with the aid of a National Science Foundation Publication Grant No. GN-528. 
PERIODS SPENT ON

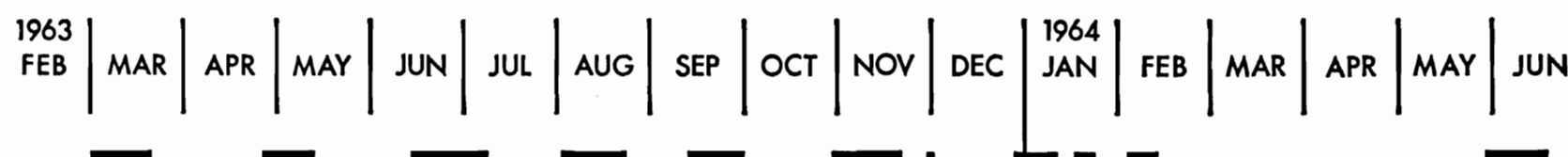
CHRISTMAS ISLAND

PERIODS IN WHICH FOOD SAMPLES WERE COLLECTED

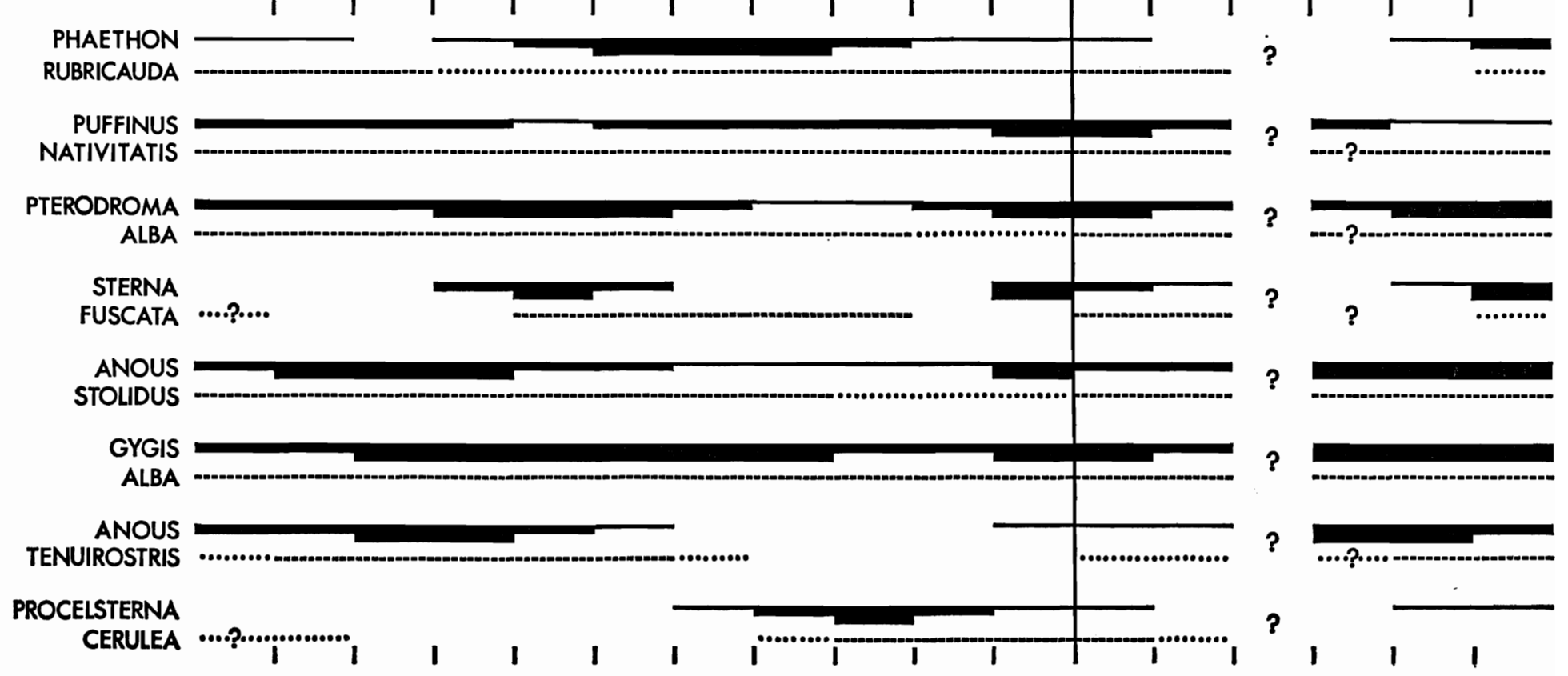


FIGURE 1. Breeding activity among eight species of sea birds on Cook Island and Motu Tabu (both in the lagoon of Christmas Island), based on observations made during the series of visits by N.P.A. in 1963 and 1964, whose timing is shown at the top.

For each species, the upper line indicates the presence of eggs, the lower line the presence of unfledged chicks. For eggs, the thinnest line indicates that only a few birds had eggs, the next that a substantial proportion of the population had eggs, and the thickest that eggs were close to their maximum abundance. For chicks only two categories are employed, the dotted line indicating the presence of a few chicks and the dashed line substantial numbers.

Information on the breeding schedules of the other species of sea birds on Christmas Island is available as follows. Puffinus pacificus: Gallagher (1960) recorded a well-marked summer breeding season with laying mainly in May; observations in 1963-64 indicated a similar breeding schedule. Nesofregetta albigularis: inadequate data, but Gallagher recorded nests in November and from January to May, while N.P.A. found a fresh broken eggshell in a burrow in September 1963; probably there is a diffuse winter breeding season. Sula dactylatra: Gallagher's statement that there was some breeding all the year, but with a peak (presumably of laying) in June-August, does not conflict with our sparse data for 1963-64. Sula sula: can be found breeding at all times of year, but mainly in summer. Sula leucogaster: Gallagher suggested that there might be a summer peak in breeding: on 31 May 1964 a small colony contained nests with eggs and with small chicks, and there was one larger chick and an empty new nest. Fregata minor: has a definite summer breeding season, with laying mainly in April and May in 1963 and 1964; however, some eggs are probably laid a good deal later. Fregata ariel: breeding is closely synchronized, with laying in 1964 mainly around the end of April and the beginning of May; in 1963 the peak was within a month of the same time. Sterna lunata: Gallagher records fresh eggs in late December 1958, but in 1964 laying was spread between the last days of February and at least the early part of May. Thalasseus bergii: in 1959 laying on Cook Island was between March and April or May (Gallagher), but in 1963 it was from early February into March, and again from late December at least into early February 1964. The last two species clearly merit further study, since they either show extremely variable but basically annual breeding, or they have cycles like that of S. fuscata on Ascension Island, in which the breeding of the members of the population is reasonably well synchronized, but the period of the cycle is less than twelve months. 
cerned, a much larger number of suitable breeding sites than are actually occupied. It is thus highly probable that the populations of the various species are ultimately limited by the availability of food (Ashmole 1963a), although certain species may have recently been adversely affected by man's activities.

\section{Christmas Island and its Sea Bird Populations}

Christmas Island, the largest member of the Line Island group in the central Pacific, lies about 1,200 miles south of Hawaii at $02^{\circ}$ N., $157^{\circ}$ W. (Fig. 2). The

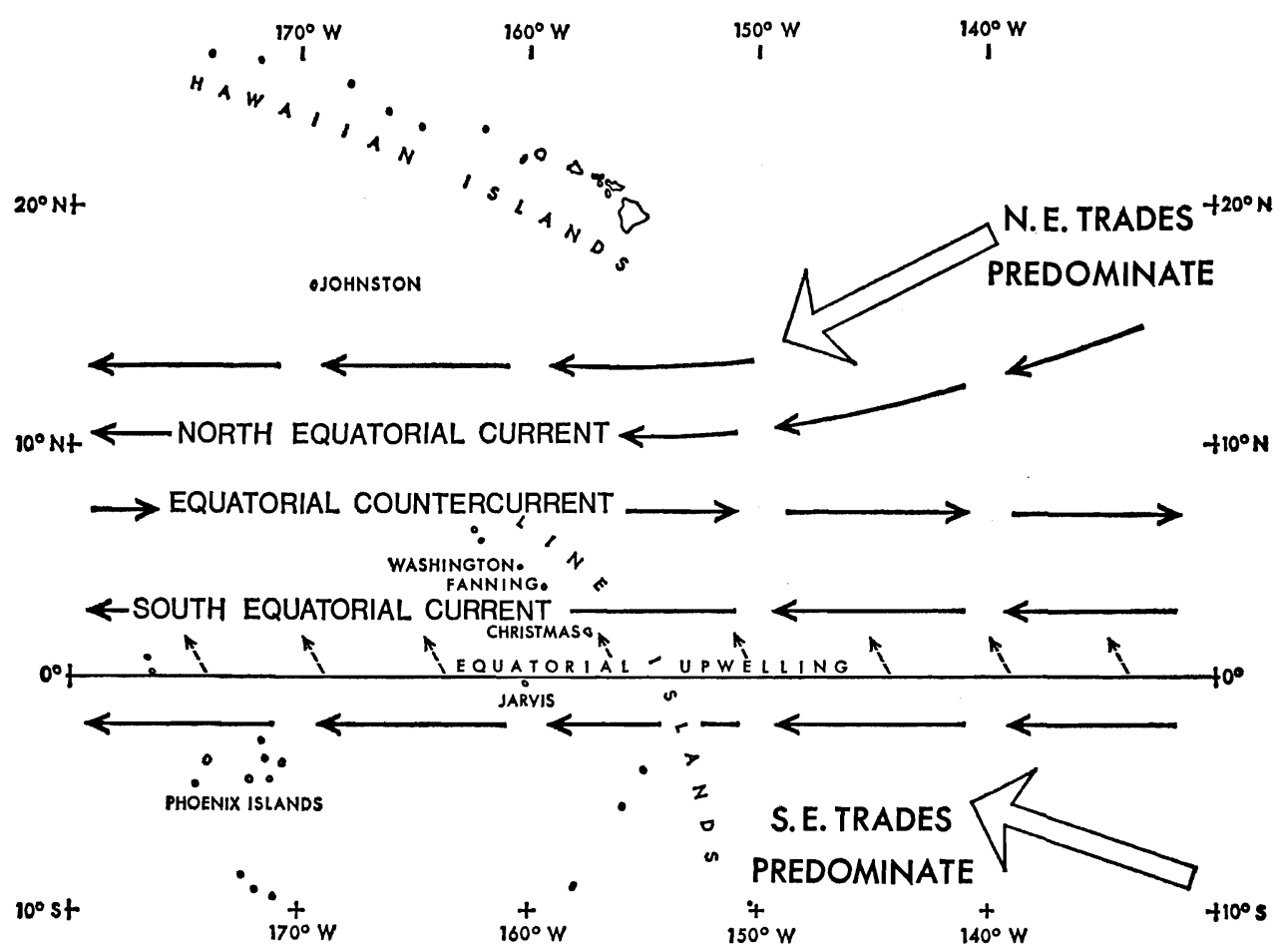

FIGURE 2. Major features of the Central Equatorial Pacific Ocean.

closest other island is Fanning Island, about 165 miles to the northwest, while to the southwest Jarvis Island is about 220 miles away. The Line Islands as a group are one of the most distant from continental land, North America being over 3,000 miles to the northeast.

Christmas Island is a coral atoll with a total length of 32 miles and a breadth of 15 miles at its western end. The eastern part of the island is solid land with various landlocked lagoons, the central part is a maze of small islets and lagoons, while at the western end is an enormous shallow lagoon which has two connections with the sea. This lagoon contains a number of islets, of which three have large colonies of sea birds, and birds also nest in several parts of the main island. The total land area of Christmas Island is about 330 square miles, while the main lagoon has an area of 142 square miles. The maximum depth of the lagoon is only about 15 feet, but the seaward slopes of the island are steep, 
TABLE 1. The sea bird populations of Christmas Islanda

\begin{tabular}{|c|c|}
\hline 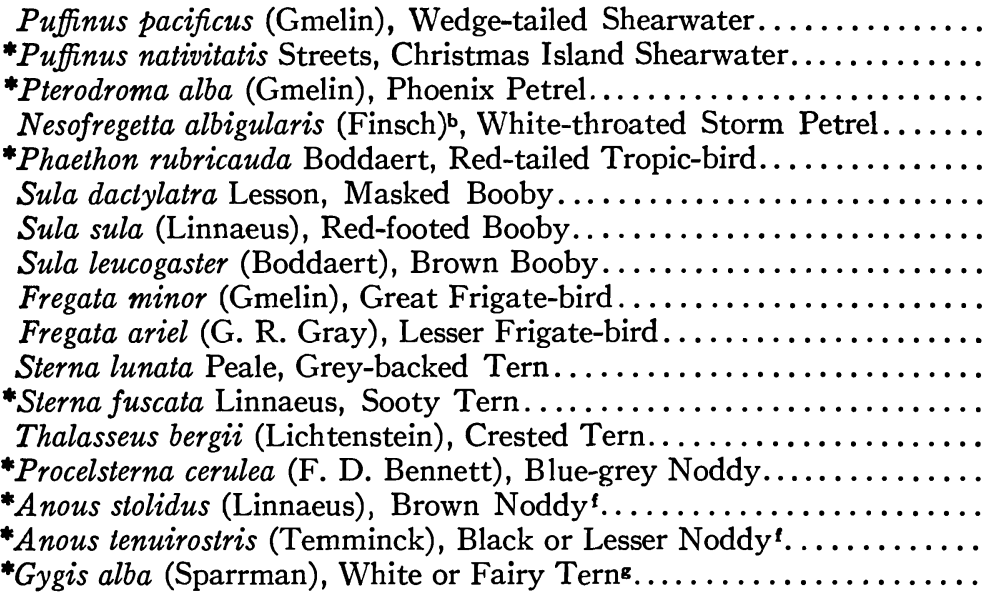 & $\begin{array}{r}2,500 \\
7,000 \\
6,100 \\
100 \\
1,300 \\
100 \\
600^{\circ} \\
100 \\
600^{\circ} \\
2,000^{d} \\
1,000 \\
1,000,000^{\circ} \\
200 \\
3,300 \\
1,900 \\
15,000 \\
1,800\end{array}$ \\
\hline
\end{tabular}

EXPLANATION. All sea birds known to breed regularly on the island are included. The figures quoted are based on estimates made by personnel of the Pacific Ocean Biological Survey Program of the Smithsonian Institution during three visits to the island in March, June and November 1964. For each species the estimates of the numbers of adults present on the main island and the three islets Motu Tabu, Motu Upua and Cook Island were summated for each visit, and the highest of the three totals was used, rounded to the nearest 100 . The figures do not represent the total breeding populations, but do give an idea of the relative abundance of the various species.

* Species whose food was studied are marked with an asterisk.

\section{NOTES FOR TABLE 1:}

a. Nomenclature is from Peters $(1931,1934)$, except that Anous minutus is considered as conspecific with $A$. tenuirostris (following Mayr 1945), and diareses are omitted from Phaethon and Anous in accordance with the International Code of Zoological Nomenclature (1961) Article 27. Trinomials are not used since they are unnecessary for present purposes: furthermore, several of the species are so badly in need of revision that subspecific assignment would be misleading.

b. This should probably be considered a form of Fregetta fuliginosa (Gmelin): see Bourne (1957).

c. These figures are probably underestimates, since not all the mainland colonies were visited consistently.

d. This figure is the estimate made by N. P. A. during a visit in 1964 to the colony recorded by Gallagher (1960).

e. It is particularly difficult to make a realistic estimate of the numbers of this species.

f. For the sake of uniformity we recommend the adoption of the English names Brown Noddy and Black Noddy respectively for $A$. stolidus and $A$. tenuirostris, as recommended by Robertson, Paulson and Mason (1961).

g. As pointed out by Eisenmann (1955), "White Tern" is the least confusing English name for this species, since "Fairy Tern" is applied to Sterna nereis. 
the 100 fathom line being generally less than a mile from the shore. A fuller description of the island is available in Gallagher (1960), and its history has been briefly described by King (1955).

The sea bird community of Christmas Island is both large in terms of numbers of individuals and unusually rich in species. General accounts of the birds have been given by various authors, especially King (1955) and Gallagher (1960). Recently the island has been visited regularly by personnel of the Pacific Ocean Biological Survey Program of the Smithsonian Institution, who have made estimates of the numbers of birds present on each visit. These estimates, kindly made available by the Smithsonian Institution, form the basis of Table 1, which gives an indication of the relative numbers of the 17 species of sea birds which are known to breed regularly on the island. The Procellariiformes are represented by two shearwaters, one gadfly petrel (Pterodroma) and one storm petrel; the Pelecaniformes by one tropic-bird, three species of boobies and two frigate-birds; and the Laridae by no less than seven species of terns.

It can be seen from Table 1 that among the larger species the numbers of Sula dactylatra and $S$. leucogaster are small, while $S$. sula is much more abundant. The two shearwaters and the gadfly petrel are present in roughly equal numbers, while the population of Nesofregetta albigularis is very small. Among the terns Sterna fuscata is by far the most abundant, but the population of Anous tenuirostris is also very large, and there are substantial numbers of all the other terns. The population of Thalasseus bergii, though absolutely small, is relatively dense since this species apparently feeds entirely within the lagoon and along the coastal beaches, whereas the other terns feed almost entirely at sea.

In the present study it was necessary to concentrate attention on the species which bred on two islets (Cook Island and Motu Tabu) in the main lagoon. This meant that among the Pelecaniformes only Phaethon rubricauda could be studied, but all three larger species of Procellariiformes and six of the seven species of tern were available. In practice, however, Puffinus pacificus and Thalasseus bergii could not conveniently be investigated in any detail. Islets in the lagoon (Cook Island, Motu Tabu and Motu Upua) are the main breeding places for all the birds studied except Sterna fuscata. This species has enormous colonies in various parts of the main island (Gallagher 1960), but the relatively small colony on Cook Island was the most convenient for investigation.

To facilitate comparisons, the eight bird species studied are treated hereafter in order of decreasing weight (Table 2; but see also Table 8, which gives other dimensions of the birds). 


\section{TECHNIQUES}

\section{Collection of SAMples}

All the food samples were collected from Cook Island or Motu Tabu, with the exception of one batch of samples (March 1963) from a mainland colony of $S$. fuscata. However, in the analysis and discussion all samples are considered as representing the food of the species on Christmas Island as a whole.

In addition to the collection of regurgitations produced by adults and chicks during routine handling, special efforts were made to catch individuals of certain species at times when they were likely to provide samples. For instance, adult Puffinus nativitatis and Pterodroma alba were always caught when seen with chicks at night, since they often regurgitated under these circumstances. Most samples from Anous stolidus and $A$. tenuirostris were obtained from roosting birds, while Procelsterna cerulea often regurgitated if caught as they returned to the island in the evening. A few regurgitations were obtained from roosting Gygis alba, but this species, alone among those studied, carries food for the young in its bill, and most samples were obtained by systematic attempts to catch (with a large long-handled net) all individuals seen carrying food.

Regurgitations (and items dropped by G. alba) were carefully collected off the ground, often with the help of a spoon; however, on occasions some food was inevitably lost. All samples were labeled with the species, date, and locality, and were preserved in formalin in individual containers for later analysis.

\section{LABORATORY TREATMENT}

Typical regurgitations contained fish and squid in various stages of digestion (the squid often with the head separated from the mantle), and also fragments of largely digested fish and squid. In addition, according to the bird species, there might be squid eye-lenses, squid beaks, severed squid arms, oil or other invertebrates.

Each sample was cleaned of sand and plant debris, and the contents were sorted initially into fish, squid, and other invertebrates. Subsequently the fish in sufficiently good condition were identified to the family level; some generic and specific identifications were made, and these are given in Appendix 3. The 869 squid collected during the first half of the study (from March to September 1963) were identified by Dr. Malcolm R. Clarke (Appendix 4); since these proved to be almost entirely of one family-and in fact largely of one species -the squid were not identified during the remainder of the study. Invertebrates other than squid occurred in significant quantity in samples from only two of the bird species: they were identified as far as possible.

The items in each food class in each sample were counted. When the food was in an advanced stage of digestion, it was often difficult to determine exactly how many items were represented, and certain arbitrary rules were followed. If the only fish materials in a sample were vertebrae, one fish was recorded as 
present. If the only squid materials were beaks, one squid was counted, regardless of the number of beaks that were present, since it is likely that beaks are retained for long periods in the stomachs of certain species, and thus do not represent only the most recent meal. Also, if 5 squid mantles and 6 heads were present 6 squids were recorded.

Two additional small points should be mentioned here. First, crustacean ectoparasites of fish were considered as food items when they occurred in the samples, even though they were probably not eaten intentionally. Second, it is possible that in some of the more digested samples, food items from the stomachs of fish and squid subsequently eaten by birds may have been considered as separate items in the diet of the birds. However, we are of the opinion that this was a very infrequent occurrence.

Volumes of all the food items were measured by displacement. These measurements were of course frequently of partially digested objects, and thus do not always represent the size of the objects at the time of capture, although they are probably reasonably proportional to the latter. In addition, lengths of all fish and squid were measured individually. For fish the measurement used was from the most anterior point to the base of the tail: this was easier than using either total length or 'fork length,' since the tails were frequently damaged. For squid, the maximum (dorsal) mantle length was used, rather than the total length of the animal, because the heads were frequently not attached. Each fish, or squid mantle, was recorded as Grade 1, Grade 2 or Grade 3 according to its condition. Grade 1 items were those in good condition, whose length could be measured accurately; Grade 2 items were slightly broken or digested, but fairly accurate measurements could be obtained; Grade 3 items were largely digested but were assigned to length classes spanning 1, 2, 4 or occasionally 8 $\mathrm{cm}$ by estimating their original length. This system made it possible to use all the data in parts of the analysis, but to restrict the treatment to the best data where appropriate. Volumetric measurements were also made of the fragments of fish and squid which could not be considered as separate food items.

\section{Methods of Analysis}

In any study of the food of an animal species, it is clearly necessary to identify, at least approximately, the various food items. However, since many animals take a wide variety of foods, including some which occur only rarely and are of negligible importance in the diet, a simple list of the food items obtained from a given species is of little value, and it is essential also to utilize quantitative methods. Hartley (1948) discussed various quantitative methods employed in the analysis of bird foods, while Reintjes and King (1953), in a paper on the food of tunas, included a discussion of methods of analysis which is largely relevant also to birds.

For both birds and fish, there are three principal methods of basic analysis, which can be applied to stomach contents or to regurgitations. Each of the methods requires initial sorting of the food into food classes or groups, which may be individual food species or appropriate higher categories if precise identification is not practicable. After this, the first method involves recording the total numbers of items in each food class, the second uses the volumes or weights of 
the different food classes in each sample, while the third-frequency-of-occurrence analysis-is based on the proportion of samples in which each food class is present, regardless of quantity. Any of the three basic methods may be supplemented by additional techniques, of which the most important are measurement of the nutritive values of the different food classes (Gibb and Betts 1963, Kahl 1964), and determination of the size-frequency distributions of the items in each food class (as in Bowman 1961). The latter is especially important in comparing the feeding ecology of species taking generally similar foods in the same area, as in the present study. One additional technique is that of estimating the original weight of the food items (Madsen and Spärck 1950, Bowmaker 1963, Skokova 1963). Use of this technique-which requires considerable knowledge of the food items concerned-can add considerably to the information gained from partly digested food.

The three basic methods of analysis provide indications of rather different aspects of the feeding ecology of the species. A food class which is present in very high numbers must clearly be abundant, and the bird must be well adapted to catching it. However, a numerical analysis alone gives little indication of the importance of each food in the diet of the bird, since it ignores the size of the food items. One serious consequence is that one or a few atypical samples can exert a disproportionate effect. To take a case from our own experience, one sample from G. alba contained, in addition to one fish with a volume of $0.5 \mathrm{ml}$, 19 fish larvae with an aggregate volume of $0.2 \mathrm{ml}$; a more typical sample obtained on the same day contained two squid with a total volume of $2.1 \mathrm{ml}$. In a solely numerical analysis the second sample would exert only one tenth of the effect of the first, although it was three times as large. This problem is overcome by measurement of the volume (or weight) of the various foods in each sample, to obtain indications of the relative general importance of the various food classes in the diet of the bird. However, neither numerical nor volumetric analysis indicate the frequency with which the different foods are available; for instance, an extremely abundant food might be eaten exclusively for a time, but be available only for a short period. Frequency-of-occurrence analysis provides the necessary information as to whether a food is consistently available (and attractive) to the bird, and so is a reliable food source.

The very different impressions which may sometimes be conveyed by the three different types of analysis are well demonstrated by the top two species in Fig. 3. Comparing the diets of the two species by number alone, fish would appear to be much more important in P. nativitatis than in Ph. rubricauda, but reference to the volumes shows that in terms of bulk, the reverse is the case. Furthermore, the frequency-of-occurrence figures show that in $P$. nativitatis, although fish are present in much greater numbers than squid, they occur with slightly less regularity.

Both Hartley (1948) and Reintjes and King (1953) concluded that it is essential to apply more than one method of analysis in order to obtain a valid picture of the diet of the animal concerned; this is especially true when it is necessary to compare the feeding ecology of different species, or of a single species at different seasons. However, analysis by volume (or weight) is perhaps the most important method, and some workers have concentrated on it; one 


\section{NUMBER VOLUME FREQUENCY OF OCCURRENCE}

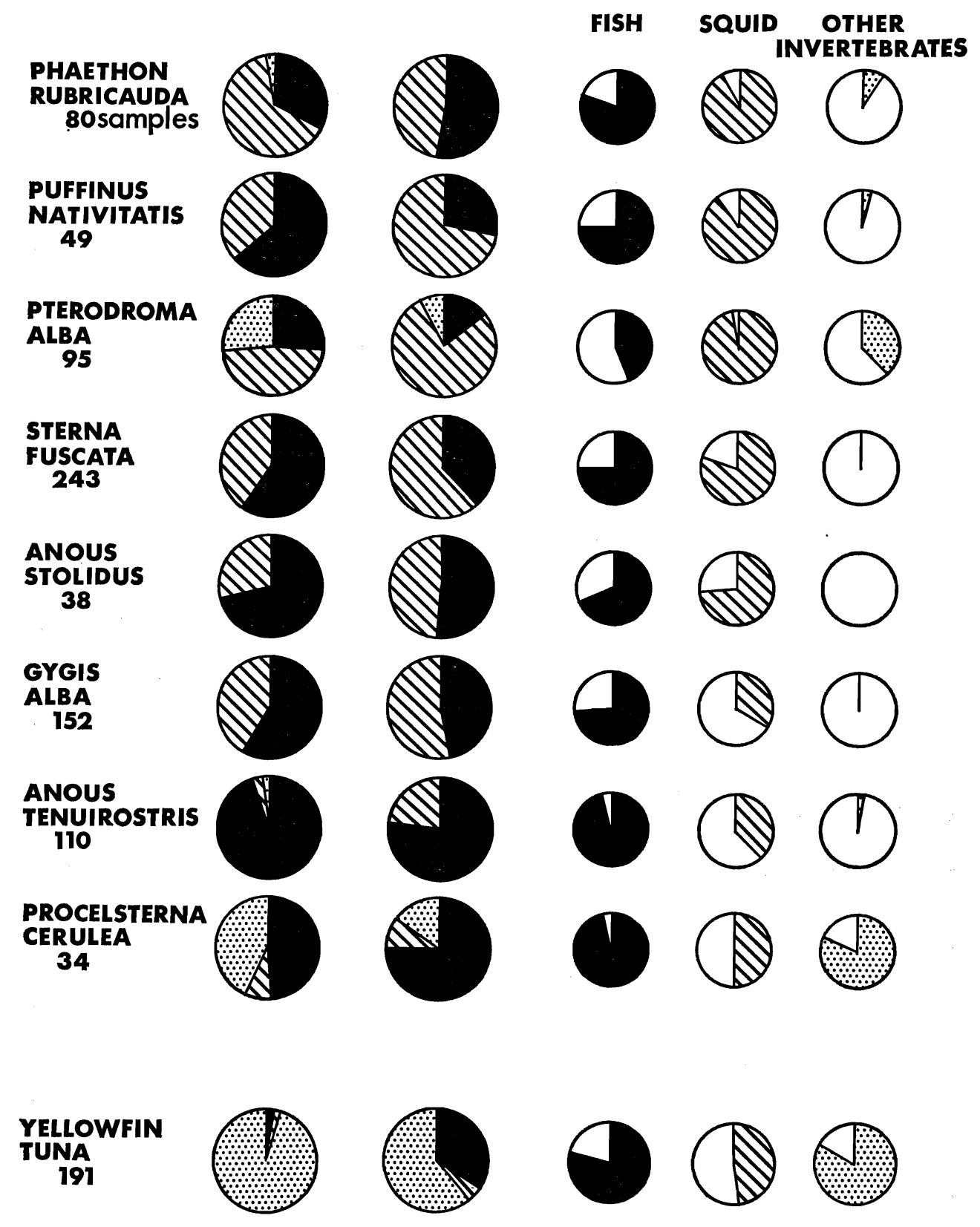

FIGURE 3. Percentage composition of samples from eight species of sea birds and from surface-caught Yellowfin Tuna.

Each complete circle represents $100 \%$. Solid black is used for fish, diagonal lines for squid, and dots for other invertebrate food. Figures below the names indicate the number of samples obtained from each species. The Frequency of Occurrence diagrams indicate the percentage of samples in which each food class was represented. 
example is Frith's (1959) fine study of the ecology of ducks in New South Wales. On the other hand Carrick (1959), in his work on the feeding of two species of ibis, Threskiornis spinicollis (Jameson) and T. molucca (Cuvier), used only analysis by number and frequency of occurrence, since he was investigating primarily the effect of ibis predation on locust numbers. Furthermore, it must be remembered that analysis by all three methods is extremely time-consuming, and may be impossible or uneconomic if the samples are in poor condition. Sometimes under these circumstances the most useful procedure is to examine a large series of samples but to use mainly frequency-of-occurrence analysis. Valuable results have been obtained in this way by Madsen (1957) in his work on the food of fish-eating birds in Denmark, by Belopol'skir (1957) in his study of the stomach contents of an enormous series of arctic birds, and by Tickell (1964), in a comparison of the diets of Diomedea melanophris Temminck and Diomedea chrysostoma Forster.

However, even if all the available methods of analysis are employed (as, for instance, in Madsen and Spärck 1950, and Olney 1964 and earlier papers), the relative importance of the different food classes can be fully understood only in the light of knowledge of the whole biology of the species concerned. For example, a prey which is not normally eaten in quantity, but which can be utilized when other food is scarce, may be of critical importance in permitting a species to survive in a particular environment; this is apparently so in the case of snails in the diet of the Song Thrush Turdus philomelos Brehm in Britain (Davies and Snow 1965).

The use of several different types of analysis enables comparisons between species or between seasons to be made with greater confidence. However, as pointed out by King and Ikehara (1956:64) "Regardless of the method or methods of analysis used, there are many uncontrollable variables inherent in food studies which detract from the precision of the results." Furthermore, for the reasons discussed by the same authors, it is generally impractical to apply statistical tests of significance to the data. Under these circumstances, it is clear that one must be very cautious when drawing conclusions from the results, and it is for this reason that we have presented much of our data in detail in the appendices.

In the present study we decided to use all the three basic methods described above: analysis by number, by volume, and by frequency of occurrence. Although we based these primary analyses on the division of the food into broad classes (fish, squid, and other invertebrates), identification of a high proportion of the less digested fish to the family level made it possible also to compare the representation of different fish families in the diets of the different birds. Furthermore, our data on the lengths and volumes of the fish and squid in the samples provide a basis for comparison of the sizes of prey which the various species are able to exploit.

In presenting information on the overall composition of the diets of the different birds, the numbers of items in each class of food are presented as per- 
centages of the total numbers of items in all food classes. The volumes of all the items in each of the different food classes are summated for each food class, and expressed as percentages of the total volume of the food in all classes. This is the 'aggregate-total-volume' method (Reintjes and King 1953:96), in which samples of different sizes exert effects proportional to their volumes. Frequency of occurrence of each food class is presented as the percentage of samples in which the class was represented. Because nearly all the samples contained more than one class of food, these percentages when summated far exceed 100 . Hartley (1948), in representing the percentage occurrence of different foods, used a method is which the total number of occurrences of all food classes is called 100, and the percentage of the total provided by each food class is calculated. It is apparently this method which is used in the majority of the tables in Belopol'skir's (1957) work on sea birds. However, it is not used here (although the figures for the calculations are available in Appendix 1) because it obscures the important information on the proportion of the samples which contain a particular food class.

Where only a small number of food classes is involved (for instance the fish, squid and other invertebrates of our primary analysis) it is useful and practicable to bear in mind continually the results of the three different types of analysis, representing numbers, volume, and frequency of occurrence. However, when it is necessary to compare the representation of larger numbers of food classes, for instance the various fish families in the present study, it is cumbersome always to use, in discussion, the results of all three methods. Trautman (1952), facing this problem in his study of pheasant food habits, recorded numbers of items, weights, and frequency of occurrence, but in his discussion relied mainly on comparison of weights. Welsh (1949, quoted by Reintjes and King 1953), in a study of the food of various Hawaiian fishes, obtained percentages for each food by number, volume, and frequency of occurrence, and then averaged these to obtain a single index of importance. Rather than combining percentages representing different types of information, we have preferred to use, in discussion of the importance of the various fish families in the diets of different birds, a composite ranking system derived from the results of the three methods of analysis. For each bird species, the fish families were ranked separately in order of overall numbers, in order of total volume, and in order of frequency of occurrence: the three rankings were summated for each fish family, so that the families could then be arranged in a single sequence for that bird. The resulting rankings avoid the implication of precision conveyed by averaged-percentage figures, and are considered to give a good indication of the relative importance of the different families in the diets of the birds. (We find that an identical ranking system has been described by Waldron and King [1962] in comparing the importance of fish families in the food of tunas.)

There are various complications in attempting to compare quantitatively the food of the different sea birds on Christmas Island, and these need to be borne in mind when considering the results. First, since the samples were either regurgitations, or food carried in the bill by G. alba, they cannot be considered as complete stomach contents. However, regurgitations probably give a better indication than stomach contents of the composition of recently taken food, 
since organisms with very durable parts are less likely to be over-represented.

There remains the difficulty that food tended to be consistently less digested in some species than in others. The extreme examples are G. alba, in which much of the food-being carried in the bill-was in perfect condition, and Pt. alba, in which the food was very largely digested (see Table 2), so that it was often hard to judge how many fish and squid were represented in a sample. These differences in condition should not in themselves seriously affect the comparison of the overall proportions by volume of fish and squid in the different bird species, since fish and squid flesh are nearly always easy to tell apart, even at very late stages of digestion. However, if the soft parts of fish and squid were digested at very different rates, the reliability of the comparisons would be reduced; although no relevant measurements are available, the data in Table 2 do not suggest that there are great differences. On the other hand, the comparison of the representation of the different fish families in the diet of the different birds must be affected to some extent by general differences in the condition of the samples from different bird species. This is because some fish families are easy to recognize, with practice, even in late stages of digestion, while others are much more difficult. For instance the very diagnostic spines of Exocoetidae are relatively resistant to digestion, Gempylus serpens Cuvier and Valenciennes (Gempylidae) have a very distinctive body form, and Scombridae can be recognized, with practice, at a much later stage of digestion than many other fish. In contrast, larval fish are frequently not identifiable even when in relatively good condition.

Regurgitations were obtained from both adults and nestlings. The two types of samples are considered together in the analysis, since it was generally not known which of the samples from adults were of food about to be fed to young. For instance the vast majority of the samples carried in the bill by G. alba, and of the regurgitations obtained from $S$. fuscata during the breeding season, were clearly of food intended for the young, but many of the samples from the two Anous species and from Pr. cerulea (and also the regurgitations from G. alba) were obtained from roosting birds and were not of food intended for nestlings.

Another problem is that the number of samples obtained was very different in the different species, as was the distribution of the samples around the year (Table 2 and Appendix 1). Clearly, only striking differences should be accepted with confidence in cases where the number of samples is small.

In comparing the size of regurgitations (or of individual food items) from the different bird species, we have expressed volumes measured in milliliters by displacement, as percentages of body size measured in grams. This procedure seems justified for comparative purposes since the specific gravities of the food of the different species must be extremely similar (and also close to one). 


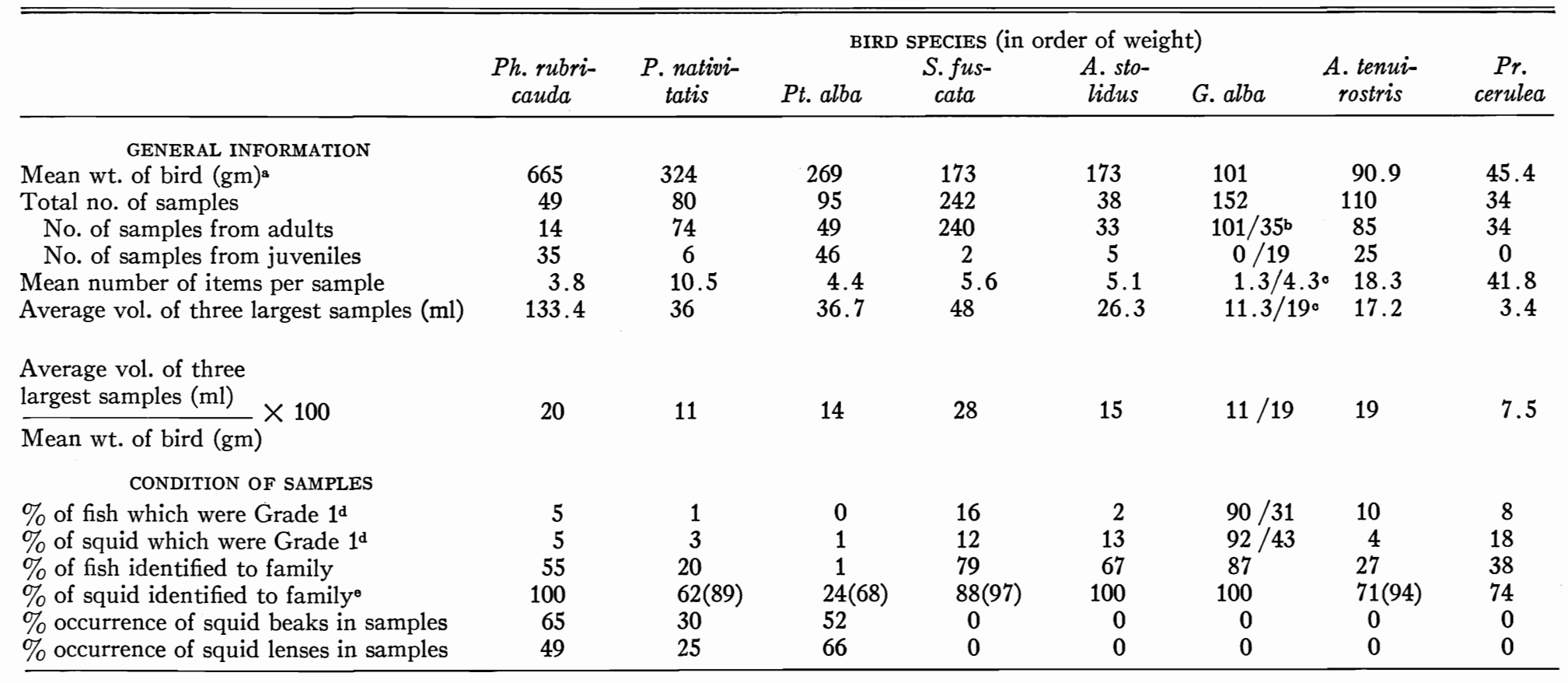

NOTES FOR TABLE 2:

a. These figures are means of all the weight records obtained on the island, the lowest number of weighings being 37 (in Ph. rubricauda and $P r$. cerulea) and the highest 964 (in S. fuscata).

b. For G. alba two separate figures are frequently given: the first refers to samples of food carried in the bill and the second to regurgitations. Three adults caught while carrying food in the bill also regurgitated, providing composite samples: thus the total number of samples from adults was 133 , not 136.

c. The three composite samples are excluded from both first and second figures: see note $\mathrm{b}$ above.

d. See "Techniques: Laboratory Treatment" for the definition of Grade 1 items. Samples from juveniles are excluded.

e. These figures are based on squid collected only up to the end of September 1963. Figures in parentheses include squid which were only tentatively identified. 


\section{SPECIES ACCOUNTS}

(The species are treated in order of decreasing body weight—see Table 2)

\section{PHAETHON RUBRICAUDA Boddaert-Red-tailed Tropic-bird}

\section{Status}

This tropic-bird, which is the only member of its family found on Christmas Island, breeds on both Cook Island and Motu Tabu, as well as on other islets and the main island; over two hundred nests were investigated on Motu Tabu during the study, while more than a thousand birds breed on Christmas Island as a whole (Table 1). Since the three resident species of boobies (Sula spp.) and the two species of frigate-birds (Fregata spp.) were not available on the islets, $P h$. rubricauda was easily the largest species studied; it is over twice the weight of the next species, $P$. nativitatis (Table 2).

\section{General Description and Condition of Samples (Table 2)}

Tropic-bird chicks regurgitate readily when they have recently been fed, and nearly three-quarters of the food samples were collected from nestlings. The 49 regurgitations contained on average 3.8 items each, a number lower than in regurgitations from any of the other species. The average volume of the three largest regurgitations $(133.4 \mathrm{ml})$ expressed as a percentage of the average weight of adults (in grams), gives a figure of $20 \%$, which is high in comparison with most of the other species. The largest regurgitation obtained (175.7 $\mathrm{ml}$ ) was more than three times the volume of the largest from any of the other species.

In comparison with the other seven species, the food items were in moderate condition; however, a few were very largely digested. In samples from adults $5 \%$ of the fish were Grade 1, and $55 \%$ of all the fish were identified to family. The squid in samples from adults included $5 \%$ which were Grade 1 , and all the squid examined were identified to family. A fairly high proportion of the samples contained separate squid beaks and lenses. Although the highest number of lenses in a sample was only three, the number of beaks was often very high, and one sample contained 192; evidently in such cases the birds regurgitated their gizzard contents.

\section{Quantitative Composition of Samples (Fig. 3 and Table 3)}

One third of the food items were fish, but these made up more than half of the food by volume. This relationship implies that the fish were generally bulkier than the squid, in contrast with the situation in all the other species studied (except Pr. cerulea), in which the fish were generally smaller than the squid. Squid had a slightly higher frequency of occurrence than fish, but $71 \%$ of the samples contained both squid and fish; this proportion is higher than in any other species studied, although each sample from $P h$. rubricauda con- 
TABLE 3. Percentage composition of food samples from the bird species

\begin{tabular}{|c|c|c|c|c|c|c|c|c|}
\hline \multicolumn{9}{|l|}{ NUMBER } \\
\hline Fish & 33 & 63 & 26 & 60 & 71 & 59 & 95 & 49 \\
\hline Squid & 64 & 36 & 48 & 40 & 29 & 41 & 4 & 9 \\
\hline Other invertebrates & 3 & 0.2 & 26 & 0.1 & 0 & 0.3 & 1 & 42 \\
\hline Total vol. of food (ml) & 2389.4 & 1312.4 & 775.0 & 3783.4 & 478.8 & 491.6 & 529.0 & 56.8 \\
\hline \multicolumn{9}{|l|}{ Percentage composition: } \\
\hline Fish & 53 & 29 & 14 & 38 & 51 & 47 & 77 & 75 \\
\hline Squid & 47 & 71 & 78 & 62 & 49 & 53 & 23 & 10 \\
\hline Other invertebrates & 0.1 & $<0.1$ & 8 & $<0.1$ & 0 & $<0.1$ & $<0.1$ & 16 \\
\hline \multicolumn{9}{|c|}{ FREQUENCY OF OCCURRENCE } \\
\hline Other invertebrates & 10 & 3 & 38 & 0.4 & 0 & 0.7 & 2 & 82 \\
\hline
\end{tabular}


tained, on average, fewer items than those from any of the other species (Table 2). A few invertebrates other than squid were found, but these clearly form a negligible part of the diet.

\section{Size of Food Items (Fig. 4, Tables 4 and 5, and Appendix 2)}

The fish taken by $P h$. rubricauda ranged in length from the $2-4 \mathrm{~cm}$ class to the 26-28 cm class, with one much larger halfbeak. This was the only bird species which took no fish in the $0-2 \mathrm{~cm}$ class, while only two fish longer than $16 \mathrm{~cm}$ were found in samples from other species. Although even in the present species only 8 of the 60 fish were more than $16 \mathrm{~cm}$ long (four of them Coryphaenidae), the volume data confirm the generally large size of the fish which it ate. The mean volume of the fish in good condition was $21.8 \mathrm{ml}$, a figure more than five times that for any other species. Furthermore, this mean volume, when expressed as a percentage of the body weight in grams, gives a figure of $3.3 \%$, much higher than that for any of the other species. The bulkiest fish obtained from $P h$. rubricauda had a volume of $84.0 \mathrm{ml}$ when partly digested, and both this and a number of other fish were enormously bulkier than any fish from the other bird species. It is also of interest that this volume of the largest fish represents more than $12.6 \%$ of body weight, which is higher than the equivalent figures in the other species.

The squid taken by Ph. rubricauda ranged in mantle length from the 2-4 $\mathrm{cm}$ class to the $10-12 \mathrm{~cm}$ class. None of the other species took any squid more than $10 \mathrm{~cm}$ in mantle length and all took some less than $2 \mathrm{~cm}$. The frequency distribution within the range also contrasted with the other species, showing a peak of $36 \%$ in the $6-8 \mathrm{~cm}$ class and 22 in the $8-10 \mathrm{~cm}$ class (Fig. 4). Correspondingly, the mean volume of the squid in good condition collected from $P h$. rubricauda was $20.7 \mathrm{ml}$, while among the other species the highest value was about $7.1 \mathrm{ml}$.

Although there was thus a large difference in the size of squid taken by $P h$. rubricauda and by the other species, it was not as large as might have been expected from the fish data. In Ph. rubricauda the mean volumes of the squid and of the fish in good condition were about equal ( 20.7 and $21.8 \mathrm{ml}$ respectively), but in all the other species (except Pr. cerulea) the squid were much larger in volume than the fish (Table 4). Considering only the largest items rather than the means, it is noteworthy that while the largest squid recorded in this study $(43.7 \mathrm{ml})$ came from $\mathrm{Ph}$. rubricauda, it represented only $6.6 \%$ of the bird's weight, and several other species took squid much larger in proportion to their size. Correspondingly, the difference in absolute terms between the largest squid from $P h$. rubricauda $(43.7 \mathrm{ml})$ and the largest from another species ( $25.3 \mathrm{ml}$ in $P t$. alba) is much less impressive than the equivalent difference in the fish $(>84.0 \mathrm{ml}$ and $>16.9 \mathrm{ml})$.

\section{Identifications of Food Items (Fig. 5 and Appendices 3 and 4)}

Fish from only four families were identified; this was fewer than for any of the other bird species except Pt. alba, in which only one fish was identified. Exocoetidae easily rank highest, followed by Coryphaenidae, Diodontidae and Tetraodontidae. Except for Exocoetidae, these are families which do not rank 


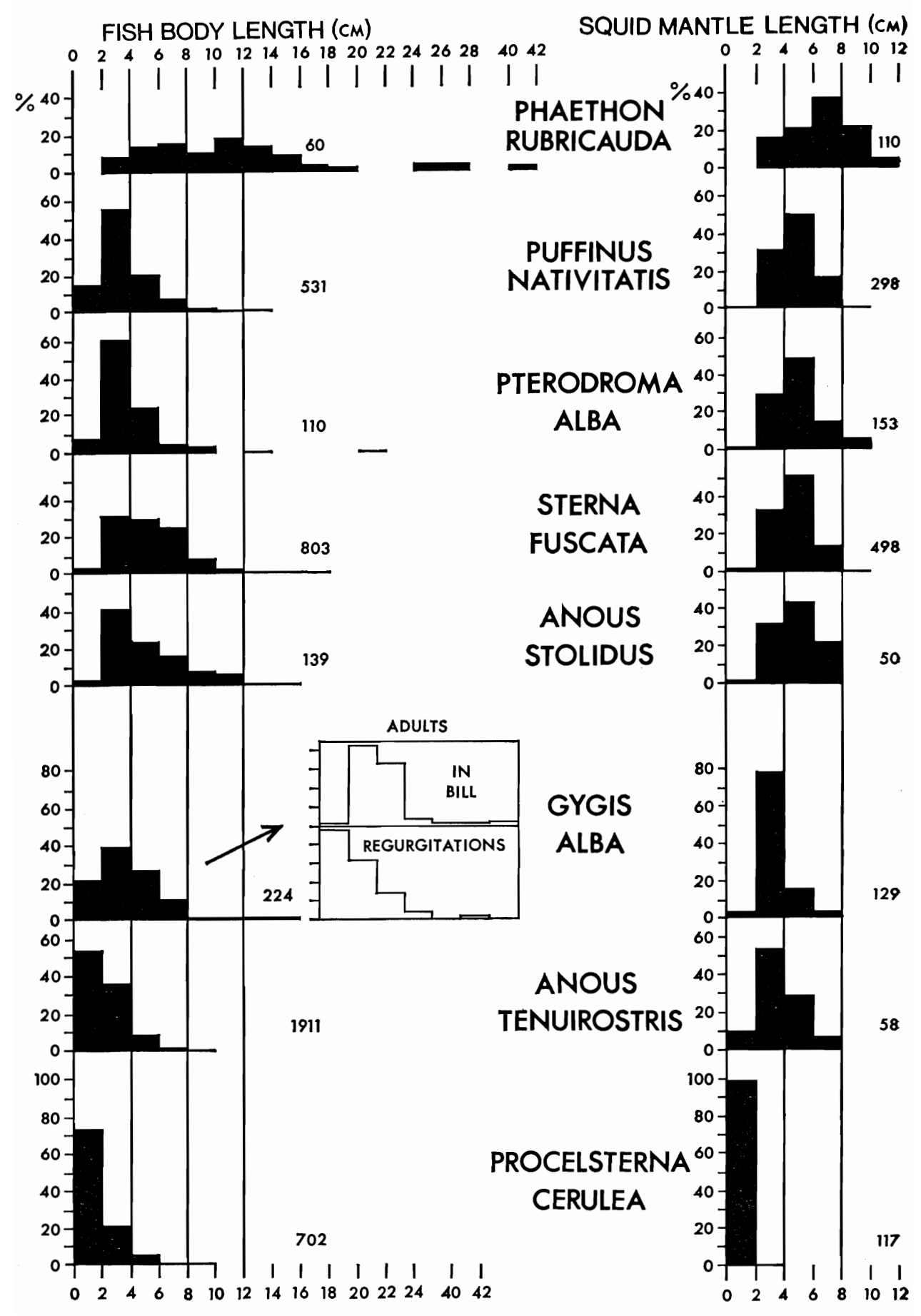


high in the diets of any of the other birds studied. (The ranking of the fish families takes into account their relative numbers, volume and frequency of occurrence: see section on Methods of Analysis for details.)

It is of special interest to find that Diodontidae (porcupine fishes) are eaten in appreciable numbers by $P h$. rubricauda (and to some extent also by $S$. fuscata), since members of this family can inflate themselves when alarmed, and their numerous sharp spines might be expected to provide an extremely effective defense against predators. That $P h$. rubricauda is affected by the spines under certain circumstances was shown on an occasion when an adult was caught, and regurgitated-after terrific efforts and obviously acute discomfort -a porcupine fish about $9 \mathrm{~cm}$ long, and the partially digested remains of another. Although the adult was with a chick at the time, it seems unlikely that these fish would have been regurgitated for it.

As in the other birds, nearly all the squid identified were Ommastrephidae, but one individual was probably a member of the Histioteuthidae-the only one found during the study. All the Ommastrephidae identified were members of the genus Symplectoteuthis - as were nearly all the squid taken by all the species of birds-but $P h$. rubricauda was unusual in providing almost as many individuals of species B as of species A. Clarke (1965) has shown that both Ommastrephes pteropus in the North Atlantic and Symplectoteuthis oualaniensis in the Indo-Pacific occur in two forms, one with and one without a large dorsal light organ. Since the nomenclature of the forms of the 'species' Symplectoteuthis oualaniensis has not yet been resolved, we refer to the form without the light organ as Symplectoteuthis species A and to the form with the light organ as Symplectoteuthis species B.

The few other invertebrates comprised three isopods, a parasitic copepod (Penella sp.), one egg cluster and one unidentified object. Two of the isopods were fish lice, and together with the parasitic copepod may be considered as accidental food.

Stonehouse (1962b) found that on Ascension Island Phaethon aethereus and Ph. lepturus fed mainly on Exocoetidae. As well as some other fish he recorded one species of squid, Hyaloteuthis pelagicus, but it is clear that squid were far less important in the diet of these Ascension Island birds than they were in that of Ph. rubricauda on Christmas Island. Gibson-Hill (1947) investigated the food of the tropic-birds Ph. rubricauda and Ph. lepturus on the Cocos-Keeling Islands and Christmas Island, Indian Ocean. His combined data show that in these populations the diet was about $35-50 \%$ squid (presumably by number) and the remainder fish; hence squid were less important than in our Christmas Island (Pacific) samples.

FIGURE 4. Size-frequency distribution of fish and squid in the diets of the birds.

For details of measuring techniques see text (Techniques: Laboratory Treatment). The diagram includes both items which could be measured accurately and those whose lengths were estimated. When items could be estimated only to be in one of two adjacent $2 \mathrm{~cm}$ classes, they were allotted alternately. Items represented only by fragments were not included. Figures at the right of each histogram indicate the number of items on which it is based. 
TABLE 4. Volumes of food items in samples from the bird species

\begin{tabular}{|c|c|c|c|c|c|c|c|c|}
\hline & $\begin{array}{l}\text { Ph. rubri- } \\
\text { cauda }\end{array}$ & $\begin{array}{l}P . \text { nativi- } \\
\text { tatis }\end{array}$ & Pt. alba & $\begin{array}{l}\text { S. fus- } \\
\text { cata }\end{array}$ & $\begin{array}{l}\text { A. sto- } \\
\text { lidus }\end{array}$ & G. alba & $\begin{array}{l}\text { A. tenui- } \\
\text { rostris }\end{array}$ & $\begin{array}{l}\text { Pr. } \\
\text { cerulea }\end{array}$ \\
\hline Mean wt. of bird (gm) & 665 & 324 & 269 & 173 & 173 & 101 & 90.9 & 45.4 \\
\hline FISH & & & & & & & & \\
\hline$\frac{\text { Total vol. of all fish }(\mathrm{ml}) \mathbf{a}}{\text { Total number of all fish }}$ & 21.0 & 0.7 & 1.0 & 1.8 & 1.8 & 1.0 & 0.2 & 0.06 \\
\hline $\begin{array}{l}\text { Mean vol. of fish in good } \\
\text { condition (ml })^{\mathbf{b}}\end{array}$ & 21.8 & $(3.7)$ & - & 2.5 & 3.7 & 1.2 & 0.4 & $(0.1)$ \\
\hline $\begin{array}{l}\text { Mean vol. of fish in } \\
\text { good condition } \times 100\end{array}$ & 33 & (1 1) & - & 1.4 & 2.1 & 12 & 0.4 & $(0,2)$ \\
\hline Mean wt. of bird & & & & & & & & \\
\hline Vol. of largest fish (ml)。 & $>84.0$ & 11.5 & $>16.0$ & $>15.8$ & $>16.9$ & 9.2 & 6.6 & 0.7 \\
\hline$\frac{\text { Vol. of largest fish }}{\text { Mean wt. of bird }} \times 100$ & $>12.6$ & 3.6 & $>5.9$ & $>9.1$ & $>9.8$ & 9.1 & 7.3 & 1.5 \\
\hline
\end{tabular}

SQUID

Total vol. of all squid (ml)d

Total number of all squid

$9.5 \quad 3.1$

4.4

4.2

1.7

1.7

0.04

Mean vol. of squid in good condition (ml)•

20.7

$6.6 \quad(7.1)$

6.6

5.0

2.1

(3.6)

0.04 
Mean vol. of squid in good condition $\times 100$

$3.1 \quad 2.0$

\section{NOTES FOR TABLE 4:}

a. These figures represent the average volumes of all the fish, irrespective of their state of digestion.

b. These figures are the mean volumes of all Grade 1 and Grade 2 fish (i.e. those which were not seriously digested; see "Techniques: Laboratory Treatment"). No figure is given for Pt. alba because hardly any Grade 1 or Grade 2 fish were obtained from this species. The figure for $P$. nativitatis is placed in parentheses because hardly any of the smaller fish obtained from this species were in good condition: in the other species there was less tendency for the large fish to be in better condition than the small ones. The figure for Pr. cerulea is placed in parentheses because it was difficult to measure accurately the volumes of the tiny fish eaten by this species.

c. These were Grade 3 fish in Ph. rubricauda, Pt. alba, S. fuscata and A. stolidus, Grade 1 in the other species.

d. These figures represent the average volumes of all the squid, irrespective of their state of digestion. No figure is given for $P t$. alba, because many samples contained only squid beaks or eye lenses.

e. These figures are the mean volumes of all Grade 1 and Grade 2 squid which had heads attached. In Pt. alba there were only two squid with heads attached, so the figure given is an estimate based on the volumes of mantles in good condition corrected to include the probable volume of the missing parts. The figure for $A$. tenuirostris is based on only six individuals, of which three were unusually large.

f. These were Grade 1 squid except in $A$. stolidus (Grade 2). 


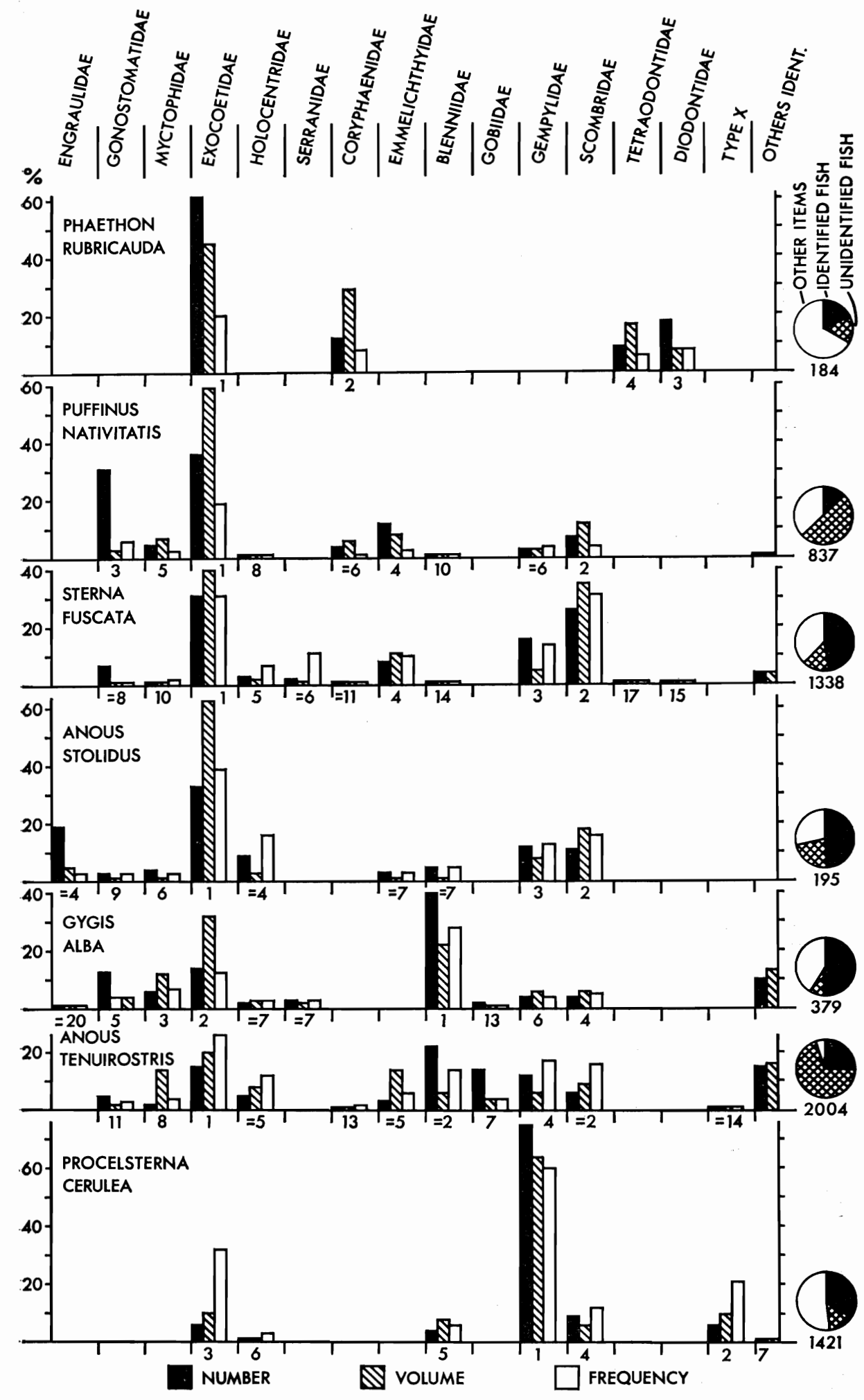




\section{PUFFINUS NATIVITATIS Streets-Christmas Island Shearwater}

\section{StATUS}

Two species of shearwater are abundant on Christmas Island, but the larger of the two, Puffinus pacificus, nests in burrows in very soft ground, and could not conveniently be studied. The present species, $P$. nativitatis, nests on the surface, and records were kept for over one hundred nests in a study area on Motu Tabu and for a few nests on Cook Island. There are also colonies on several other islets in the lagoon, and the total population must be close to 10,000 birds (Table 1). The diet of this species can usefully be compared with that of Pt. alba, the third member of the Procellariiformes which breeds commonly on Christmas Island. Pt. alba has slightly longer wings than P. nativitatis, but is distinctly lighter (Table 8).

\section{General Description and Condition of Samples (Table 2)}

Although a few regurgitations were obtained from nestlings, most were from adults caught at night, either when they were about to feed chicks or while they were courting. The 80 regurgitations contained on average 10.5 items each; this figure is easily the highest among the larger species studied. The average volume of the three largest regurgitations was $36.0 \mathrm{ml}$, or $11 \%$ of the body weight of the bird; this percentage is lower than in any of the other species (except Pr. cerulea), which is of interest in view of the high number of items per sample.

The food items were generally largely digested. Only $1 \%$ of the fish in samples from adults were Grade 1 , and only $20 \%$ of the fish were identified to family; $3 \%$ of the squid obtained from adults were Grade 1, and $62 \%$ of the squid were definitely identified to the family level. Separate squid beaks and eye lenses were each present in about one quarter of the samples, the highest number of beaks in a single sample being 14, and that of lenses 13. However, one

FIGURE 5. Important fish families in the diets of the birds.

Within each bird species, the representation of each fish family is shown by three columns, indicating respectively number, volume, and frequency of occurrence. The number and volume of members of each fish family are given as percentages of the totals of all fish identified in samples from that bird species; to obtain the frequency of occurrence the number of samples which contained members of the family is expressed as a percentage of the total number of samples. The rankings (see Techniques: Methods of Analysis) of the various fish families in each bird species are indicated by the numbers below the columns: where two families share a ranking, it is preceded by an = sign. The diagram includes all families which rank seventh or higher in the diet of any bird species. At the right of the diagram are given the total numbers of items obtained from each bird species, while in the circles are shown the proportions of these items which were fish identified to family, fish not identified, and other items (including squid, Crustacea and insects). Type $\mathrm{X}$ were a distinct group of small fish whose identity has still not been determined. The family Mullidaeaccidentally omitted from the diagram-ranked $=6$ th in $S$. fuscata, providing $1 \%$ by number, $2 \%$ by volume and $2 \%$ frequency of occurrence; this family ranked 9 th in $A$. tenuirostris and also in G. alba. 


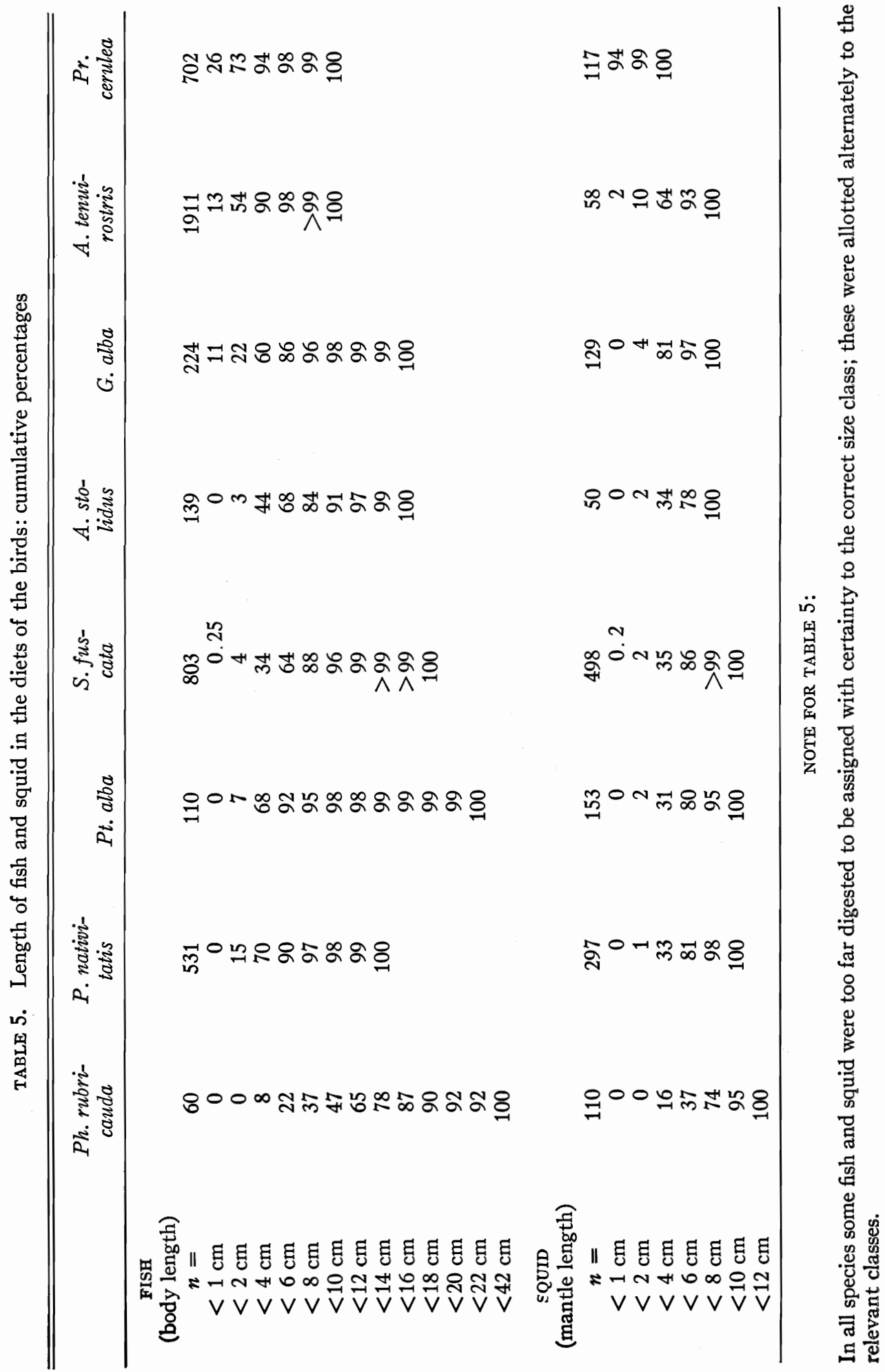


$P$. nativitatis was dissected and the gizzard contained 230 squid beaks, indicating that they must be retained over a considerable period. In contrast to the situation in Pt. alba, these beaks and lenses were apparently all from squid similar in size to those found only partly digested in the regurgitations.

\section{Quantitative Composition of Samples (Fig. 3 and Table 3)}

Nearly two thirds of the food items were fish, but these made up less than one third of the food by volume. Squid, on the other hand, were present in smaller numbers but much larger volume, showing that the individual squid were on average bulkier than the individual fish. In spite of the large number of fish taken, squid had a higher frequency of occurrence $(90 \%)$ than fish $(75 \%)$. This relationship, which was also found in some other species, is discussed in the comparative section. Only two items other than fish and squid were recorded, in separate samples-both were small crustaceans. In contrast to $P t$. alba, none of the samples were noted to contain large quantities of stomach oil.

\section{Size of Food Items (Fig. 4, Tables 4 and 5, And Appendix 2)}

The fish taken by $P$. nativitatis ranged in total length from the $0-2 \mathrm{~cm}$ class to the $12-14 \mathrm{~cm}$ class, but of the 531 fish obtained only 17 were longer than 8 $\mathrm{cm}$. The length-frequency distribution shows a strong peak in the $2-4 \mathrm{~cm}$ class ( $55 \%$ of the total), as in several of the other species studied; the distribution for the present species is especially similar to that for Pt. alba. The mean volume of the fish in good condition was $3.7 \mathrm{ml}$, very different from the figure of 0.7 $\mathrm{ml}$ which was the average volume of all the fish regardless of their condition (Table 4). Looking at the details of the samples it was clear that in this species the small fish which were an important part of the diet were very rarely Grade 1 or 2. The length-frequency distributions (Fig. 4) confirm that $P$. nativitatis took a much lower proportion of large fish than did $S$. fuscata and $A$. stolidus. Furthermore, the bulkiest fish obtained had a volume of only $11.5 \mathrm{ml}$, or $3.6 \%$ of the body weight, a figure much lower than those for any of the other species except Pr. cerulea.

The squid taken by $P$. nativitatis ranged in mantle length from the $0-2$ $\mathrm{cm}$ class to the $8-10 \mathrm{~cm}$ class, but $98 \%$ were between 2 and $8 \mathrm{~cm}$, with a peak in the $4-6 \mathrm{~cm}$ class. The mean volume of the squid in good condition was $6.6 \mathrm{ml}$ and the volume of the largest squid was $19.8 \mathrm{ml}$. Both these figures are similar to those for $S$. fuscata and $A$. stolidus, but are lower relative to body weight.

\section{Identifications of Food Items (Fig. 5 and Appendices 3 and 4)}

Fish from ten families were recorded among the 107 fish which were identified to the family level. Exocoetidae were by far the most important, comprising $36 \%$ of the identified fish by number and $59 \%$ by volume. However, it must be remembered that Exocoetidae were among the easiest fish to identify in largely digested samples, so their pre-eminence in the diet of $P$. nativitatis may be somewhat exaggerated. Scombridae, then Gonostomatidae, Emmelichthyidae and Myctophidae were next in importance.

All the cephalopods identified were Ommastrephidae; the only genus re- 
corded was Symplectoteuthis, and 19 individuals were determined as species A, one as species B. One of the two Crustacea recorded was an isopod and the other either a mysid or euphausiid.

We know of no published information on the food of this species of shearwater, but it is clear from accounts of stomach contents of other members of the genus Puffinus that Crustacea, as well as fish and squid, are an important food of some members of the group (see, for instance, Murphy 1936 and Palmer 1962).

\section{PTERODROMA ALBA (Gmelin)-Phoenix Petrel}

\section{Status}

Pterodroma alba is the only gadfly petrel which breeds on Christmas Island; it is most abundant on the islets Motu Tabu and Motu Upua, but also breeds in small numbers on Cook Island. The total population is probably between 7,000 and 10,000 birds, of which perhaps 2,000 breed on Motu Tabu. A study area on the latter island was chosen in March 1963 and contained over 500 marked nests by the end of the study. Most of the food samples were obtained from Motu Tabu, but a few were from Cook Island.

\section{General Description and Condition of Samples (Table 2)}

Almost half of the regurgitations were obtained from nestlings, while the other half were produced by adults, usually when they had arrived to feed chicks. Regurgitations from this species presented special problems in collection and analysis, mainly because many of them consisted largely of oil (whose significance is discussed in the section on Feeding Zones) which it was impossible to collect quantitatively from the ground. Because of this, no attempt was made to measure the amount of oil in each sample, although notes were kept of its presence; neither was oil in a sample considered as a "food item." It must therefore be remembered throughout the discussion of this species that only the discrete food organisms, or identifiable remains, were considered. A related problem is the large number of samples containing only squid beaks and/or lenses. As mentioned in the section on Laboratory Treatment, such remains were arbitrarily considered as only one food item, irrespective of how many were present, because they do not necessarily represent recently collected food.

The 95 samples collected from Pt. alba contained on average 4.4 items each, one of the lowest figures among the species studied. The average volume of the three largest regurgitations (disregarding oil) was $36.7 \mathrm{ml}$, very similar to that for P. nativitatis (Table 2); this figure represents $14 \%$ of the body weight.

In Pt. alba, even more than in P. nativitatis, the food items were generally largely digested-almost none of the fish or squid were Grade 1. Only one fish was identified to the family level, and only $24 \%$ of the squid examined could be definitely assigned to family; both these figures are lower than in any of the other bird species. An interesting feature of the samples was that sev- 
eral contained pieces of very large squid, especially arms, eye lenses and beaks. Beaks and lenses were found in over half the samples, and in more than one third of the samples they provided the only evidence of the presence of squid. The highest number of beaks found in a single sample was 22, and of lenses was 24. One Pt. alba was dissected and 172 squid beaks were found in the gizzard, indicating, as in the case of $P$. nativitatis, that beaks must be retained there over a considerable period.

\section{Quantitative Composition of Samples (Fig. 3 and Table 3)}

One quarter of the food items were fish, but they made up only $14 \%$ of the volume of the food because they were, on average, much smaller than the squid. This percentage of fish, both by number and by volume, is much lower than in the other species studied. About half of the food items were squid, and they made up over three quarters of the total volume, a proportion higher than in any of the other species. The remainder of the food consisted of other invertebrates, which were far more important in the diet of this species than in any of the others except Pr. cerulea. These invertebrates were mainly marine water striders (Gerridae) and Crustacea (see Table 6); together, they comprised one quarter of the total food items, although only $8 \%$ of the total volume. The frequency-of-occurrence figures show that virtually all the samples contained squid (or squid beaks), while fish were present in nearly half, and other invertebrates in rather less. As already mentioned, many samples from this species contained oil, but the presence of oil was not correlated with the presence of any one class of food.

\section{Size of Food Items (Fig. 4, Tables 4 and 5, and Appendix 2)}

The fish taken by $P t$. alba ranged in length from the $0-2 \mathrm{~cm}$ class to the $8-10 \mathrm{~cm}$ class, plus two longer individuals, of which one was a Gempylus sp. in the $20-22 \mathrm{~cm}$ class. The length-frequency distribution indicates a great preponderance of small fish, as in $P$. nativitatis. However, the largest fish taken was about as bulky as any obtained from other species except Ph. rubricauda, although it was not exceptionally large in relation to body weight.

The squid taken ranged in mantle length up to $10 \mathrm{~cm}$, but there were a negligible number in the $0-2 \mathrm{~cm}$ class. The length-frequency distribution has a peak in the $4-6 \mathrm{~cm}$ class, and except for a higher proportion in the $8-10 \mathrm{~cm}$ class, is similar to those for the birds of similar size. The volume data also show

TABLE 6. Invertebrates other than cephalopods in the diets of Pterodroma alba and Procelsterna cerulea

\begin{tabular}{|c|c|c|c|c|c|c|}
\hline & \multicolumn{3}{|c|}{ Pterodroma alba } & \multicolumn{3}{|c|}{ Procelsterna cerulea } \\
\hline & $\begin{array}{r}\% \text { o } \\
\text { number }\end{array}$ & $\begin{array}{l}\text { total } \\
\text { volume }\end{array}$ & $\begin{array}{l}\text { Frequency of } \\
\text { occurrence }\end{array}$ & $\begin{array}{r}\% \text { of } \\
\text { number }\end{array}$ & $\begin{array}{l}\text { total } \\
\text { volume }\end{array}$ & $\begin{array}{c}\text { Frequency of } \\
\text { occurrence }\end{array}$ \\
\hline Gerridae (Hemiptera) & 13 & $<0.5$ & 11 & 16 & 7 & 68 \\
\hline Crustacea & 6 & 2 & 23 & 24 & 5 & 47 \\
\hline Other & 7 & 6 & 19 & 1 & 5 & 26 \\
\hline TOTALS & 26 & 8 & 38 & 42 & 16 & 82 \\
\hline
\end{tabular}


this resemblance, although the bulkiest squid taken $(25.3 \mathrm{ml})$ was larger than those obtained from any other species except Ph. rubricauda.

The other invertebrates taken by this species were mostly extremely small. Halobates micans, a marine water strider, was the commonest item; it has a body length of about $0.6 \mathrm{~cm}$, and about 13 are needed to contribute a volume of $0.1 \mathrm{ml}$. However, a few of the Crustacea and some unidentified objects were several centimeters long and had volumes of a few milliliters.

It is thus clear that there is a very large range in the size of the food items taken by this species; it catches insects less than $1 \mathrm{~cm}$ long, while one took a fish over $20 \mathrm{~cm}$ long, and the volumes range from less than $.01 \mathrm{ml}$ to $25 \mathrm{ml}$. In addition, Pt. alba was apparently unique among the species studied in that it evidently regularly ate pieces of squid much larger than any of the ones which it swallowed whole. For example, several samples contained arms of very large squid-probably some over $30 \mathrm{~cm}$ in overall length. Furthermore, many of the isolated eye lenses in the samples were clearly from squid far larger than any of those encountered whole. Thus ten of the larger lenses from the samples had diameters between $1.0 \mathrm{~cm}$ and $1.76 \mathrm{~cm}$, while some of the larger squid obtained whole during the study, with mantle lengths between $6 \mathrm{~cm}$ and $9.5 \mathrm{~cm}$, had lens diameters between 0.3 and $0.5 \mathrm{~cm}$.

The largest squid obtained were unfortunately not available for measurement of the lenses. However, a personal observation by N.P.A. of a stranding of large squid on the beach of North Chincha Island, Peru, is relevant in that of the nine dead individuals observed, two lacked heads entirely, two lacked most of the arms, while the other five were more or less intact; however, all lacked both eyes. The missing parts may have been eaten by gulls after the stranding occurred, but the fact that it was the eyes and arms which were attacked throws some light on the occurrence of large lenses and arms in regurgitations of Pt. alba. A similar, but moribund and still intact squid (Dosidicus gigas), was found on the beach at Paracas, Peru. This had a mantle length of $55.5 \mathrm{~cm}$ and weighed six kilograms. Its eye lenses had a diameter of $1.7 \mathrm{~cm}$, which is almost the same as the largest lens obtained from Pt. alba regurgitations, showing clearly the very large size of some of the squid on which this species feeds.

\section{Identifications of Food Items (Fig. 5 And Appendices 3 And 4)}

Only one fish was identified to family, and was a member of the Gempylidae. All the whole squid which were identified to family were Ommastrephidae, but families other than Ommastrephidae were well represented among the cephalopod fragments which were frequently present in samples from Pt. alba. Regurgitations obtained in the first five sampling periods yielded: 5 arms (in four samples) of either Onychoteuthidae or Enoploteuthidae, 3 beaks (in one sample) of Onychoteuthidae, one beak probably of Chiroteuthidae, one beak of a pelagic octopus, and a few other beaks and pens from cephalopods other than Ommastrephidae.

Of the 111 food items classed as "other invertebrates" (Table 6) the most interesting were marine Gerridae (Insecta: Hemiptera), of which 51 were present in eight samples; those identified were Halobates micans. The other 
invertebrates comprised: 6 Stomatopoda, 1 decapod shrimp, 3 Euphausiidae, 9 other Crustacea; 5 Nematoda; 8 spermatophores, possibly of squid; and 27 unidentified objects, in one sample looking much like faecal matter.

We know of no published information on the food of this species, but other members of the genus clearly feed largely on squid (Falla 1934, Murphy 1936). However, Crustacea have also been recorded as important in the diet of young Pterodroma neglecta (Oliver 1930), and remains of pteropods and coelenterates have been found in the stomachs of Pt. phaeopygia (Loomis 1918).

\section{STERNA FUSCATA Linnaeus-Sooty Tern}

\section{STATUS}

Sterna fuscata is by far the most abundant breeding bird of Christmas Island, as of many other tropical oceanic islands. Vast numbers can be found breeding twice each year in various parts of the main island, and there is also a colony on Cook Island in which breeding is more or less synchronous with the mainland colonies. The total population of Christmas Island is probably well over one million birds. The Cook Island colony was chosen for study of the breeding cycles of individuals (Ashmole 1965), and most of the food samples were obtained from there. However, all of the samples collected in March 1963 were from a colony on the main island. $S$. fuscata is very similar in size to $A$. stolidus, a species much less common on the island but from which samples were also obtained. A close relative, S. lunata, breeds in one part of Christmas Island, but there was unfortunately no opportunity to study its food.

\section{General Description and Condition of Samples (Table 2)}

Virtually all the samples were regurgitations from adult birds, and threequarters, collected in March, August and September 1963, were obtained from birds which were about to feed chicks, or were in the process of feeding them. A high proportion of the samples thus represent food intended for chicks. The 242 samples contained on average 5.6 items each. The average volume of the three largest regurgitations was $48.0 \mathrm{ml}$, a figure much higher than in $P$. nativitatis and Pt. alba, which were both considerably heavier birds, and surpassed only by $P h$. rubricauda. Expressed as a percentage of body weight, this gives a figure of $28 \%$, which is higher than in any of the other species.

The food items were not in an advanced stage of digestion in comparison with those from the other bird species. Of the fish, $16 \%$ were Grade 1, and $79 \%$ were identified to family. Of the squid $12 \%$ were Grade 1 , and $88 \%$ of those examined were definitely identified to family.

\section{Quantitative Composition of Samples (Fig. 3 and Table 3)}

By number, fish comprised $60 \%$ of the food items, but by volume the figure was only $38 \%$. Conversely, squid were present in smaller numbers but larger volume. In spite of the higher numbers of fish, squid had a slightly higher frequency of occurrence; this relationship is discussed under Comparison and Summary of the Diets of the Birds. Apart from fish and squid, only one other item-a small crustacean-was found. 


\section{Size of Food Items (Fig. 4, Tables 4 and 5, and Appendix 2)}

The fish taken by $S$. fuscata ranged in length from the $0-2 \mathrm{~cm}$ class to the $16-18 \mathrm{~cm}$ class. However, $85 \%$ were between 2 and $8 \mathrm{~cm}$, and $S$. fuscata was unique among the birds studied in that the three classes $2-4 \mathrm{~cm}, 4-6 \mathrm{~cm}$ and 6-8 $\mathrm{cm}$ were about equally important; all the other species of similar size had strong peaks in the $2-4 \mathrm{~cm}$ class. The volume data also show the large size of fish taken; the mean volume of the fish in good condition was $2.5 \mathrm{ml}$, while the bulkiest single fish had a volume of $>15.8 \mathrm{ml}$, or $>9.1 \%$ of the body weight, a figure among the highest obtained.

The squid ranged in mantle length from the $0-2 \mathrm{~cm}$ class to the $8-10 \mathrm{~cm}$ class, but as in nearly all the other species the vast majority (98\%) were between 2 and $8 \mathrm{~cm}$. In contrast to the situation in the fish, the length distribution of the squid, and the average volume of those in good condition, are similar to those for P. nativitatis and Pt. alba.

\section{Identifications of Food Items (Fig. 5 and Appendices 3 and 4)}

The 633 fish identified to the family level provided representatives of 21 families, a figure exceeded only by G. alba. Although the number of families is high, over $80 \%$ of the identified fish belonged to the four commonest families. Exocoetidae ranked first, very closely followed by Scombridae, while Gempylidae and Emmelichthyidae were also important. Of the 77 Scombrids examined in detail, 69 proved to be Yellowfin Neothunnus macropterus (Temminck and Schlegel).

Of the 380 cephalopods identified to family, 1 was a small Argonauta sp. (Octopoda), while all the rest were Ommastrephidae. 300 specimens were identified as members of the genus Symplectoteuthis, and of these 186 could be assigned definitely to species A and 16 to species B. A single euphausiid crustacean was found.

Available published information on the food of $S$. fuscata was summarized by Ashmole (1963b). The diet of this species on Ascension Island was similar to that on Christmas Island in that it consisted of fish and squid. The small number of samples obtained there yielded representatives of only five fish families, all of them also found in the samples from Christmas Island. In addition, Bruyns and Voous (1965) recorded about six Vinciguerria cf. lucetia (Garman) (Gonostomatidae) regurgitated at night by an individual in the Pacific.

\section{ANOUS STOLIDUS (Linnaeus)—Brown Noddy}

\section{Status}

Anous stolidus is not present in large numbers on Christmas Island, but some hundreds breed on Cook Island, Motu Tabu and especially Motu Upua, the total population being of the order of 2,000 birds. The species was not studied intensively, but food samples were obtained whenever there was an opportunity: most were collected on Motu Tabu. This species invites comparison with $S$. 
fuscata, which is almost exactly the same size and nests on many of the same islands in the tropical oceans, and with its small congener, $A$. tenuirostris.

\section{General Description and Condition of Samples (Table 2)}

Nearly all the regurgitations were obtained from adult birds, mostly while they were roosting at night. The 38 samples contained on average 5.1 objects each. The average volume of the three largest regurgitations was $26.3 \mathrm{ml}$, which is $15 \%$ of the body weight. This is much lower than in S. fuscata, but it must be remembered that a relatively small number of regurgitations were obtained from the present species and that most were from roosting birds.

Few of the fish were in Grade 1 condition, but two-thirds were identified to family. More squid were in Grade 1 condition and all of the ten examined were identified.

\section{Quantitative Composition of Samples (Fig. 3 and Table 3)}

By number, $71 \%$ of the food items were fish, but by volume fish and squid were of equal importance, and the frequency of occurrence of squid was slightly higher than that of fish. No other invertebrates were found.

\section{Size of Food Items (Fig. 4, Tables 4 and 5, and Appendix 2)}

The fish taken by $A$. stolidus ranged in length from the $0-2 \mathrm{~cm}$ class to the $14-16 \mathrm{~cm}$ class; there was a definite peak in the $2-4 \mathrm{~cm}$ class, but as in $S$. fuscata fish larger than this made up more than half the total (56\%). The mean volume of the fish in good condition was $3.7 \mathrm{ml}$, or $2.1 \%$ of the body weight, and the bulkiest individual fish had a volume of $>16.9 \mathrm{ml}$, or $>9.8$ of the body weight. All these figures are higher than in any of the other species except Ph. rubricauda.

The length-frequency distribution for the squid is similar to those in the birds of similar size, virtually all squid being in the range $2-8 \mathrm{~cm}$ mantle length. However, in the small sample available both the mean volume of the squid in good condition and the volume of the largest individual squid were slightly lower than in the comparable species.

\section{Identifications of Food Items (Fig. 5 and Appendices 3 and 4)}

The 93 fish identified to the family level provided representatives of 9 families. Exocoetidae were by far the most important and occurred in $40 \%$ of all the samples. They were followed by Scombridae, Gempylidae, Engraulidae and Holocentridae. However, the high ranking of Engraulidae was produced by a single sample with 18 individuals.

All of the ten cephalopods identified to family were Ommastrephidae; of the four identified to species, three were Symplectoteuthis species A and one Symplectoteuthis species B.

On Ascension Island Dorward and Ashmole (1963) found that the food of $\boldsymbol{A}$. stolidus consisted largely of fish. They also summarized most of the published reports on the food of the species, but in addition it should be noted that Anderson (1954) mentioned it taking fish and squid up to about four 
inches long, while Baker (1948) recorded the presence of small fish and crustaceans in the stomachs of birds collected in Micronesia.

\section{GYGIS ALBA (Sparrman)-White Tern}

\section{Status}

Gygis alba is common on Christmas Island, with a total population of two or three thousand individuals. However, there are far more $S$. fuscata and $A$. tenuirostris, while $A$. stolidus and Pr. cerulea are about equal to G. alba in abundance (Table 1). The species breeds all the year round on islets in the main lagoon, with probably the most important concentration on Cook Island, where most of the samples were obtained: the rest came from Motu Tabu. G. alba is very similar in size to $A$. tenuirostris, but is very different in plumage, the form of the bill and legs, and in many aspects of its biology.

\section{General Description and Condition of Samples (Table 2)}

A total of 152 food samples were obtained, of which all but 19 were from adults. The majority of the samples were of food carried in the bill, since food for the chick is normally carried in this way, and whenever a bird was seen carrying food an attempt was made to catch it. However, 54 regurgitations were also obtained, of which 35 were from adults. Dorward, in his study of the species on Ascension Island, only once saw an adult regurgitate; this was at night during handling (pers. comm.). Most of our regurgitations from adults were obtained from roosting birds in the early part of the night. On one occasion, however, an adult was caught near its large chick while carrying one fish, but readily regurgitated 19 larval fish, which it clearly could not have carried all at once in its bill. It seems very possible that these would have been fed to the chick, by regurgitation, if it had not been caught. The fact that the samples include regurgitations as well as food carried in the bill complicates the analysis, and various figures in Table 2 are given separately for the two different categories of samples.

The 152 samples contained 379 food items. The samples carried in the bill contained, on average, only 1.3 items, but the regurgitations contained 4.3 items each, which is comparable to the number in regurgitations of most of the other species. The greatest number of objects carried in the bill of a single bird was four. The average volume of the three largest samples carried in the bill was $11.3 \mathrm{ml}$ and of the three largest regurgitations $19.0 \mathrm{ml}$. Expressed as percentages of body weight these volumes are comparable to those from the other species.

Food items from G. alba were generally in excellent condition. Of the fish from samples carried in the bill $90 \%$ were Grade 1, and in regurgitated samples $31 \%$ were Grade 1. For squid the figures are $92 \%$ and $43 \%$ respectively. These proportions are far higher than for any of the other species, both for the samples carried in the bill and for the regurgitations. The good condition of the regurgitations probably reflects a tendency for the birds to feed at dusk, only a few hours before the majority of the regurgitations were obtained (see 
section on Feeding Methods). Of the fish, $87 \%$ were identified to the family level, and of the squid examined, all could be assigned to families. No separate squid beaks or lenses were recorded.

\section{Quantitative Composition of Samples (Fig. 3 and Table 3)}

Well over half $(59 \%)$ of the food items were fish, although they made up less than half $(47 \%)$ of the volume of the food. Conversely, squid provided less than half the number of items, but more than half the volume. More than half of the squid were obtained in a short period in February 1964, and if this period is excluded the percentage of fish in the diet becomes $77 \%$ by number and $59 \%$ by volume. The frequency-of-occurrence figures are of special interest: $74 \%$ of the samples contained fish, but only $34 \%$ contained squid. It can thus be seen that there was an almost complete separation of the samples into those containing fish alone and those containing squid alone, with only $7 \%$ containing both: the latter figure is enormously lower than in any other species. This certainly results partly from the fact that many samples carried in the bill contained only a single item. However, the regurgitations contained on average 4.3 items each, which is comparable to the samples from several other species (Table 2). They contained $42 \%$ fish and $58 \%$ squid by number, and yet only $14 \%$ of them contained both.

In one sample a single crustacean was found, but it is obvious that other invertebrates are not a significant part of the diet of this species on Christmas Island.

\section{Size of Food Items (Fig. 4, Tables 4 and 5, And Appendix 2)}

The fish obtained from G. alba ranged in length from less than $1 \mathrm{~cm}$ to the 14-16 cm class. However, considering the samples from adults only, the sizefrequency distribution of fish carried in the bill is very different from that from regurgitations (Fig. 4). As might be expected, small fish are underrepresented in samples carried in the bill, almost all the fish less than $2 \mathrm{~cm}$ long being from regurgitations. Since a large majority of the samples were of food carried in the bill, the distribution obtained from all the samples combined (Fig. 4 and Table 5) is probably biased in favor of large fish. This problem is discussed further in the section comparing the diets of the species.

An additional complication in this species is that since the food brought to the young by the adults is usually (possibly always) carried in the bill, fish from regurgitations of juveniles should have a size distribution similar to those carried in the bill by adults and not to those from regurgitations of adults. The small number of fish obtained from juvenile regurgitations satisfy this expectation, since they comprise 8 fish in the $2-4 \mathrm{~cm}$ class, 8 in the $4-6 \mathrm{~cm}$ class, and 4 in the $6-8 \mathrm{~cm}$ class. In contrast, $48 \%$ of the fish from adult regurgitations were in the $0-2$ class (Fig. 4 ).

The eight fish obtained from G. alba which were over $8 \mathrm{~cm}$ in length were all either halfbeaks (often separated from the Exocoetidae as the family $\mathrm{He}$ miramphidae) or Gempylus sp.; the latter have length more disproportionate to their volume than any other fish occurring in our samples, and the long beaks 
of the halfbeaks add much to their length and very little to their volume: thus these long fish were not particularly bulky. The mean volume of all the fish in good condition obtained from G. alba was $1.2 \mathrm{ml}$. This is $1.2 \%$ of the body weight of the bird, a figure comparable to those obtained for the other species. The largest fish was $9.2 \mathrm{ml}$, representing $9.1 \%$ of the body weight.

The squid obtained from G. alba ranged in mantle length from the $0-2 \mathrm{~cm}$ class to the $6-8 \mathrm{~cm}$ class, but the length-frequency distribution shows an enormous peak (of $77 \%$ ) in the $2-4 \mathrm{~cm}$ class. However, it should be pointed out that of the 100 squid in this class, 71 were obtained in 15 samples (of which 14 were regurgitations) during a single week in February 1964. All the squid collected from G. alba during this period were in the $2-4 \mathrm{~cm}$ class, while at other times squid in other size classes were also found commonly. Thus the apparent tendency for G. alba to take a lower percentage of large squid than A. tenuirostris may not be a real one; in the other samples (excluding February) $41 \%$ of the squid taken by G. alba were over $4 \mathrm{~cm}$, while the comparable figure for $A$. tenuirostris is $35 \%$ (also excluding February, although only four squid were obtained then).

The mean volume of the squid in good condition obtained from G. alba was $2.1 \mathrm{ml}$, which is $2.1 \%$ of the body weight of the bird. The bulkiest squid taken was $8.5 \mathrm{ml}$, or $8.4 \%$ of the body weight. Both the mean and maximum volumes are lower than in any of the other species except Pr. cerulea, but in relation to body weight they are not exceptional. Furthermore, the mean figure is strongly influenced by the large number of small squid obtained in February 1964.

\section{Identifications of Food Items (Fig. 5 And Appendices 3 and 4)}

A total of 195 fish obtained from $G$. alba were identified to the family level, and provided representatives of 22 families, a higher number than in any of the other bird species. By contrast, 633 fish from $S$. fuscata were identified, but in only 21 families, while for A. tenuirostris the figures are 519 fish in 17 families. Five fish families represented in the food of G. alba were not recorded from any of the other birds. There thus seems to be a real tendency for G. alba to take a very wide variety of fish. Furthermore, among the common families which provide the bulk of the food, there were striking differences between $G$. $a l b a$ and all the other birds. Whereas in most of the other species Exocoetidae were easily the most important family, in G. alba Blenniidae ranked highest, although the percentage by volume of Exocoetidae was higher. Among the Exocoetidae, halfbeaks were more important than in the diets of the other bird species. Myctophidae and Gonostomatidae also ranked unusually high.

The Blenniidae are of special interest, since in most of the other bird species they were unimportant, and even in A. tenuirostris, where they shared second place, about seven other families were of comparable importance. Of the 79 Blenniidae obtained from G. alba, 30 (in 26 samples) were Aspidontus filamentosus, 15 (in 11 samples) were Runula tapeinosoma, 23 (in 3 samples in November) were larval Petroscirtes mitratus and only 11 (in 4 samples, all in November) were Cirripectus sp. By contrast, it was only Cirripectus sp. which was eaten by other bird species, principally $A$. tenuirostris, but also $A$. 
stolidus, S. fuscata, Pr. cerulea and P. nativitatis. Unlike Cirripectus sp., Aspidontus filamentosus and Runula tapeinosoma "are not associated with coral, but tend to swim in open waters over reefs and elsewhere" and both have been encountered "on the high seas, often near glass floats, etc." Larval Petroscirtes mitratus are "pelagic, and at times surface dwellers" (Donald W. Strasburg, pers. comm.).

Of the 15 squid obtained from G. alba during the period March through September 1963, all but one were Ommastrephidae (Symplectoteuthis species A). However, the other one belonged to the genus Abralia (Enoploteuthidae), and examination by Dr. Malcolm Clarke of a few of the regurgitations obtained from G. alba in February 1964 (when squid were unusually important in its diet), showed that most of the squid were Abralia sp., although Symplectoteuthis species A was also present.

In his study of G. alba on Ascension Island, Dorward (1963) examined 37 food samples. Eleven fish families were recorded, but the only fish which occurred frequently were members of the families Blenniidae, Exocoetidae and Trichiuridae. Only one cephalopod was found, implying that squid are much less important than in the Christmas Island population. Gibson-Hill (1951) recorded that in the Cocos-Keeling Islands (Indian Ocean) the fish obtained from this species were mostly a species of Stolephorus (Engraulidae) while Fisher (1906) mentioned that halfbeaks were among the fish taken at Laysan Island. Both Murphy (1936) and Baker (1948) recorded the presence of marine crustaceans in stomachs of this species, but Baker also mentioned insects (see section on Feeding Methods).

\section{ANOUS TENUIROSTRIS (Temminck)—Black Noddy}

\section{Status}

Anous tenuirostris is by far the most abundant small tern breeding on Christmas Island (Table 1). Although its numbers do not approach those of the larger $S$. fuscata, it is present in much greater numbers than S. lunata, Pr. cerulea, and G. alba; it is also far commoner than its larger relative, $A$. stolidus. $A$. tenuirostris nests in trees, mainly on the islets in the lagoon of Christmas Island; the largest colony is probably that on Cook Island, and a small section of this was studied in some detail, but observations were also made on Motu Tabu, and food samples were obtained from both. A tenuirostris is the smallest of the birds studied except for Pr. cerulea, but it is very close in size to G. alba (Table 8).

\section{General Description and Condition of Samples (Table 2)}

Over three-quarters of the samples obtained from this species were from adults, and all were regurgitations. A large proportion of those from adults were obtained by catching roosting birds in the early part of the night. The 110 samples contained on average 18.3 items each, which is much higher than in any of the other species except Pr. cerulea. The average volume of the three largest regurgitations was $17.2 \mathrm{ml}$, which is $19 \%$ of the body weight. 
The regurgitations often consisted of tightly packed masses of small fish, and much of the food was in a fairly advanced stage of digestion. Of the fish in samples from adults $10 \%$ were Grade 1 , and $27 \%$ of all the fish were identifiable to family. The latter low figure reflects the fact that most of the fish were very small, and for this reason were generally hard to identify. Of the squid, $4 \%$ were Grade 1 and more than two-thirds were identified to family. No separate squid beaks or lenses were found.

\section{Quantitative Composition of Samples (Fig. 3 and Table 3)}

A very high proportion of the food of this species was fish. Fish accounted for $95 \%$ of the number of food items, while $4 \%$ were squid. By volume, fish made up $77 \%$ and squid $23 \%$ of the diet. Fish had a very high frequency of occurrence, being found in $96 \%$ of the samples. Squid, in spite of their low numbers, were found in $38 \%$ of the samples; this reflects the facts that they were spread over samples from all the different periods, and that in almost every individual sample they were heavily outnumbered by fish-no sample contained more than five squid. Other invertebrates were unimportant in the diet of this species. They made up only $1 \%$ by number and less by volume, and occurred in only two samples.

\section{Size of Food Items (Fig. 4, Tables 4 and 5, ANd Appendix 2)}

Fish taken by this species ranged in length from less than $1 \mathrm{~cm}$ to the 8-10 $\mathrm{cm}$ class, but over half were less than $2 \mathrm{~cm}$ and $90 \%$ less than $4 \mathrm{~cm}$ long. The three fish in the $8-10 \mathrm{~cm}$ class were Gempylus sp., and were exceeded in volume by many shorter fish. The volumetric data also demonstrate the generally small size of the fish taken. The mean volume of the fish in good condition was 0.4 $\mathrm{ml}$, which represents about $0.4 \%$ of the body weight; both these figures are far lower than in any of the other terns except Pr. cerulea. However, the largest fish by volume was $6.6 \mathrm{ml}$, or $7.3 \%$ of the body weight, which is not far below the equivalent figures for the other terns.

Squid in samples from this species ranged in mantle length from the 0-2 $\mathrm{cm}$ class to the $6-8 \mathrm{~cm}$ class; $64 \%$ were less than $4 \mathrm{~cm}$. The mean volume of the six complete squid was $3.6 \mathrm{ml}$, a high figure resulting from the fact that three unusually large individuals were included. The figure for the average volume of all the squid ( $1.7 \mathrm{ml}$ : Table 4$)$ indicates that $A$. tenuirostris took squid hardly larger than G. alba. The bulkiest individual squid was $10.0 \mathrm{ml}$, which is $11 \%$ of the body weight.

Thus, $A$. tenuirostris feeds mainly on very small fish, although it is capable of taking much larger individuals. Squid, while taken in far smaller numbers, are on average much larger and are thus a significant part of the diet.

\section{Identifications of Food Items (Fig. 5 And Appendices 3 And 4)}

The identified fish in the samples from $A$. tenuirostris belonged to 17 families, of which two were not represented in any of the other species. Looking at the representation of the various families, the most striking feature is that no one or a few families were of outstanding importance, but about ten made significant contributions to the diet. Exocoetidae ranked first and were followed 
by Scombridae and Blenniidae, ranking equally. Almost as important were Gempylidae, Holocentridae, Emmelichthyidae, Gobiidae, Myctophidae, Mullidae and Mugiloididae. It is worth noting that in contrast to the situation in $G$. alba all the 113 Blenniidae identified were Cirripectus sp. which "lives among coral branches on shallow reefs. It is abundant in the lithothamnion ridge area near the outer edges of atolls" (Strasburg, pers. comm.).

All the squid identified to family were Ommastrephidae; those identified to genus were all Symplectoteuthis and the eight which could be determined specifically were species A. Invertebrates other than squid were unimportant in the diet, only 22 being recorded; of these 21 were mysids or euphausiids in a single sample and the other was a stomatopod larva.

On Ascension Island, as on Christmas Island, fish formed the main part of the diet, squid being present in only three out of 25 regurgitations examined (Ashmole 1961). Representatives of eight fish families were identified, Blenniidae, Holocentridae and Exocoetidae being most fequent.

\section{PROCELSTERNA CERULEA (F. D. Bennett)-Blue-grey Noddy}

\section{Status}

Procelsterna cerulea nests in loose colonies of a hundred or so on a number of the islets on Christmas Island, both in the main lagoon and in some of the smaller lagoons. The total population must number three or four thousand birds, which is roughly equal to that of G. alba; it is however much smaller than that of its close relative $A$. tenuirostris. The species was studied, and food samples collected, on both Motu Tabu and Cook Island. Pr. cerulea is by far the smallest of the species studied, averaging half the weight of $A$. tenuirostris, the next smallest, and only $7 \%$ of the weight of Ph. rubricauda, the largest.

\section{General Description and Condition of Samples (Table 2)}

No samples were collected from this species before August 1963, so the data do not quite span a year. All of the 34 samples were regurgitations from adults and most were obtained by catching the birds in flight, with a hand net, shortly after they returned to the islets in the evening; the rest were from roosting birds in the early part of the night. The samples contained an average of 41.8 food items each, a figure far higher than in any of the other species; even A. tenuirostris had less than half as many items per sample. The average volume of the three largest regurgitations $(3.4 \mathrm{ml})$ represents only $7.5 \%$ of the body weight of the bird, a figure much lower than for any other species, and less than half that for $A$. tenuirostris.

Many of the food items were in good condition, although their minute size made analysis difficult. Of the fish, $8 \%$ were Grade 1 , and $38 \%$ could be identified to the family level. Of the squid, $18 \%$ were Grade 1 , and $74 \%$ of those examined were identified to family.

\section{Quantitative Composition of Samples (Fig. 3, Tables 3 and 6, ANd Appendix 1)}

Half of the food items obtained from Pr. cerulea were fish, but they made up 
three-quarters of the diet by volume; squid comprised $9 \%$ of the food by number $^{2}$ and $10 \%$ by volume. Fish had a very high frequency of occurrence $(97 \%)$, while squid occurred in just half of the samples.

Invertebrates other than squid were much more important in the diet of this species than in any of the other birds studied. They comprised $42 \%$ of the total number of food items, but even in this small species they were small in relation to the fish and squid eaten and so contributed only $16 \%$ to the volume of the diet. Considered together, other invertebrates had a frequency of occurrence of $82 \%$, more than double that for any other species. These invertebrates fall into three groups: Crustacea, insects and other invertebrate items (Table 6). The Crustacea were all extremely small and, although they comprised $24 \%$ of the total food items, they contributed only $5 \%$ of the volume. The insects were all marine water striders, which provided $16 \%$ of the total numbers and $7 \%$ of the volume; their frequency of occurrence $(68 \%)$ was higher than that of the Crustacea $(47 \%)$ in spite of the higher numbers of the latter. Finally there is a group of other items, mostly unidentified, which comprised only $1 \%$ of the total numbers but contributed $5 \%$ to the total volume and occurred in $26 \%$ of the samples.

\section{Size of Food Items (Fig. 4, Tables 4 and 5, And Appendix 2)}

The fish taken by Pr. cerulea were small in comparison with those taken by most of the birds and ranged in length from less than $1 \mathrm{~cm}$ to the $8-10 \mathrm{~cm}$ class. However, nearly three-quarters of the fish were less than $2 \mathrm{~cm}$ long, while the longer fish were nearly all Gempylidae, with relatively low volumes. The fish taken by $P r$. cerulea were not only small in absolute volume, but were remarkably small in relation to the weight of the bird. Thus the mean volume of the fish in good condition was only about $0.1 \mathrm{ml}$, or about $0.2 \%$ of the body weight, while the largest fish represented only $1.5 \%$ of the body weight.

All but one of the 117 measurable squid had mantle lengths in the $0-2 \mathrm{~cm}$ class, in strong contrast to the situation in all the other birds; however, fourfifths of these small squid occurred in three samples. The mean volume of the squid was $0.04 \mathrm{ml}$, and the bulkiest squid was $1.1 \mathrm{ml}$, representing $2.4 \%$ of the body weight of the bird; this is a much lower figure than in any other species.

The various arthropods found in the samples never exceeded $1 \mathrm{~cm}$ in body length, and most were much less than this. The body lengths of the water striders were about $0.6 \mathrm{~cm}$, while some of the Crustacea were only $0.5 \mathrm{~cm}$. The volumes of the arthropods were extremely small; about 13 of both water striders and the Crustacea are needed to make up $0.1 \mathrm{ml}$, and much of this is chitin.

\section{Identifications of Food Items (Fig. 5, TABle 6, AND Appendices 3 AND 4)}

Fish from seven families were identified in the diet of this bird, but members of one family-Gempylidae-were of overwhelming importance. It is of interest that this family did not form a specially large part of the diet of $\boldsymbol{A}$. tenuirostris, although the latter species took many fish in the same size range as

2 However, 102 out of the 123 squid were from three regurgitations in August. 
those caught by Pr. cerulea. Next in importance was Type $\mathrm{X}$ (see note to Fig. 5), which among the other birds was found only in small numbers in the diet of $A$. tenuirostris. Exocoetidae, Scombridae and Blenniidae, in this order, were also of some importance.

Of the squid identified two were Loligo (Loliginidae); all the rest (from a single sample) were Rhynchoteuthis larvae of an ommastrephid, probably Symplectoteuthis sp.

As already mentioned, the other invertebrates in the diet of this species were mostly Crustacea and marine water striders (Gerridae). The Crustacea were mostly Pontella sp. (Copepoda), while all the water striders identified were Halobates micans.

Our general impression of the diet of Pr. cerulea is that it consists of any small animals, with a volume between about 0.01 and $1 \mathrm{ml}$, which are available at the surface of the ocean. In the area of Christmas Island at the time of our study the vast majority of such animals were apparently tiny fish, but this need not be so at all Procelsterna colonies at all times. For instance, Murphy (1936: 1148) records that stomachs of Procelsterna albivitta from the San Ambrosio Group were mostly filled with small shrimp-like crustaceans about $10 \mathrm{~mm}$ in length. Specimens from other islands in the southeast Pacific contained small cephalopod mandibles, remains of crustaceans, and tiny fish with silvery eyes, resembling larval eels. Oliver (1930) also noted that small red crustaceans have been found in the stomachs of $P$. albivitta on Lord Howe Island. 


\title{
4. COMPARISON AND SUMMARY OF THE DIETS OF THE BIRDS
}

\author{
Proportions of Fish, Souid, and Other Items \\ (Fig. 3 and TABle 3)
}

The main elements in the diets of the species studied were fish and squid; the frequency of occurrence of fish varied among the species from $45 \%$ to $97 \%$, and of squid from $34 \%$ to $97 \%$. Other invertebrates were frequent in samples from only two species and even in these they were of little volumetric importance.

A striking general result of the present study is the demonstration of the major part played by squid in the diet of the species investigated. In three out of the eight species squid formed well over half of the food by volume, and in another three it formed about half; only the two small inshore-feeding terns, A. tenuirostris and Pr. cerulea, took much less squid than fish. Among the other six species the diet comprised on average $60 \%$ squid and $38.5 \%$ fish by volume, or $43 \%$ squid and $52 \%$ fish by number. The squid fraction of the diet was restricted almost entirely to one genus-Symplectoteuthis-of the family Ommastrephidae, only $0.4 \%$ of the identified squid belonging to other families. In contrast, among the fish, a number of families were well represented and 12 families each contributed more than $1 \%$ of the identified fish.

These figures are based on averaged data for bird species which were sampled unequally and were of widely different abundance; however, the results are similar if $S$. fuscata, which is by far the most numerous species breeding on Christmas Island, is considered alone. By volume, its diet was $62 \%$ squid to $38 \%$ fish, while by number it was $40 \%$ squid to $60 \%$ fish. All of the identified squid were Ommastrephidae of the genus Symplectoteuthis. Among the fish, eight families were represented by more than $1 \%$ of the total number of identified fish, and five families by more than $5 \%$ (Appendix 3). The family Exocoetidae, which was the most important fish family in this and four of the other bird species, provided nearly one third of the total number of identified fish in the diet of $S$. fuscata, and $40 \%$ by volume (Fig. 5). Thus even Exocoetidae did not approach Ommastrephidae in their importance in the diet of this species.

These results imply that in the open ocean in the vicinity of Christmas Island, squid of the genus Symplectoteuthis are available to the birds in remarkable quantity and may rival in available biomass the whole of the rich fish fauna. Although at least some of the bird species feed to some extent at night, it seems certain that Symplectoteuthis spp. must be available at the surface in quantity during the day.

Another interesting aspect of the availability of squid is their remarkably high frequency of occurrence, relative to their numbers, in the diets of a number of the species (Table 3). In Ph. rubricauda and Pt. alba, in which a greater number of squid than fish were eaten, one would expect the frequency of oc- 
currence of squid to be higher than that of fish, but in P. nativitatis, S. fuscata and $A$. stolidus fish were far more numerous than squid, and yet the frequency of occurrence of squid was higher. In A. tenuirostris and Pr. cerulea, in which squid formed a tiny proportion of the diet by number, the frequency of occurrence of squid was nevertheless rather high. Only in G. alba is this trend reversed, squid occurring with relatively low frequency. This tendency for squid to have a very high frequency of occurrence in samples from a wide variety of species suggests that they are available at the surface of the ocean with great regularity. However, the observational evidence on the behavior of small squid in the open ocean is so scanty that no further discussion is profitable at present.

Ph. rubricauda, the largest of the birds studied, took about twice as many squid as fish, but in contrast to the situation in all the other birds (except Pr. cerulea) the squid were of smaller average volume than the fish, so that they provided just under half of the diet by volume. In spite of the fact that the samples contained, on average, a very low number of food items, the frequency of occurrence of both fish and squid is high, resulting in an outstandingly high proportion of samples $(71 \%)$ containing both fish and squid. Comparing the figures with those for the other species (Table 3), it is clear that in $P h$. rubricauda the frequency of occurrence of fish is peculiarly high in relation to their numbers, suggesting that this species contrasts with the others in feeding more on individual, dispersed fish rather than on shoals. It obtains large fish with great regularity, but often takes squid of much smaller volume in the same samples.

The diet of $P t$. alba contains a higher proportion of squid than those of any of the other species, and it also differs from all but $\mathrm{Pr}$. cerulea in the high incidence of other invertebrates, mostly insects and Crustacea. Squid provide $48 \%$ of the food by number, but this figure becomes $65 \%$ if the other invertebrates are excluded. Thus $P t$. alba takes nearly twice as many squid as fish, while all the other species (except $P h$. rubricauda) take greater numbers of fish. By volume, squid form $78 \%$ of the diet, since although fish and other invertebrates each contribute $26 \%$ of the total numbers of food items, by volume they make up only $22 \%$ together. $P t$. alba is unique among the species studied in eating parts of large squid, but, as discussed later, it is possible that it attacks only dead or moribund ones.

The diets of $P$. nativitatis, $S$. fuscata, and A. stolidus on Christmas Island were very similar in overall composition; they took respectively $63 \%, 60 \%$ and $71 \%$ of fish by number, the remainder being squid. In all three the percentage of fish by volume was lower (respectively $29 \%, 38 \%$ and $51 \%$ ), but the difference was most dramatic in $P$. nativitatis, emphasizing the small size of the fish taken by this species. Although in all three species the numbers of fish were substantially greater than those of squid, the frequencies of occurrence of squid were higher. This suggests that squid were available to these species with greater regularity, although fish were apparently more abundant when available.

G. alba forms an interesting contrast with these three species, since although the composition of its diet was extremely similar (fish $59 \%$ by number, 
$47 \%$ by volume), the overall frequency of occurrence of fish was $74 \%$ and of squid only $34 \%$. However, during the short visit in February 1964 squid were predominant in the diet, comprising $89 \%$ of the food items, $90 \%$ of the volume, and having a frequency of occurrence of $75 \%$. It thus appears that $G$. alba is more dependent on fish than any of the larger species-although less so than the two smaller noddies-but eats a high proportion of squid in certain periods when they are easily available.

The diets of the two remaining species, A. tenuirostris and Pr. cerulea, were similar to each other-and contrasted with those of all the other birds studiedin the overall importance of fish in the diet; in both, fish formed three-quarters of the food by volume and occurred in almost all the samples. In $A$. tenuirostris squid formed a tiny proportion of the food by number, but their relatively large size and the fact that they had a fairly high frequency of occurrence made them a significant part of the diet. In Pr. cerulea squid were of much less importance, but other small invertebrates, mostly marine water striders and tiny Crustacea (Table 6), were present in large numbers $(42 \%)$, appreciable volume $(16 \%)$ and in a high percentage of the samples $(82 \%)$. In this respect the diet of $\mathrm{Pr}$. cerulea contrasts strongly with that of the closely related $A$. tenuirostris, which feeds in mixed flocks with it, but which is just twice its weight; $A$. tenuirostris takes a very small number of Crustacea and no water striders. On the other hand one of the much larger species, Pt. alba, took $26 \%$ of invertebrates other than squid, of which half were fairly large Crustacea and other items, but the other half were water striders of the same species as those taken by Pr. cerulea (Table 6). We are therefore faced with the problem of why the catching of water striders should be impossible or uneconomic for $A$. tenuirostris, which is only twice the weight of Pr. cerulea and has similar feeding adaptations, and yet should be practicable for Pt. alba, which is more than five times the weight of Pr. cerulea. Presumably the answer lies in the method of feeding of Pt. alba, but as yet this is largely unknown (see section on Feeding Methods).

This discussion so far has been based on the overall composition of the diets, but it is useful also to consider the extent of variation among the sampling periods in the proportions of fish, squid, and other items. There is little sign of consistent seasonal variation in the composition of the diets of any of the species (see Fig. 8 and the section on Seasonal Variation), but it is clear that the diets of some of the species are much more variable than of others. For instance, the consistent dependence of $A$. tenuirostris on fish is noteworthy, while $P t$. alba never took more than a small proportion of fish. It is of interest to note in this connection that Belopol'skir (1957), in studies of sea birds extending over several years, found that birds feeding almost entirely on one type of food (for instance fish), did so in different years, even though the species composition sometimes changed markedly. The diets of $P$. nativitatis and $S$. fuscata both showed considerable variation, the latter being especially interesting since the number of samples involved was large, so that the observed contrasts are unlikely to be due to sampling errors. The most extreme variation was seen in G. alba, where the overall diet was about half fish and half squid, but the percentage of fish (by volume) reached $93 \%$ in August and was only $10 \%$ in February. 
The generally high level of variation in the composition of the diets suggests that most of the species take fish or squid indifferently as they become available, rather than hunting specifically for either fish or squid. Even A. tenuirostris and Pr. cerulea, which take very little squid, may not be exceptions, since they are the species known to feed close to the island (see section on Feeding Zones); it is very possible that Symplectoteuthis squid are less common in this area than in the open ocean where the other species feed.

\section{Size of Food Items (Fig. 4, Tables 4 and 5, And Appendix 2)}

In view of the general similarity in the composition of the diets of the various species studied, a comparison of the size of the individual food items taken by the different birds is clearly important in assessing the possibility of competition between them. Direct comparison of the length-frequency distributions of the prey of the different bird species can be made from the histograms of Fig. 4. The same data are used in the cumulative treatment in Table 5, showing more clearly how the birds fall into groups as regards the size of their prey. The most striking differences are between Ph. rubricauda and the other birds, as might be expected from the large difference in body weight. Of the fish taken by $P h$. rubricauda, $63 \%$ were longer than $8 \mathrm{~cm}$ (Table 5), while among the other species the highest proportion of fish longer than $8 \mathrm{~cm}$ was $16 \%$ (in $A$. stolidus). The length-frequency distribution of the fish obtained from Ph. rubricauda was of interest in that it showed no strong peak, a large number of classes being roughly equally represented. Of the squid taken by this species, $63 \%$ were more than $6 \mathrm{~cm}$ in mantle length, while among the other species the highest proportion was $22 \%$. It is noteworthy that in spite of its large size, $P h$. rubricauda produced regurgitations containing fewer items, on average, than those of any of the other species (Table 2). Since the regurgitations were as large relative to body size as in most of the other species, the small number of items per sample must reflect the fact that the fish taken were exceptionally large in relation to body size (Table 4). The squid, however, were of similar size relative to body weight as in most of the other birds. The fact that the fish and squid taken by $P h$. rubricauda averaged about the same in volume, whereas in all the other species except Pr. cerulea the squid were much bulkier than the fish, suggests that Symplectoteuthis squid larger than $12 \mathrm{~cm}$ in mantle length are not readily available. The large isolated eye-lenses, beaks and arms found in samples from $P t$. alba clearly came from much larger squid, but those that were identifiable proved to belong to members of different squid families (see Species Accounts). These squid may have been unavailable to Ph. rubricauda, or they may have been too large for it to swallow whole. Since this species lacks the adaptations of the bill which enable Pterodroma spp. and the albatrosses to tear off pieces from objects too big to swallow, it is not surprising to find such large squid unrepresented in its diet.

The next two species in size, $P$. nativitatis and $P t$. alba, fed upon prey of similar size; the length-frequency distributions for both fish and squid were closely parallel. However $P$. nativitatis took rather more fish in the $0-2 \mathrm{~cm}$ class and Pt. alba more squid in the $8-10 \mathrm{~cm}$ class. The latter difference is reflected in the volume data (Table 4), which show that the largest squid-and also the 
largest fish-taken by $P t$. alba were considerable bulkier both absolutely and in relation to the size of the bird than any taken by $P$. nativitatis.

These two Procellariiformes took unexpectedly small fish in comparison with the two largest terns, $S$. fuscata and $A$. stolidus, which are much lighter. $P$. nativitatis and Pt. alba took respectively $70 \%$ and $68 \%$ of fish less than $4 \mathrm{~cm}$ long, while for the terns the figures are respectively $34 \%$ and $44 \%$ (Table 5). This difference is not paralleled in the squid data; the length-frequency distributions for the four species are all extremely similar, although $P t$. alba was the only one to take an appreciable number of squid in the $8-10 \mathrm{~cm}$ class. As might be expected from this, the mean volumes of the squid taken by these species are fairly similar, while the volumes of the largest individual squid obtained from them show only minor differences (Table 4). Both Figure 4 and Table 4 show the similarity in the size of the prey taken by $S$. fuscata and $A$. stolidus, and even the apparent differences in the length-frequency distributions could be the result of inadequate sampling in $A$. stolidus. However, one fish obtained from $A$. stolidus had a larger volume than any from $S$. fuscata, and the mean volume of the fish in good condition was also considerably higher in A. stolidus.

G. alba, though closely similar in size to $A$. tenuirostris, took a higher proportion of large fish. The mean length of the fish obtained was close to those for $P$. nativitatis and Pt. alba, but the length-frequency distribution differed in the relative lowness of the peak in the $2-4 \mathrm{~cm}$ class and the larger numbers of fish both shorter and longer than this. As mentioned in the Species Account, regurgitations from adult G. alba (presumably of food not intended for chicks) contained more small fish than the samples carried back in the bill for chicks (Fig. 4, inset). It is certain that most-if not all-of the food for the chick is carried in the bill, and this habit could not have evolved, nor be maintained by selection, if a high proportion of the food items captured for the chick were very small. This is made clear by reference to A. tenuirostris, in which both adults and juveniles frequently regurgitated 50 or more tiny fish. If the adults carried food for their chicks in the bill, they would obviously need to make many more trips. In spite of possible bias in the sampling, the fact that $G$. alba took a substantial number of fish in the $4-6 \mathrm{~cm}$ and $6-8 \mathrm{~cm}$ classes, while $A$. tenuirostris took only a tiny number in the $6-8 \mathrm{~cm}$ class and few in the 4-6 cm class, is sufficient to show that $G$. alba makes much greater use of large fish than $A$. tenuirostris, at least while feeding young.

It is unlikely that the sample of squid obtained from $G$. alba is biased in favor of large individuals, since the majority were obtained from regurgitations in a short period in February, and all of these were in the $2-4 \mathrm{~cm}$ class, while at other times many squid in the $4-6 \mathrm{~cm}$ class were also obtained. Thus all that can be said is that neither $G$. alba nor $A$. tenuirostris took many very small squid, and neither took any more than $8 \mathrm{~cm}$ long. On the other hand it is certain that both took generally smaller squid than did the two petrels and the two larger terns (Table 4 and Fig. 4).

The size distribution of the fish taken by Pr. cerulea is very similar to that for $A$. tenuirostris, but even more heavily weighted towards the $0-2 \mathrm{~cm}$ class. Breaking this $0-2 \mathrm{~cm}$ class into two parts we find that the proportion of all the 
fish which are between 1 and $2 \mathrm{~cm}$ long is almost the same in the two species, but $P r$. cerulea takes twice as many in the $0-1 \mathrm{~cm}$ group (Table 5). This difference is reflected in the volume data (Table 4), which show that the fish taken by $\operatorname{Pr}$. cerulea average only about one-quarter the size of those eaten by $A$. tenuirostris. The relatively few squid taken by $P r$. cerulea were almost all smaller than those obtained from any of the other species.

\section{Representation of Different Kinds of Fish and SQuid (Fig. 5 And Appendices 3 AND 4)}

Since the diets of a number of the bird species are similar in general composition and in the size of the food items taken, it is of interest to consider whether there are important differences in the kinds of fish and squid taken. The comparisons have necessarily been made mainly at the family level, although some generic comparisons were possible in the case of the Blenniidae. The percentage representation of important fish families by number, volume and frequency of occurrence are shown in Figure 5, where the overall rankings are also indicated (see Methods of Analysis for details of the ranking system). The numbers of representatives of all the fish families obtained by each species are given in Appendix 3, together with the few precise fish identifications. The figure and the appendix must be used with the reservation-discussed in the section on Methods of Analysis-that in partly digested samples members of certain fish families are much easier to recognize than others. Pt. alba does not appear in Fig. 5 because the samples from this species were so far advanced in digestion that only one fish could be assigned to a family.

Fish from 33 families were identified, but many of these were represented in single or very few samples, and the 15 families shown in Fig. 5 include all those which rank high in the diet of any of the bird species. These families make up $93 \%$ of the identified fish by number.

In the diet of five of the seven species, the family Exocoetidae ranked first; furthermore, in G. alba, in which Blenniidae ranked first, Exocoetidae provided a higher percentage of the diet by volume. In Ph. rubricauda, P. nativitatis and $A$. stolidus Exocoetidae were of far greater importance than any other fish family, while in S. fuscata and A. tenuirostris other families were almost as important. Although the distinctiveness of remains of Exocoetidae must bias the results to some extent, there is no reason to doubt the pre-eminence of this family in the diets of these birds. Furthermore, the fact that Exocoetidae were not identified from Pt. alba may indicate that they did not make up a large proportion of the fish which it obtained. If so, this is a distinct difference between the diet of this species and those of all the other birds.

The main interest in the fish obtained from Ph. rubricauda is that although Exocoetidae were of outstanding importance, the other three families represented-Coryphaenidae, Diodontidae and Tetraodontidae-which all provided a significant fraction of the diet, were of little importance or were absent from the diets of the other birds. This evidence supplements the data on the frequency of occurrence of fish and squid, in suggesting that the feeding habits of Ph. rubricauda contrast strongly with those of the other species investigated. 
The fish portions of the diets of $P$. nativitatis, $S$. fuscata and A. stolidus were strikingly similar, although twice as many fish families were represented in the diet of $S$. fuscata as in the other two species (undoubtedly partly due to the fact that more samples were obtained from $S$. fuscata). In all three species Exocoetidae were important, but in $S$. fuscata Scombridae were almost equally important, and this feature differentiates the diet of this species from all the others studied; Gempylidae and Emmelichthyidae were also present in quantity, but none of the other 17 families was of great importance. In $A$. stolidus Exocoetidae, besides being far more abundant than the members of any other family, were on average much larger than the other fish taken. However, Scombridae and Gempylidae ranked second and third respectively, as in S. fuscata.

G. alba, in which nearly all the fish were identifiable, fed on a very different selection of fish. Blenniidae were the most important family, and it has already been mentioned that most of these blennies were kinds not taken at all by the other birds (see Species Accounts). Over half the Exocoetidae were halfbeaks, which were relatively unimportant in the diets of the other bird species; Myctophidae ranked third. In all, 22 families were represented, the highest number for any of the bird species. Although these included five families not identified in samples from the other birds, the four families Emmelichthyidae, Coryphaenidae, Diodontidae and Tetraodontidae were absent.

In $A$. tenuirostris, whose diet was almost entirely fish, more than two thirds were unidentifiable, but the remainder were sufficient to indicate that a wide variety of families were important in the diet, with no one outstanding. Exocoetidae ranked first, but nine other families were important either by virtue of their numbers, volume, or frequency (Fig. 5), and a total of 17 families were recorded. Pr. cerulea, which appeared to feed largely in the same places as $A$. tenuirostris, had a very different diet, in that Gempylidae were enormously more abundant than any other fish family. Next in importance were Type $\mathrm{X}$ (see note to Fig. 5), a group represented elsewhere only by two individuals from $A$. tenuirostris; Exocoetidae ranked third. Only seven families were recorded in the diet.

The cephalopods collected up to the end of September 1963 were individually examined by Dr. Malcolm Clarke, and identified as far as possible. Because the vast majority of these proved to be squid of a single genus, and because nearly all the squid obtained later in the study were similar, only a few of the latter were sent for identification. A summary of the data for the period March through September 1963 is given in Appendix 4. Of the 869 cephalopods examined $790(91 \%)$ were definitely or provisionally identified to the family level. Of these, $84 \%$ were definitely Ommastrephidae, while an additional $15 \%$ were recorded as being 'probably' or 'possibly' Ommastrephidae. However, fragmentary remains of cephalopods belonging to families other than Ommastrephidae were also obtained from Pt. alba (see Species Account), and squid obtained from G. alba in February 1964 were largely Enoploteuthidae (see Species Account). Of the Ommastrephidae which were identified definitely to the generic level, all were Symplectoteuthis. 257 Symplectoteuthis squid were definitely assigned to species, and another 117 were tentatively identified; only two species were present, and of the individuals definitely 
identified $92 \%$ were species $\mathrm{A}$ and $8 \%$ species $\mathrm{B}$ (see definition under Identification of Food Items in Ph. rubricauda Species Account). However, the data suggest that Ph. rubricauda takes a higher proportion of species B than the other birds; 15 individuals (in 6 samples) were definitely or tentatively assigned to species $\mathrm{A}$, and 10 individuals (in 4 samples) to species $\mathrm{B}$. 


\section{FOOD OF SURFACE-CAUGHT YELLOWFIN TUNA}

Through the cooperation of the Biological Laboratory, Honolulu, of the Bureau of Commercial Fisheries, U.S. Fish and Wildlife Service, we are able to present details of the food of Yellowfin, Neothunnus macropterus (Temminck and Schlegel), caught at the surface in the Christmas Island region. Although other predatory fish species, in particular Skipjack, Katsuwonus pelamis (Linnaeus), undoubtedly feed extensively in the surface layers of the sea in this area, there are fewer data on their food. A comparison of the food of tunas with that of tropical oceanic birds is of particular interest since there is evidence that many species of birds depend very largely on schools of aquatic predators, probably mainly tunas, to make their prey available at the surface of the sea. At least close to islands, most fish schools feeding at the surface have birds associated with them (Murphy and Ikehara 1955), and one might expect to find a close correlation between the food of the two groups.

The Yellowfin is common in the Central Pacific and frequently feeds in the surface layers when young, especially close to islands. Large numbers were caught in the region of the Line Islands and Phoenix Islands during 12 cruises of Fish and Wildlife Service Vessels in 1950 and 1951. Data on the food of Yellowfin obtained during these cruises were presented by Reintjes and King (1953). However, in the present context it seemed important to limit consideration to surface-caught fish, so we have re-analysed the relevant data.

Our analysis is of quantitative data and identifications-filed on punch cards - of the stomach contents of the 191 Yellowfin caught by surface trolling within 10 miles of Christmas Island, and also of Fanning, Washington and Jarvis Islands, its closest neighbors. Fish caught with pole-and-line were excluded since they were almost all obtained in one month, while the troll-caught fish were relatively well distributed by season, as follows; February (1951) 24, April (1951) 34, May (1950) 50, May (1951) 15, June (1951) 4, September (1950) 11, November (1950) 53. A few Yellowfin were caught at the surface more than 10 miles from the islands. These fish were excluded from the analysis because of their small numbers, although if more had been available it would have been especially interesting to compare their food with that of the birds, since most of the bird species feed far from land. The Yellowfin involved in the present analysis were mostly rather small, $36 \%$ being less than $1000 \mathrm{~mm}$ in fork length, while only $2 \%$ were more than $1300 \mathrm{~mm}$. Larger individuals are more often caught on longline gear than at the surface.

As far as possible the tuna food data were treated in the same way as those for the bird food, although the samples consisted of stomach contents and not regurgitations, and were collected in different years and with different seasonal distribution. However, it does seem reasonable to suppose that these tuna were feeding at times in close association with some of the bird species studied. In particular A. tenuirostris and Pr. cerulea are inshore feeders, whilst $A$. stolidus and G. alba probably do a fair proportion of their feeding within 10 miles of land. 
The details of the analysis are given in Appendix 5, but the overall proportions of fish, squid (with which we have included 4 small octopods) and other invertebrates in the Yellowfin stomachs are shown in Fig. 3. The very high proportion by number $(96 \%)$ of other invertebrates is immediately evident, being far greater than in any of the bird species. However, these items were mostly very small and provided only $61 \%$ of the volume. Thus although Yellowfin are capable of taking very large items (one carangid of $540.0 \mathrm{ml}$ was obtained) most of the food items were tiny (about $0.5 \mathrm{ml}$ ). The frequencies of occurrence of squid and especially of fish were high, considering their low total numbers: few stomachs contained neither fish nor squid.

The fish in the diet of the Yellowfin, although only $3 \%$ by number, formed $34 \%$ by volume. Nineteen fish families were identified in our sample of Yellowfin stomachs (Appendix 5), which is just under half of those recorded in Reintjes and King's study of their whole series of 1,097 stomachs. Of the identified fish, only $9 \%$ (both by number and by volume) were from families represented on Figure 5-i.e., families that ranked high in the diet of at least one of the bird species studied. Furthermore, $10 \%$ of the identified fish $17 \%$ by volume) were from families not identified at all in the diets of the birds. The most important fish families in the diet of Yellowfin were Carangidae, Acanthuridae, and Ostraciontidae; of these the first and third were not found in the food of the birds, while Acanthuridae were identified only in very small numbers. Together, these three families formed $84 \%$ of the identifiable fish $(74 \%$ by volume). Blenniidae and Myctophidae, two families which occurred regularly in the diets of some of the bird species, were next in importance. The identified Blenniidae were Petroscirtes sp., the same genus as a few larval blennies obtained from G. alba.

Three families of fast-swimming fish which ranked high in the diets of the birds were not important in the diet of the Yellowfin included in our sample: Exocoetidae and Scombridae each occurred in only one Yellowfin stomach and Gempylidae in two. Yellowfin do obtain Exocoetidae (flying fish and halfbeaks) at times: for instance, in Reintjes and King's full study 24 individual Exocoetidae were recorded. Nevertheless, the overwhelming importance of members of this family in the diets of the birds, and their relatively infrequent occurrence in stomachs of surface-caught Yellowfin, suggests that the ability to "fly" above the surface of the water is a rather effective defence against aquatic predators, but renders the animals extremely vulnerable to predation by agile sea birds. Scombridae and Gempylidae were also better represented in Reintjes and King's full study than in our samples; however, their ability to swim at high speed might be expected to make them relatively less vulnerable to predation by other fish than by birds, so their better representation in the samples from the birds than in those from the tunas is reasonable.

Very few of the squid found in the stomachs of Yellowfin were identified, even to family level. However, of the two species occurring in the study as a whole, one was Symplectoteuthis oualaniensis, the same 'species' that occurred commonly in the diets of most of the birds. Two individuals of this form were the only identified squid in the Yellowfin stomachs now under consideration.

The other invertebrates were mostly very small, and a large number of them 
were unidentified megalops (crab larvae). During two days in May 1950, an exceedingly dense aggregation of megalops was in the vicinity of Christmas Island and the Yellowfin caught at this time contributed very largely to the high numbers of other invertebrates. If such a concentration had been present during 1963/64, it might well have been utilized by the birds, especially Pr. cerulea. No water striders were recorded in the tuna stomachs.

Thus, although there are many biases in this type of comparison, it does seem that there is surprisingly little overlap in the food of Yellowfin feeding at the surface close to land and the food of the bird species in this study. One important consideration is that all the tunas whose stomachs were analysed were caught within ten miles of land, while a number of the bird species probably fed almost entirely outside this range (see Feeding Zones). This partly explains the fact that the percentage of fish in the diet of the Yellowfin which are members of primarily reef-originating families is far higher $195 \%$ : data in Appendix 5) than in any of the birds studied. (For details of the designation of "reef-originating" fish families, and of the proportions of reef-originating fish in the diets of the birds, see text under Feeding Zones, Table 7, and Appendix 3.) However, it must also be remembered that, as described elsewhere, most of the bird species can catch prey only when it is very close to the surface, and this happens mainly when the prey animals are pursued from below by predatory fish; it may well be that certain fish hardly ever come right to the surface, even when pursued. These fish would not be available as food for most of the birds even if they were common below the surface and were eaten extensively by tunas. This situation might apply, for instance, to members of the family Acanthuridae, which are common in inshore waters and were eaten in numbers by the Yellowfin, and yet were found in very few samples obtained from the birds. 


\section{THE BIRDS IN THEIR MARINE ENVIRONMENT}

\section{The Environment, and the Availability of Food}

The environment of the sea birds of Christmas Island, apart from their nest sites, is provided by the Central Equatorial Pacific, a region which has been the subject of extensive research by the staff of the U. S. Bureau of Commercial Fisheries Biological Laboratory in Honolulu. The following brief account is based almost entirely on the results of this work, and especially on an able discussion by Murphy and Shomura (manuscript) of the distribution of tunas in relation to environmental factors, which the authors have kindly allowed us to see before publication.* We consider in the present paper only those aspects of the oceanography and biology of the region which are most relevant to the feeding ecology of the birds; seasonal aspects are treated in a later section.

The dominant features at the surface in the Central Equatorial Pacific are three currents, the North Equatorial Current flowing to the west north of about latitude $10^{\circ} \mathrm{N}$., the South Equatorial Current flowing to the west south of about latitude $5^{\circ} \mathrm{N}$., and the Equatorial Countercurrent flowing to the east between them (Fig. 2). The northeast trade winds blow over the North Equatorial Current and the southeast trades over the South Equatorial Current. Christmas Island, at $2^{\circ} \mathrm{N}$., lies in the South Equatorial Current, about 200 miles south of its boundary with the Countercurrent. The oceanography of the region has been described in a series of reports (references in Austin, 1960). Recently Roden (1963) has analysed variations in sea level, temperature and salinity of the Central Tropical Pacific, while Wyrtki (1965) presented results of harmonic analysis of the sea surface temperatures. The climatology of the region is also discussed by Hutchinson (1950), Riehl (1954), and Wiens (1962).

A critical feature of the oceanography of the Central Equatorial Pacific is the upwelling of nutrient-rich water which occurs in the South Equatorial Current at the Equator (Cromwell 1953). Ryther (1963) explained: "Briefly, the effects of Coriolis's force north and south of the equator on the westerly drift of the Equatorial Current results in the poleward divergence of the surface layers, which are replaced with water upwelling from depths within the thermocline $(150-200 \mathrm{~m})$." The equatorial upwelling is responsible for the fact that zooplankton abundance is generally higher between $112^{\circ} \mathrm{S}$. and $5^{\circ} \mathrm{N}$. than further from the Equator (King and Hida 1957), although it is still low in comparison with many other regions (King and Demond 1953). Similarly, King and Iversen (1962) found that forage organisms sampled by midwater trawls (mainly at night) were more abundant within $5^{\circ}$ of the Equator than further to the north and south.

Murphy and Shomura argue that the upwelled westerly-flowing water north of the Equator is deflected towards the northwest to an extent which varies, spatially and temporally, according to the regularity and strength of the southeast trade winds. The region between about $112^{\circ} \mathrm{N}$. and the southern boundary

\footnotetext{
*While this paper was in press we encountered the discussion by Blackburn of the role of fronts in concentrating food for tunas (1965, Oceanogr. Mar. Biol., Ann. Rev. 3: 299-322).
} 
of the Countercurrent is a zone of convergence. Plankton concentrations are highest close to the Equator, but as the water moves to the northwest it "matures"; that is to say it becomes warmer, the concentrations of phosphate and zooplankton decline, and deep-swimming Yellowfin become more abundant, presumably because they congregate to feed on the forage animals responsible for the decline of the zooplankton. It appears that the Line Islands lie in a region (about longitudes $140^{\circ}-160^{\circ} \mathrm{W}$.) which benefits most from the equatorial upwelling, since the upwelled water is richer in nutrients than further east, and the wind stress is generally sufficient to cause vigorous upwelling but not so. strong as to transport the upwelled water to the convergence south of the Countercurrent before it has time to mature.

However, it must be remembered that most tropical sea birds depend partly or entirely on schools of predatory fish (mainly tunas) to drive their prey close to the surface and so make it available. Murphy and Shomura demonstrate that the distribution of these surface schools of small tuna is at variance with that of the larger deep-swimming tuna and cannot be explained in terms of the general distribution of zooplankton.

In the Central Equatorial Pacific surface schools of tuna are on average far more abundant close to land, where they comprise mainly small Yellowfin, than in the open ocean, where Skipjack predominate (Murphy and Ikehara 1955). However, there are certain zones of open ocean which have relatively high densities of surface schools. Thus the latter authors, considering oceanic areas far from land, found that in the latitudinal zone between $0^{\circ}$ and $5^{\circ} \mathrm{N}$. (in which Christmas Island lies), less than half as many fish schools were seen per day as in the Countercurrent $\left(5^{\circ}-10^{\circ} \mathrm{N}\right.$.) or in the South Equatorial Current south of the Equator $\left(0^{\circ}-10^{\circ} \mathrm{S}\right.$.). Abundance was again low in the North Equatorial Current (north of $10^{\circ} \mathrm{N}$.).

Murphy and Shomura suggest that the abundance of tuna schools in certain zones of the open ocean may be explained by their association with "fronts," and also that phenomena similar to "fronts" may occur close to islands, resulting in concentration of tuna schools there. A "front" is defined by Cromwell and Reid (1956) as " a band along the sea surface across which the density changes abruptly." However, fronts are normally detected by abrupt changes in the surface temperature, which may be of the order of degrees per hundredth or tenth miles, but are often much less (Voorhis and Hersey 1964). Although it is clear that there are many different types of fronts, many of them are associated with convergence and sinking (Uda 1938, Cromwell and Reid 1956, Knauss 1957). The biological significance of such fronts is that they tend to concentrate plankton species which are capable of resisting the downward currents. As pointed out by King and Demond (1953): "When a strong convergence has persisted for a sufficient length of time, an area of relatively high-plankton abundance should result, providing rich pasturage for plankton-feeding animals" (see also Ragotzkie and Bryson 1953). We do not know of published accounts of measurements of the abundance of plankton or nekton at fronts, but Uda (1938) noted "yellow-greenish water-colour due to the densely concentrated planktons" at a "siome" (i.e., a front visible at the surface) in the North Pacific near Japan, while the fascinating account by Beebe (1926: 41-70) of a major cur- 
rent rip (i.e., front) in the Eastern Pacific at $2^{\circ}$ N., $86^{\circ}$ W., demonstrated the remarkable concentrations of organisms which are sometimes produced. Beebe said: ". . . here was a concentration of organisms greater than I have ever seenthe larger dotting the water and making visible its depths, the minute so abundant that in places they were of the consistency of soup." It is clear that even slow sinking of converging water at a front must rapidly cause enormous differences between the abundance of plankton along the line of the front and in the areas away from it. The narrowness of the rich zone was particularly noted by Beebe (p. 50): "Again and again I was impressed with one outstanding feature of the Current Rip, this uncharted zoölogists' paradise-the narrowness of its limits and the sharpness with which these limits were defined. It was a world, not of two, but to all intents and purposes of a single plane-length. From first to last we followed its course along a hundred miles, and yet ten yards on either side of the central line of foam, the water was almost barren of life. The thread-like artery of the currents' juncture seethed with organisms-literally billions of living creatures, clinging to its erratic angles as though magnetized." Beebe clearly recognized the convergent nature of the front, although he did not speak in terms of sinking water. However, the narrowness of the rich zone is a clear indication that this was the concentrating mechanism.

The overriding importance of fronts in producing local concentrations of forage animals probably accounts for the fact that although zooplankton abundance in general is higher between the Equator and $5^{\circ} \mathrm{N}$. than between $5^{\circ} \mathrm{N}$. and $10^{\circ} \mathrm{N}$. (King and Hida 1957), surface schools of tuna are much more abundant in the latter zone. In the best-studied region, between $140^{\circ} \mathrm{W}$. and $170^{\circ}$ W., Murphy and Shomura demonstrate a close correspondence between the average rate of sighting tuna schools (generally accompanied by birds) in three different latitudinal zones of the open ocean, and the rate of crossing fronts in the different zones. To give an idea of the actual abundance of fronts and birds it should be mentioned that in the area between $0^{\circ}$ and $5^{\circ} \mathrm{N}$. fronts were crossed at an average rate of 0.34 per $11 / 2$ hours, while fish schools were detected at a rate of 0.34 per day. (A front was defined in this case as "a temperature change of any magnitude that was completed during 15 minutes or less at a speed of about 8 knots.") It thus appears that although there is a zone of convergence (and often an "Equatorial Front") between $112^{\circ} \mathrm{N}$. and $5^{\circ} \mathrm{N}$. (Cromwell 1953), the greater number of fronts in the area of the Countercurrent provides more rich feeding grounds for tuna and birds. Presumably the high frequency of fronts in this area results partly from the complex interactions of the westward or northwestward flowing water at the northern boundary of the South Equatorial Current with the variable eastward flow of the Countercurrent. Probably many of the fronts are local and transitory, but whenever they are associated with sinking they could be important in concentrating plankton and the forage animals on which the tunas and birds feed. Whereas the zone between the Equator and $5^{\circ} \mathrm{N}$. has much less than half as many tuna schools and fronts than the Countercurrent, the South Equatorial Current between the Equator and $5^{\circ} \mathrm{S}$. is almost as rich as the Countercurrent, both in tuna schools and fronts.

The great importance of fronts associated with convergence, as well as areas of upwelling, in providing favorable feeding grounds for fish and whales has pre- 
viously been recognized (Beebe 1926, Uda 1938, 1953, 1954). However, Murphy and Shomura's demonstration of the correspondence between the abundance of fronts and the abundance of surface schools of tuna in different parts of the Central Pacific may prove to be an important advance in the understanding of this area, and perhaps provides the explanation of its relatively high populations of surface-feeding tunas and sea birds, in spite of the low average abundance of zooplankton (cf. King and Demond 1953: 141).

It has long been known by ornithologists that marine birds often congregate to feed at the boundaries between currents (for example, Beebe 1926, Brooks 1934, Murphy 1936: 88-89, Stonehouse 1962a, King and Pyle 1957, Bourne 1959: $15,1963,1965)$, but the richness of such areas has often been attributed to the effects of upwelling or vertical mixing in making nutrients available, whereas it now appears that concentration of organisms as a result of convergence and sinking at fronts is frequently the critical phenomenon. Simple observations at sea should generally permit differentiation of the two phenomena, since upwelling of nutrient-rich waters produces a broad zone of enrichment tens or hundreds of miles wide, while the concentration of organisms at a convergent front may be only a few tens of yards in width, as noted by Beebe (1926). A zone in which there are many fronts, for instance the Equatorial Countercurrent in the Pacific (Murphy and Shomura), may give a superficial appearance of homogeneity, but the fact that fronts can easily be detected by thermograph readings, even when they are not visible at the surface, provides interesting opportunities for further investigation.

While the above discussion has concerned fronts in the open ocean, Murphy and Shomura point out that "front-like" circulation cells and eddies are found near islands, especially on the leeward sides. They are produced by flow of a current past the island, and involve some vertical mixing, and so can result in local enrichment (Sette 1955, McGary 1955, Hardy 1928). While the data of King and Hida (1957, Appendix A) did not show any great abundance of zooplankton round Palmyra Island, it is probable that concentrations in eddies are often so local as to be difficult to detect by routine sampling. However, the importance of reef-dwelling fish (especially Acanthuridae) in the diet of Yellowfin caught close to islands (Appendix 5) suggests that the availability of food close to reefs, as well as concentrations of plankton and forage animals in eddies, may be important in maintaining the tuna populations close to islands. Both these factors are compatible with the fact that a very high percentage of the tunas caught by live-baiting and trolling in the vicinity of the Line Islands and Phoenix Islands are obtained within a few miles of the islands on the leeward side (Bates 1950, Ikehara 1953).

This discussion of the distribution of surface schools of tunas in the Central Pacific is directly relevant to the feeding ecology of the birds of Christmas Island, for two closely linked reasons. First, since tunas are highly mobile predators feeding on many of the same types of foods as the birds, their distribution should be a fair indication of the distribution of potential food for the birds. Second, probably all the tern species, and the other birds to a greater or lesser extent, are dependent on the presence of marine predators such as tunas to make potential prey available at the surface. We may therefore come to the prelimi- 
nary conclusion, which needs confirmation by direct systematic observations, that for oceanic birds breeding on Christmas Island there are several widely separated areas which may provide abundant available food. First, there will be a favorable feeding area to leeward of the island, whose size is not known but which probably does not extend more than about twenty miles to the west. Second, for birds which are adapted to feeding far from the colony, exceptionally favorable feeding areas may be present in the Countercurrent a few hundred miles to the north, and a roughly equal distance in the opposite direction, in the South Equatorial Current south of the Equator. There is also the possibility that there may sometimes be a fairly rich feeding zone for Christmas Island sea birds at a distance intermediate between the inshore zone and the distant oceanic areas to north and south; this would be associated with convergence and sinking at the "Equatorial Front" which is sometimes present within the South Equatorial Current at about $2^{\circ} \mathrm{N}$.

The importance of the inshore feeding area to certain bird species is apparent from our observations, which are discussed in the next section. There are many indications that the Countercurrent is rich in birds (see especially King and Pyle 1957, Bruyns 1965, as well as Murphy and Ikehara 1955 and Waldron 1964). King and Pyle's observations suggest that the northern boundary of the Countercurrent has especially high densities of birds, but the nature of the oceanographic features responsible for the richness of this zone is not yet fully understood (see discussion in Austin 1960). Bates (1950) reported Captain Castle (an experienced commercial fisherman) as having several times observed "booby birds" [probably Red-footed Boobies] "by the thousands" working over tremendous concentrations of Yellowfin in an area some 200 miles north of Christmas Island, in the region of the convergence of the Equatorial Countercurrent with a northwesterly current originating at Christmas Island. Of interest also is Captain Castle's opinion that in the Line Islands the local current interfaces or "tide rips" (i.e., fronts) and not the reef areas contain the greater concentrations of tuna.

It was not practicable to sample directly the food available to the sea birds during the study on Christmas Island. However, in 1951 and 1952, U. S. Fish and Wildlife Service research vessels sampled the forage animals in the surface layers of the sea (down to $400 \mathrm{~m}$ ), mainly with Isaacs-Kidd trawls, in connection with their studies of the food of tunas (King and Iversen 1962). The results of this work showed a good general correlation between the trawl-catch volumes and zooplankton volumes, both being highest in the South Equatorial Current between $5^{\circ} \mathrm{S}$. and $5^{\circ} \mathrm{N}$., slightly lower in the Countercurrent, and yet lower further to the north and south (King and Iversen 1962, King and Hida 1957).

The usefulness of the results of this trawling in considering the feeding ecology of the birds is limited by the fact that nearly all the trawling was done at night, while the few daytime hauls gave dramatically different results. For instance in the Countercurrent at about $6^{\circ} \mathrm{N}$., between $161^{\circ} \mathrm{W}$. and $163^{\circ} \mathrm{W}$., four hauls were made two hours after sunrise and two hauls one hour after sunset, all within 110 meters of the surface. The day hauls had an average volume of $11.4 \mathrm{ml}$. , with an average of 158 organisms, while the night hauls averaged 106.4 ml., with 614 organisms. Thus, far fewer animals were obtained during the day 
and they, were on the average much smaller, nearly all the fish and squid captured being larval forms.

Although some of the stronger swimming animals may have been able to dodge the net during the day (Pearcy and Laurs 1966), the difference between day and night hauls must be primarily related to the nightly movement to the surface waters of animals which are mesopelagic during the day, forming the "deep scattering layers." (The mesopelagic zone is that between about 200 and $1000 \mathrm{~m}$-Hedgpeth 1957.) The animals in the deep scattering layers which reflect back sound from echo-sounders are evidently mainly fish, especially Myctophidae (Hersey and Backus 1962), but some Crustacea (especially Euphausiidae and Sergestidae) apparently show similar movements. King and Iversen's data suggest that in the Central Pacific Myctophidae form a large proportion of the fish which are close to the surface only at night, but that Stomiatidae, Gonostomatidae and Nemichthyidae are also important, and a number of other families probably fall into the same category (see also Marshall 1960). These groups of fish and Crustacea are not represented to a large extent in the stomach contents of Yellowfin and Skipjack caught at the surface and on longline gear in the Central Pacific (Reintjes and King 1953, Waldron and King 1962) suggesting that although the animals of the deep scattering layers doubtless constitute the major part of the biomass of the forage animals of the area, their migration during the day to depths to which light hardly penetrates is a rather effective way of avoiding predation by tunas, which apparently feed mainly during the day.

Since the birds included in this study depend largely on tunas to make their prey available, Myctophidae and other fishes with similar habits should not normally be available to them. However, several of the bird species did in fact obtain some Myctophidae and Gonostomatidae, suggesting that they sometimes feed at night, or during twilight periods when some Myctophidae and similar fish are sometimes still present close to the surface (Pearcy 1964). It is clear that for the animals of the deep scattering layers there must be a very critical balance of selective pressures operating to determine the light intensities at which they should arrive at and leave the surface; individuals arriving earlier or staying later will obtain more food, but will run a higher risk of predation. The occurrence of some of these fish in food samples from birds is presumably a manifestation of the latter type of selection.

The foregoing discussion of the representation in the diets of the birds of fish which are at the surface only at night should not be allowed to obscure the fact that a vast proportion of the food of the birds consists of fish and squid which are epipelagic and are present in the surface layers during the day; these animals are very rarely caught by trawling. Of the fish, Exocoetidae, Scombridae and Gempylidae are all of great importance in the diets of the birds; probably none of these are actually available to birds feeding at the surface except when pursued from below, but all are normally found close to the surface. Blenniidae are also important in two of the bird species and are eaten to some extent by Yellowfin and Skipjack. However, they are totally absent from samples obtained by midwater trawling in the open ocean (King and Iversen 1962); they may perhaps be commoner close to land, although some of the species concerned are not reef dwellers. 
In general, squid are apparently present at the surface more commonly at night than during the day (see, for instance, Baker 1960), but small squid are sometimes seen at the surface in daylight. Furthermore, the importance of Ommastrephidae of the genus Symplectoteuthis in the diets of so many of the bird species (including some that do not normally feed at night) strongly suggests that these squid are regularly available at the surface during daylight, although perhaps especially in the morning and evening (see data for G. alba-Table 9). Certain squid (including a number of Ommastrephidae) are known to be able to jump clear of the water (Arata 1954, Lane 1957, Clarke, 1966), while Heyerdahl (1950) reported that in the South Pacific, small squid were regularly seen in daylight gliding several feet above the water. Although there are no records of flying behavior in Symplectoteuthis spp., this may well be because of the small number of observations of flying squid in which the species concerned has been identified, and there is already enough evidence to indicate that some members of the family Ommastrephidae have evolved a method of escape from marine predators similar to that used by the flying fish (Exocoetidae). This adaptation is probably very effective in relation to predators approaching from below, but it must render the animals especially vulnerable to predation by those birds-such as $S$. fuscata-which are specialists in catching their prey in the air. It is doubtless more than coincidence that Exocoetidae and Ommastrephidae-both groups of animals noted for their flying ability-are much more important in the diets of tropical sea birds than in those of tunas.

\section{Feeding Zones, and Adaptations for Feeding FAR FROM THE COLONY}

It was argued in an earlier paper (Ashmole 1963a) that population size and many features of the biology of tropical sea birds are profoundly influenced by the fact that "their breeding distribution is largely governed by the distribution of islands suitable for breeding, and while breeding they must either use only a small proportion of the total available feeding areas, or they must spend much time flying to and from more distant feeding areas." It is clear that some of the birds of Christmas Island are adapted to the first of these alternatives, feeding only close to the island, while others exploit the second, commuting great distances between their feeding grounds and the breeding colonies.

Since direct observations were made on the feeding zones of only a few of the species, we must use for the others negative evidence and observations from other areas. However, for most of the species we also have information on the lengths of incubation shifts and data on the relative proportions of reeforiginating and pelagic fish in the diets (see below).

It can be seen from Table 7 that among the species studied there was enormous variation in the mean length of the incubation shifts, the extremes being Sterna fuscata with a mean of seven days, and Anous tenuirostris with a mean of $171 / 2$ hours. In general, long incubation shifts in a population indicate that abundant food is not available close to the nest, since short shifts are uneconomic if the time required to fly to and from the feeding grounds is long. Shifts lasting several days, which are found in many petrels in the temperate zones as well as in the majority of tropical sea birds, occur when birds have to travel great 
TABLE 7. Length of incubation shifts of some sea birds on Christmas Island, and percentages of identified fish in their diets belonging to primarily reef-originating families (for details see text under "Feeding Zones ...", and Appendix 3)

\begin{tabular}{lccc}
\hline \hline \multicolumn{1}{c}{ Species } & $\begin{array}{c}\text { Mean length of } \\
\text { shifts observed }\end{array}$ & $\begin{array}{c}\text { Number of 'bird days' } \\
\text { of observations on } \\
\text { incubation shifts }\end{array}$ & $\begin{array}{c}\text { Percentage of identified } \\
\text { fish designated as } \\
\text { reef-originating }\end{array}$ \\
\hline Phaethon rubricauda & 6 days & $17 \frac{1}{2}$ & $0^{\mathrm{b}}$ \\
Puffinus nativitatis & $4 \frac{1}{2}$ days & 9 & 3 \\
Pterodroma alba & 5 days & 36 & No information \\
Sterna fuscata & 7 days & $69 \frac{1}{2}$ & $9 \mathbf{b}^{\mathrm{b}}$ \\
Anous stolidus & No information & 0 & $34^{\mathrm{a}}$ \\
Gygis alba & 3 days & 31 & 56 \\
Anous tenuirostris & $17 \frac{1}{2}$ hours & $31 \frac{1}{2}$ & 5 \\
Procelsterna cerulea & 20 hours & 14 & \\
\hline
\end{tabular}

NOTES FOR TABLE 7 :

a. Calculated by summating the periods of observations at all the nests and dividing by the total number of change-overs recorded. Nests were inspected at $0700 \mathrm{hrs}, 1300 \mathrm{hrs}$, and 1900 hrs each day.

b. Diodontidae and Tetraodontidae omitted: see text.

c. Some Blenniidae omitted: see text.

distances to their feeding grounds from the nearest available breeding locality. However, selection for shifts lasting several days will be strong, even if the feeding grounds are only a relatively short distance away, if the food there is patchy in distribution or sometimes unavailable (for instance during storms). The longer a fishing trip is, the less likely it is to be unproductive as a result of bad luck in searching for food, or of short-term fluctuation in its availability. This factor will be important in the evolution of shifts of a particular modal length, since the off-duty bird cannot return until it has built up sufficient reserves to last through the subsequent shift. If it fails to obtain enough food during the period of the normal shift, and so does not return at the expected time, its mate is likely to desert. This has been observed, for example, by Vogt (1942, reprinted 1964) in Phalacrocorax bourgainvillii and by Dorward (1962) in Sula dactylatra. In burrow-nesting petrels, eggs are sometimes left unattended for periods of a few days during incubation, but are brooded again when an adult returns, and eventually hatch (Davis 1957, Warham 1964). However, in surface-nesting birds, unattended eggs are usually quickly predated or the embryo is killed by extremes of temperature.

Since birds which utilize a patchy or unreliable food supply must anyhow be capable of fasting for considerable periods, the development of long shifts probably does not present physiological problems requiring extensive special adaptations. However, it should be noted that in at least some of the species involved (for instance, $S$. fuscata) incubating birds leave the egg at intervals to drink sea water. The flexibility of the length of incubation shifts is emphasized by the large differences sometimes found between different populations of single species, which are evidently related to differences in the characteristics of the food supply (this point is further treated in the discussion). 
In the period when the adults are feeding a chick, the situation is rather different. When away from the colony fishing, the adults no longer need to build up their reserves for a long fast, but can return to the colony as soon as they have satisfied their immediate needs and have obtained a full load of food for their chick. Unfortunately we have no data on the frequency of feeding of the chicks by the adults in the species concerned; however, it is fairly certain that the adults return to the island more frequently when they are feeding chicks than when they are incubating. Even in the species with very long incubation shifts, it is probable that the chick normally receives food from one of its parents about every two or three days, and in G. alba, A. tenuirostris and Pr. cerulea the chick is probably often fed more than once a day.

It is clear that the Christmas Island sea birds, which have such long incubation shifts, could be foraging at enormous distances from the island even when incubating. To take the most extreme example, if it is assumed that $S$. fuscata flies at 30 miles per hour, and that flight continues throughout the night, a seven-day incubation shift would enable an offduty bird to make a one-day flight to a feeding area 700 miles away, followed by five days searching for and catching food, and building up reserves for the subsequent fast, and then to return in one more day. Even though the birds doubtless normally feed closer than this, the long shifts could carry a selective advantage as an insurance policy, as discussed above.

The use of information on the relative proportions of reef-originating and pelagic fish in the diets, in assessing the feeding zones of the different bird species, was suggested by the work of Nakamura (1965) on the feeding of Skipjack in the area of the Marquesas and Tuamotu Islands. Nakamura divided the fish families (and also the other groups of prey animals) represented in the diets of Skipjack into a group which may be considered primarily reef-originating, in that they spend their adult life on reefs or in other non-pelagic areas (even though their larval or juvenile stages are often pelagic), and a group which are pelagic as adults. Separating the Skipjack into those caught within 75 miles of points roughly in the center of the island groups, and those caught between 75 and 150 miles and between 150 and 225 miles out, Nakamura showed that the percentages of reef-originating forms in the stomachs were much lower in the areas far from the islands (respectively 61.5, 39.9 and 8.8\%). We have undertaken a similar analysis of the diets of the birds, but considering only the fish portion of the diet. The fish families designated as primarily reef-originating are marked with an asterisk in Appendices 3 and 5. These designations are taken mainly from Nakamura's Table 2, while Dr. Donald Strasburg has assisted us in assigning the families not represented there. Diodontidae and Tetraodontidae have been omitted from the calculations, since those taken by Ph. rubricauda and $S$. fuscata may well have been pelagic forms, although most members of these families are reef-originating. Among the Blenniidae we have considered Cirripectus sp. as reef-originating, but have omitted the other species of Blenniidae which occurred only in G. alba, as these are at least sometimes pelagic (see Species Accounts).

In Table 7 are given the percentages (by number) of fish in the diets of the various birds which belonged to reef-originating families. The low incidence of 
reef-originating forms in $P h$. rubricauda, $P$. nativitatis and $S$. fuscata is noteworthy, while $A$. tenuirostris eats largely reef-originating forms. and $A$. stolidus and G. alba are intermediate. The very low percentage of reef-originating fish in the diet of Pr. cerulea is due mainly to the large numbers of minute Gempylidae in its diet: direct observations on the feeding of this species showed that it must be obtaining them very close to the island. Although squid were not considered in this analysis, it is of interest that since Symplectoteuthis spp. are pelagic rather than reef-originating, the low proportion of squid in the diet of $A$. tenuirostris must also reflect the fact that this species feeds very largely close to land. Finally, it may be mentioned that if the fish portion of the diet of the Yellowfin Tuna caught within ten miles of land in the Line Islands is treated in the same way as that of the birds (but omitting all Blenniidae) it is found that $95 \%$ of the fish are from reef-originating families. The Yellowfin stomachs in question contained an exceptionally high proportion of the reef-originating Acanthuridae, but even if these are omitted more than two thirds of the remaining fish are from reef-originating families.

Using both the scanty direct evidence and the indirect evidence from the length of the incubation shifts and the proportions of reef-originating and pelagic fish in the diets, it seems worthwhile to define as far as possible the feeding zones (in relation to distance from Christmas Island) utilized by the different bird species.

We never saw Ph. rubricauda fishing close to land and suspected that they were foraging far out to sea. Similarly, Murphy, Bailey and Niedrach (1954) say that the feeding range of this species "is, for the most part, much farther from shore than that of the red-footed booby." However, Gibson-Hill (1947) several times saw Ph. rubricauda feeding in the afternoon close to Christmas Island (Indian Ocean). He did not obtain information on the incubation shifts, but on Christmas Island in the Pacific they last about six days, which would clearly permit individuals to travel great distances from the island even while breeding. That they do not normally feed close to the island is also suggested by the fact that reef-originating fish families are not represented in their diet, except by Tetraodontidae and Diodontidae, which include some pelagic species, as already mentioned. Outside the breeding season tropic-birds in general are truly pelagic (Jesperson 1929; Murphy 1936: 91, 799; Baker 1947), and clearly do not need to come to land to roost. It also appears that they feed individually rather than in flocks, and our evidence from the food of $P h$. rubricauda suggests that they feed on dispersed prey. We may therefore conclude, provisionally, that $P h$. rubricauda scatter over the ocean around Christmas Island in search of their food, probably exploiting areas where flying fish and other surface-dwelling fish and squid are especially abundant, but not necessarily feeding in association with other birds or with schooling fish.

$P$. nativitatis and $P t$. alba appear to have incubation shifts of about five days, although we have few data for the first of these species. There are no indications that they feed especially close to shore (we never saw them feeding), and they probably travel to feeding grounds several hundred miles away. In $P$. $n a-$ tivitatis, only $3 \%$ of the identified fish in the diet were from families designated as reef-originating (Table 7). Observations by Bruyns (1965) showed that in 
November 1960 both $P$. nativitatis and Pt. alba were common in the Countercurrent at about $7^{\circ} \mathrm{N}$., in the area north of Christmas Island. Bruyns comments that $P$. nativitatis were not seen more than 250 miles from land, whereas $P t$. alba were seen at much greater distances from the nearest breeding grounds. Although it cannot be shown that the birds seen furthest from land are involved in breeding, the advanced state of digestion of the samples which we obtained from Pt. alba suggests that they travel great distances even when breeding. Other species of Pterodroma apparently also travel considerable distances from their breeding grounds to feed; for instance, Falla (1934) says that in northern New Zealand Pt. macroptera is rarely seen within fifty miles of the coast during the day, although considerable numbers breed in the area.

The two large terns, $S$. fuscata and $A$. stolidus, are so similar in size and diet that they merit careful comparison. It seems certain that $S$. fuscata often feeds very far from land, even when breeding. Its incubation shifts on Christmas Island averaged seven days, which is a little longer than on Ascension Island, and only $9 \%$ of the identified fish in its diet were from reef-originating families (Table 7). This species was not seen feeding immediately offshore, although individuals were seen flying past feeding flocks of other species of terns. In $A$. stolidus, more of the identified fish $(33 \%$ : Table 7$)$ were from reef-originating families, but we unfortunately have no data on the length of the incubation shifts on either Christmas Island or Ascension Island. The only colonies for which information is available are Christmas Island (Indian Ocean), where GibsonHill (1951) said that the shifts were normally short, the birds sometimes making as many as five changes in the course of a day, and the Dry Tortugas, where the shifts average less than five hours (data in Watson 1908). Although in the Tortugas colony $S$. fuscata has much shorter shifts than elsewhere (a little more than 24 hours-Watson), they are still much longer than those of $A$. stoli$d u s$, and there is probably a difference of similar proportions elsewhere. (See Discussion on relations between these species in the Tortugas.) A. stolidus was not observed feeding in the area within about three miles of the coast of Christmas Island which was favored by small noddies, but since the population of $A$. stolidus is small this might have been due to chance. At Onotoa Atoll, Gilbert Islands, Moul (1954) frequently saw this species feeding close to the shore, alongside $A$. tenuirostris. Evidence from other areas shows that in general $A$. stolidus feed closer to land than S. fuscata. Data from the central Pacific obtained recently during the "at-sea" work of the Pacific Ocean Biological Survey Program, Smithsonian Institution, support this view, but show that $S$. fuscata also sometimes feed close to shore (P. J. Gould, pers. comm.). In the area of Oahu (Hawaii) where there are large colonies of both S. fuscata and $A$. stolidus, N. P. A. saw none of the former species, but many of the latter, feeding over fish schools within a few miles of the island during a cruise on the "Charles H. Gilbert" during April 1963. This observation conforms to the experience of Royce and Otsu (1955) during six cruises in the area of the Hawaiian Islands in 1953. They found that $A$. stolidus were more abundant near the islands, while $S$. fuscata ranged as far as the vessel searched, which was up to 350 miles from Oahu. Similarly, Murphy (1936: 1154) quotes the notebooks of R. H. Beck to the effect that he found $A$. stolidus feeding regularly as far as 50 
$\mathrm{km}$ from their homes, but $S$. fuscata as far as $300 \mathrm{~km}$. Again, Ridley and Percy (1958) comment that in the Seychelles (Indian Ocean) A. stolidus seem to fish much closer to land than $S$. fuscata, while Bailey (1965) found that in the northern part of the Indian Ocean in March and April, S. fuscata was the commonest bird at sea, while noddies were very rarely recorded more than fifty miles from their breeding islands.

It therefore seems reasonable to conclude that the Christmas Island population of $S$. fuscata range up to several hundred miles from the island, doubtless feeding mainly in the Countercurrent (cf. Bruyns 1965), but that $A$. stolidus feeds closer to the island, although not commonly as close to land as $A$. tenuirostris and Pr. cerulea.

The next species, G. alba, has incubation shifts lasting on average about three days on Christmas Island, which is about the same as on Ascension Island (Dorward 1963). This species is thus intermediate between $S$. fuscata and the two small noddies which change over about once each day. The proportion of identified fish in the diet which were from reef-originating families is also intermediate, being $34 \%$ (Table 7). An incubation shift of three days would easily permit the off-duty bird to feed in the region of the Countercurrent. It is of interest in this connection that although birds can be found breeding on Christmas Island at any time of the year, banded individuals which had finished breeding were not seen on the island for several months; during this absence they underwent a complete molt (Ashmole, in press). It seems likely that after completing their breeding activities they migrate away from the island to be closer to the best feeding grounds, and they may even spend this time at sea. Although it should be mentioned that Baker (1951) was of the opinion that outside the breeding period, G. alba was less pelagic in its habits than A. stolidus, Bruyns (1965) records some individuals several hundred miles from land in the Countercurrent, and the Pacific Ocean Biological Survey Program have comparable records (Gould, pers. comm.). Observations on the feeding of G. alba, and the form of the legs and feet, suggest that it does not normally rest on the water. Any opportunity should be taken of performing experiments similar to those of Watson (in Watson and Lashley 1915) on $A$ stolidus and S. fuscata, to determine whether G. alba can rest on the water without becoming waterlogged. We suspect that this species will prove to be capable-like $S$. fuscata-of spending indefinite periods in the air, over its oceanic feeding grounds. On the other hand, individuals feeding chicks may obtain most of their food close to the colony; as already noted, members of this species were seen fishing within a few miles of the coast at dawn, and the food for the young is carried back in the bill, suggesting that it is generally caught within a few hours' flight of the island (see also Gibson-Hill 1950). However, few G. alba were seen fishing with the two small noddies during the day, within about three miles of Christmas Island.

A. tenuirostris and Pr. cerulea can be treated together, since they appear to exploit very similar feeding zones. Both have incubation shifts averaging a little less than one day, indicating that each member of the pair normally fishes for one day, and then returns to relieve its mate. In fact, the conspicuous evening arrivals of these species at the colonies, and the steady departures in the morning, suggest that they nearly always return to the island at night. In keeping with this, 
both these species are seen commonly feeding within a few miles of the island during the day. In A. tenuirostris $56 \%$ of the identified fish were from reeforiginating families, a figure much higher than in any of the other birds (Table 7). In Pr. cerulea, however, only $5 \%$ of the identified fish were from reeforiginating families, although this species certainly feeds in roughly the same zone as $A$. tenuirostris; tiny Gempylidae were of great importance in its diet, while fair numbers of larval Scombridae and small Exocoetidae were also eaten. This discrepancy is probably related to the very small size of the organisms taken by Pr. cerulea: it appears that this species, with its small size, short bill, and habit of staying very close to the surface while feeding, rather than always making energy-consuming swoops from a height, has the ability to exploit many of the smaller animals of the neuston (i.e., organisms floating or swimming in surface water or inhabiting the surface film: see David 1965). All three of the major constituents of the diet of Pr. cerulea-Halobates, pontellid copepods and very small fish larvae-appear in David's short list of the organisms most commonly occurring in hauls of the "Neuston net" in the Indian Ocean. The larger birds studied-with the partial exception of $A$. tenuirostris-evidently cannot economically catch the smaller animals of the neuston, and are more dependent on predatory fish to drive larger prey to the surface. Storm petrels and phalaropes, however, are examples of other avian exploiters of the neuston. It may well be that for the two small noddies the generally calm waters in the lee of Christmas Island at the western end are especially favorable feeding areas. It is doubtless significant that Bruyns (1965) failed to see either of these species (or A. stolidus) in the Countercurrent north of Christmas Island, although $S$. fuscata were common there. There are indications that other populations of $A$. tenuirostris also feed mainly close to land. For instance, Morris (1963) found that in the Gilbert Islands the large flocks of noddies, which consisted mainly of this species, were usually near the reefs but sometimes as far as 50 miles from land.

Before leaving the subject of feeding zones, it is worth considering a few of the special problems faced by birds feeding at great distances from the island. It is clear that for such birds it will be especially important to be able to carry a large load of food for the chick, because the length of the time required for travelling will make it uneconomic to visit the colony frequently. It is thus of interest to find that $S$. fuscata, which had the longest incubation shifts and were probably feeding at great distances, were capable of arriving back at the colony with a load representing about one fifth of their total weight (Table 2). The loads brought back by $S$. fuscata, in addition to being relatively larger than in any of the other species, were also in strikingly good condition (Table 2), raising the question as to whether this and other sea birds feeding far from their breeding colonies may have mechanisms for retarding digestion of food intended for the young. This problem was discussed briefly by Murphy (1936: 660) and also by Dorward (1962) in relation to tropical boobies (Sula spp.), but it does not seem to have been directly investigated. In $S$. fuscata, it is possibly relevant that the regurgitations given to the young are often accompanied by a conspicuous 
amount of mucus, which presumably could be specialized for retarding digestion. Since digestion of fish by birds is generally rapid ${ }^{3}$ it does appear that in the absence of some mechanism for retarding it, the foraging range of a bird collecting food for its young might be limited by the need to get back to the colony before too great a proportion of the load was digested.

In striking contrast with $S$. fuscata, the samples from Pt. alba were small in volume relative to body weight (Table 2). However, in addition to the items which were collected and from which the volumes of the samples were calculated, the samples from this species often contained considerable quantities of oil, which could not all be collected. It is also relevant that the food items were nearly all in very poor condition, and that isolated squid beaks and lenses were often found (Table 2). The presence of oil in many of the samples indicates that Pt. alba, like many other petrels, has the ability to secrete stomach oil. Furthermore, the advanced state of digestion of most of the food items, and the fact that oil was obtained in quantity both from adults which had chicks, and from chicks, suggests that the secretion of stomach oil is an adaptation connected with foraging far from the colony.

Matthews (1949) reviewed available information on the chemical composition of the oil, and presented circumstantial evidence that it is a secretion of the proventriculus. He discussed in detail the various hypotheses as to the functions of stomach oil, but came to no definite conclusion. On the other hand, Rice and Kenyon (1962) presented evidence that in albatrosses the oil serves as a food for the young, and suggested that this is its primary function also in petrels and shearwaters. Previously, this possibility had sometimes been discounted on the grounds that the oil does not contain appreciable quantities of protein (Carter and Malcolm 1927, Murphy 1936: 473). However, Kritzler (1948) suggested that the proteins requisite for differentiation and growth could be supplied in the form of semidigested material regurgitated with the oil, while the oil could provide sufficient energy for growth, as well as for survival.

Since stomach oil is given by adults to chicks, it seems reasonable to suppose that it functions as a food for the young, and its widespread occurrence in the Procellariiformes is explicable on the basis that many members of this group have to collect food at great distances from their breeding places. A mechanism for retarding digestion of food to be given to the chick would be an alternative adaptation, but it would have the disadvantage of requiring the adult to carry back to the colony the intact food, containing a large percentage of water. On the other hand, by digesting food as it is caught-and excreting excess waterthroughout the period until they return to feed the chick, the birds are presumably able to build up reserves which can later be secreted as stomach oil and transferred to the chick, together with those food items which are not yet entirely digested. Although we know of no measurements of the calorific value of petrel stomach oil, it seems likely that it is somewhere between five and ten times that

3 F. Ward (1914, quoted by Harris 1965) found that Larus marinus had fully digested a fiveinch fish in three hours. Skokova (1963), in a study of birds feeding on fresh water fish, records fish being three-quarters digested after 8 hours. Van Dobben (1952) found that it took 15 hours for Phalacrocorax carbo to digest a large fish, while Bowmaker (1963) found that $P$. africanus took about three hours to digest a meal early in the day and five hours for later meals. 
of whole fish or squid (see data in Arimoto 1962). Since there must be, for each species, a critical limit to the weight of the load of food which can be brought back to the chick, the ability to carry food for the chick in the form of a lipid reserve represents an important adaptation to foraging far from the colony while breeding.

Since in chicks fed largely on stomach oil the rate of differentiation is likely to be limited by the low intake of essential amino acids, the tendency for members of the Procellariiformes to have extremely long fledging periods is an expected correlation. Similarly, the fact that petrel chicks often become enormously fat suggests a tendency for the supply of lipids to outrun that of amino acids. However, these lipid reserves accumulated by chicks (both in the alimentary tract and elsewhere in the body) are themselves important safeguards against starvation in unusually long intervals between successive feedings: the ability of young petrels to survive for long periods without food is well documented (e.g., Richdale 1945). This ability probably depends on the fact that when they are fed, the chicks are given large meals of unusually high nutritive value. It seems inevitable that a chick given a meal of fresh fish or squid (of which about $75 \%$ by weight will be water-Arimoto 1962), and then starved, would survive for a much shorter period than a chick given the same quantity of stomach oil. Thus the secretion of stomach oil by adults may probably be regarded as an important part of the adaptation of many Procellariiformes to infrequent feeding of the chick, and hence to exploiting food sources at great distances from the breeding grounds.

Although it seems almost certain that the prime function of stomach oil is as a food for the young, the ability to accumulate oil in the digestive tract may sometimes be of value to the adults themselves, as are the reserves of subcutaneous and peritoneal fat deposited by many birds (including Procellariiformes). A point which is relevant in this connection is that Kritzler (1948) reported that his Fulmars (Fulmarus glacialis) accumulated "prodigious deposits of subcutaneous and visceral fat" after being fed on a diet of hog tissues supplemented with additional lard. It may be significant that the individual from which Kritzler obtained his samples of stomach oil first regurgitated oil in March, about a month after its capture, suggesting that this nonbreeding bird may not have accumulated stomach oil until after it had laid down large fat deposits in its tissues.

The hypothesis that stomach oil is primarily a reserve food supply which is fed to chicks by their parents does not conflict with the generally accepted view that in many Procellariiformes the 'spitting' of foul-smelling oil (especially by chicks) is an important adaptation for defence against predators (see, for instance, Warham 1964). However, it seems most probable that this use of the oil, and also its employment in preening and during courtship (Fisher 1952), is evolutionarily secondary to its nutritional function.

While this paper was in press Lewis (1966) published the results of a study showing that glyceryl ethers are major constituents of the stomach oil of Leach's Petrels (Oceanodroma leucorhoa). Lewis also analysed representatives of animal groups eaten by Procellariiformes, and found that anchovies (Engraulis mordax), squid (Loligo sp.), shrimp (Peneus sp.) and zooplankton all contained ap- 
preciable quantities of phosphorylated glyceryl ethers. Lewis discussed the possible function of petrel stomach oil, and inclined to the view that it is an excretory product. However, he recognized that a role in the nutrition of the young is the major alternative possibility, and we see no reason to change our conclusion that the secretion of stomach oil is primarily a nutritional adaptation.

\section{Feeding Methods, and Associated Structural Adaptations}

Since all the bird species included in this study depend upon food at or close to the surface of the sea, it is of interest to compare their feeding methods, and to consider the associated structural adaptations. To aid in this comparison, various dimensions of the species are presented in Table 8, and their bills are shown in Fig. 6, while feeding methods are sketched in Fig. 7.

In Figure 7 we have divided feeding methods into those in which the bird remains airborne and those in which it does not. The first group includes two types of Dipping: prey actually in the air may be captured without contact of the bird with the water surface (Air Dipping), while if the prey is at or just below the surface there is brief contact of the bird's bill with the water (Contact Dipping), but forward flight does not stop. Some birds obtaining food by Contact Dipping may push off with their feet, and this action thus grades into Pattering, in which the feet make frequent contact with the water; this is a method used by many avian plankton feeders which need to maintain themselves at a roughly constant distance above the surface, even in fairly rough water. Some species (especially the noddies) also Hover, generally close to the surface; their feet may or may not come into contact with the water, the essential features being that forward motion more or less stops, and that the body weight is supported principally by the rapidly beating wings; objects are then picked from the surface or just above it. In the second group we distinguish Plunge to Surface, in which the bird splashes into the water but does not normally submerge fully and takes off again immediately, from Air Dive, in which the bird disappears below the water surface and reappears only after an appreciable interval. Air Dives may probably be subdivided into those in which the impetus of the dive is used to reach the prey, and those in which there is a pursuit by swimming. Surface Dives are those made by birds which are swimming at the surface before they submerge; they always involve swimming pursuit of the prey. Finally, we have the heterogeneous category of Feeding on Surface. Although our terminology is not intended to be exhaustive, it is hoped that it may help in describing more precisely the feeding behavior of sea birds.

We did not observe the feeding methods of Ph. rubricauda, but Gibson-Hill (1947) said that the birds dive from a height of 20-40 feet, dropping with half folded wings into the water (Air Dive, Fig. 7). One bird which he watched remained submerged for an average of 26.6 [sic] seconds in ten consecutive dives. Gibson-Hill commented on the shortness of these periods, but it seems that tropic-birds often spend much less time under water. For instance, Bailey (1966) recorded that $P h$. aethereus feeding in opaque water in the Indian Ocean remained submerged for less than a second. It is not certainly known whether tropic-birds pursue their prey under water or whether they rely on the impetus of the dive for capture. However, the lack of streamlining of the tarsometatarsus 


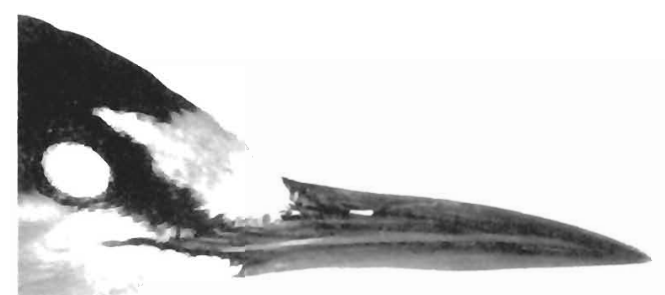

Sterna fuscata
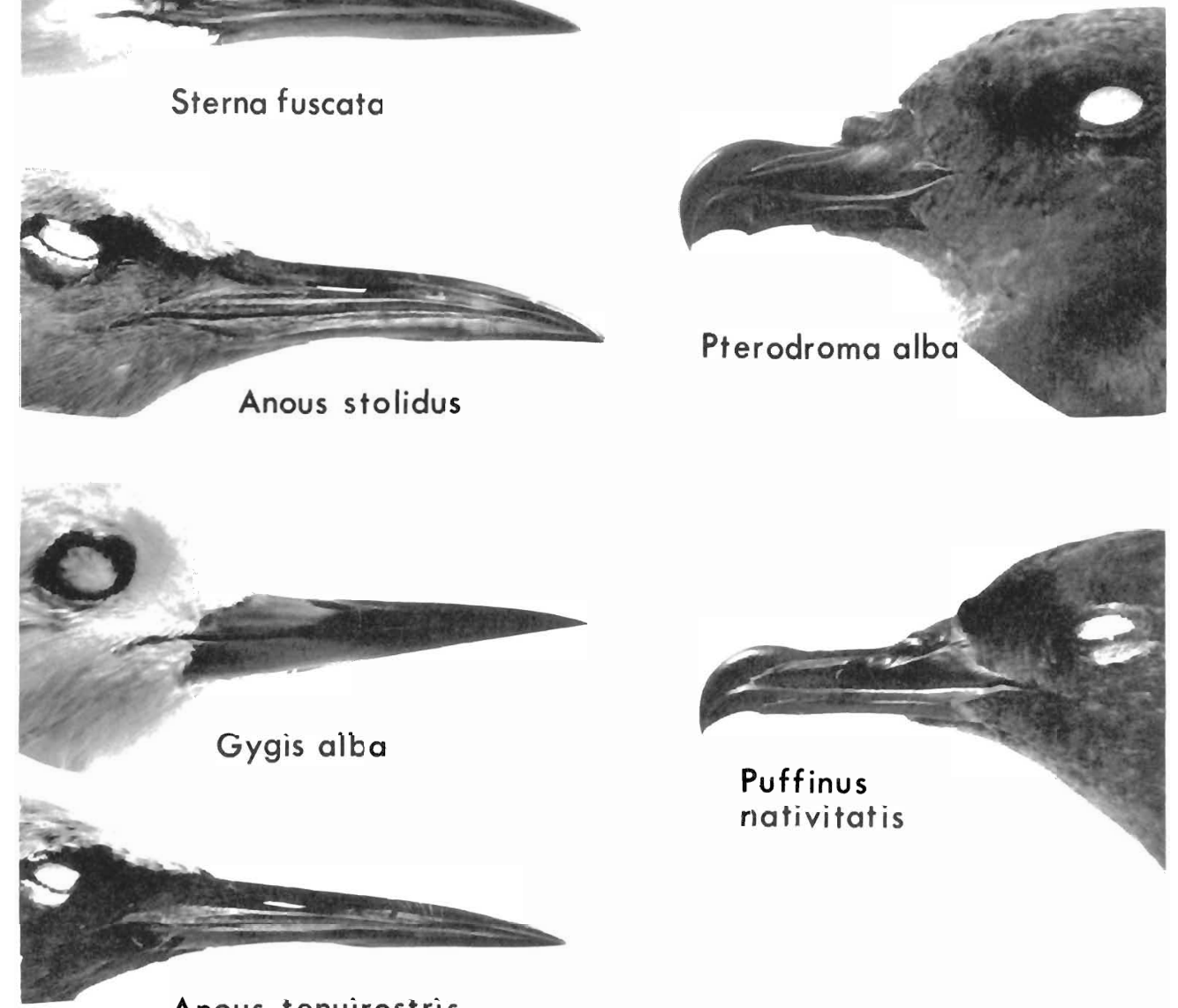

Anous tenuirostris

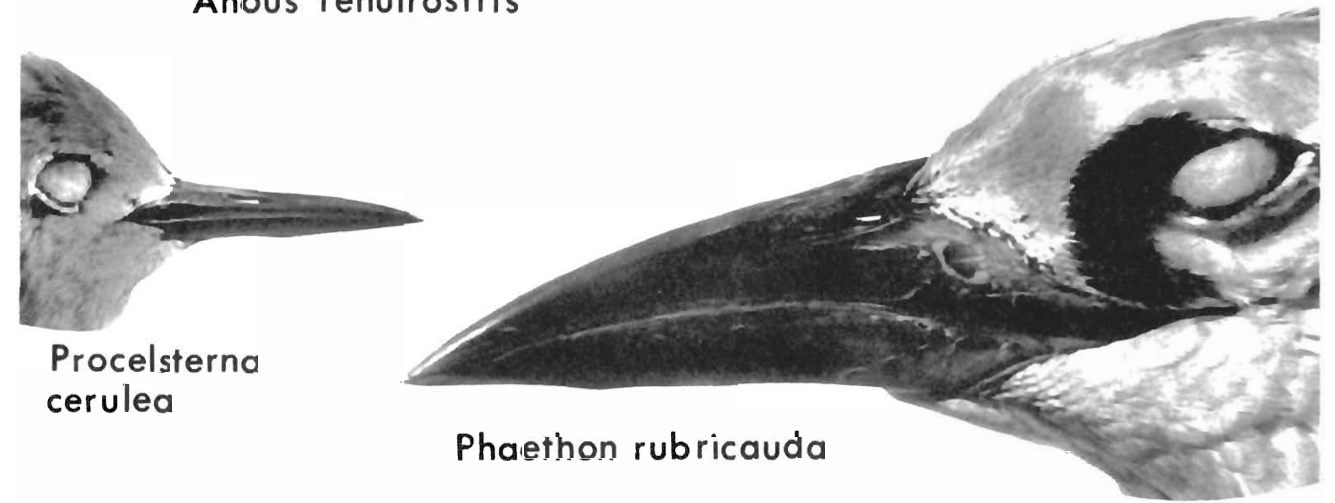

FIGURE 6. Bills of the sea birds studied on Christmas Island: natural size photographs of specimens preserved in alcohol. 
(Ph. rubricauda has min. lateral width $7.7 \mathrm{~mm}$., ant.-post. $6.5 \mathrm{~mm}$.) ${ }^{4}$ supports the later alternative and suggests that the webbed feet may be important mainly for steering and for taking off from the surface; they are also of use during flight, especially in landing, when they clearly function as flaps. Stonehouse (1962b) suggested that tropic-birds catch some of their prey-for instance Exocoetidaeon the wing (Dipping, Fig. 7); however, there is still no direct evidence supporting this idea.

The great strength of the bill of $P h$. rubricauda is presumably connected with the ability of this species to catch fish which are very large, both absolutely and relative to body weight, including, for instance, Coryphaenidae between 20 and $30 \mathrm{~cm}$ long. However, it is also relevant that tropic-birds frequently engage in fighting for nest sites, in which the bills of the contestants are interlocked and subjected to considerable stresses (Stonehouse 1962b). That the bill of Ph. rubricauda is not unnecessarily strong was made evident by the discovery on Cook Island of an adult in which the distal third of the upper mandible had been snapped off cleanly. The injury was quite recent (still bleeding slightly) and the bird appeared healthy, was of normal weight and was brooding its chick. It

\section{FEEDING WHILE FLYING}

DIPPING

PATTERING

HOVERING

Air Dipping Contact Dipping
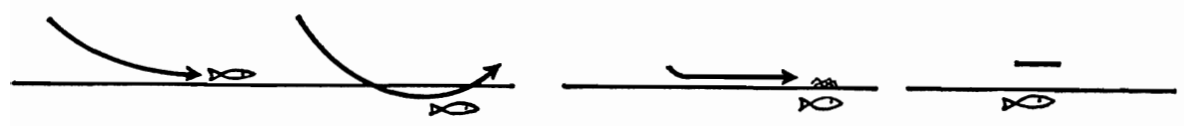

\section{FEEDING WITH CESSATION OF FLIGHT}

PLUNGING TO SURFACE

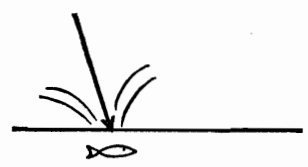

Surface Dive followed by pursuit

DIVING

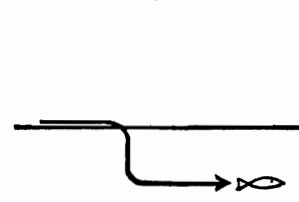

FEEDING ON SURFACE

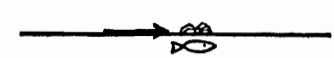

Air Dive

followed by pursuit

direct to prey

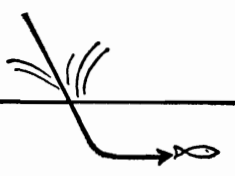

FIGURE 7. Feeding methods employed by the sea birds studied. See text for explanation.

4 Measurements of this and the tarsometatarsi of the two Procellariiformes were made on single spirit specimens from Christmas Island. 
TABLE 8. Mean dimensions of Christmas Island sea birds, and some dimensional relationships

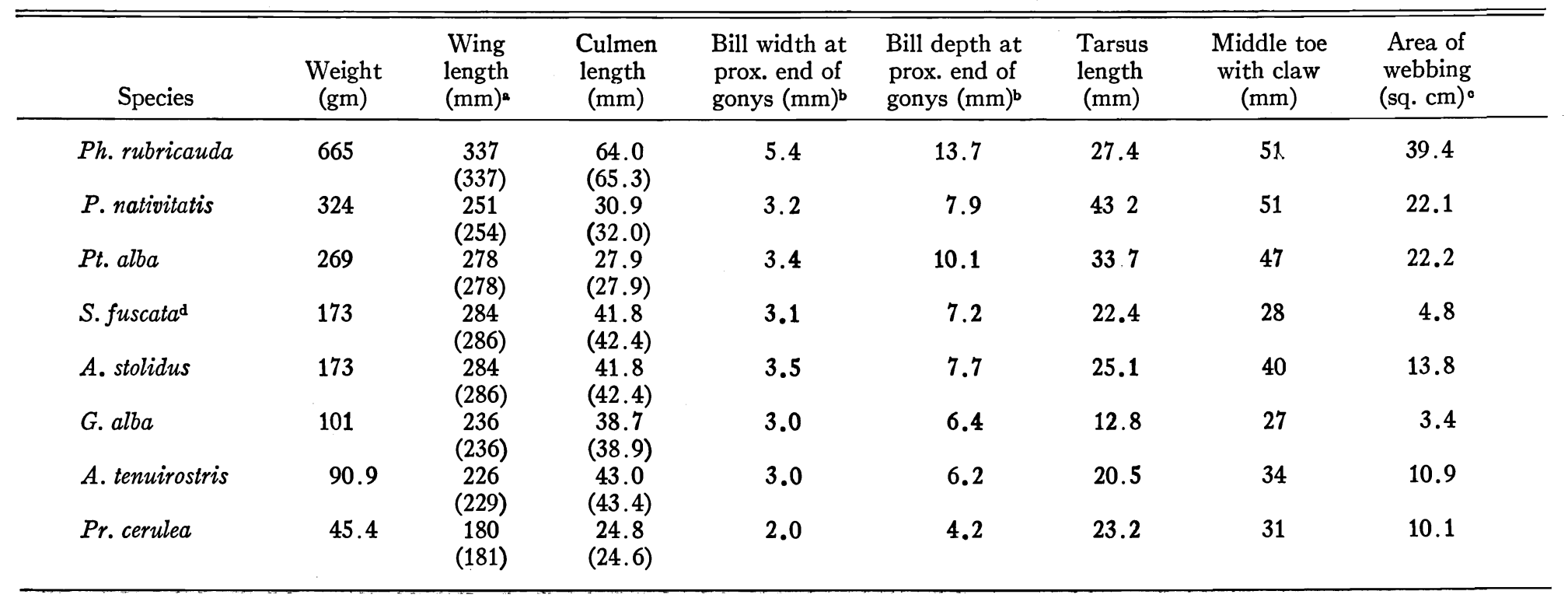


Culmen length Tarsus length

Cube root Cube root

of weight

of weight
Bill cross-section
area at prox.

of gonys (sq. $\mathrm{mm}$ )
Weight
Index to bill stoutness ${ }^{f}$

\begin{tabular}{llllll} 
Ph. rubricauda & 7.3 & 3.1 & 58.1 & .119 & 17 \\
P. nativitatis & 4.5 & 6.3 & 19.9 & .144 & 15 \\
Pterodroma alba & 4.3 & 5.2 & 27.0 & .186 & 12 \\
S. fuscata & 7.5 & 4.0 & 17.5 & .100 & 36 \\
A. stolidus & 7.5 & 4.5 & 21.2 & .110 & 13 \\
G. alba & 8.3 & 2.8 & 15.1 & .100 & 30 \\
A. tenuirostris & 9.6 & 4.6 & 14.6 & .089 & 8.3 \\
Pr. cerulea & 7.0 & 6.5 & 6.6 & .104 & 4.5 \\
\hline
\end{tabular}

$\overline{\text { Area of webbing }}$ (gm/sq. cm)

NOTES FOR TABLE 8:

a. Linear measurements were made on specimens from Christmas Island in the American Museum of Natural History, supplemented in a few cases with birds from other islands nearby. For each species, five adults of each sex were measured. Means were calculated separately for the two sexes, but have here been combined for the sake of simplicity. However, for wing and culmen length the mean for males alone is placed in parentheses below the figure for the two sexes combined, and it can thus be seen that the birds concerned do not show striking sexual dimorphism. It should be noted that the identity of the first five entries in $S$. fuscata and in $A$. stolidus is genuine, and not a printer's error.

b. The proximal end of the gonys is the point at which the two rami of the lower mandible come together. It is often visible as an inflection when the bill is viewed in profile (see Fig. 6).

c. These figures represent the approximate area of the lower surfaces of the two feet, when the toes are fully spread; claws are excluded. The measurements were made on single specimens preserved in alcohol, collected on Christmas Island, except for the G. alba which was from Phoenix Island.

d. Sterna lunata, which also occurs on Christmas Island, has slightly shorter wings than S. fuscata (ca. $270 \mathrm{~mm}$ ), but is very similar in most other dimensions, including bill length (culmen ca. $42 \mathrm{~mm}$ ).

e. Estimated on the assumption that the bill is elliptical in cross-section at the proximal end of the gonys, our measurements of the bill width and depth representing the diameters of the ellipse.

f. Calculated by dividing the square root of the bill cross-section area by the culmen length. 
seemed most likely that this accident occurred at sea, since nest sites were abundant on Cook Island and there was little fighting for them, but other causes cannot be excluded. Also worth mentioning is the enormous gape of this and other tropic-birds, which is one of the adaptations which enables them to exploit prey of very large size relative to their body weight. The large gape must also be critical in eating Diodontidae (porcupine fish), whose protective adaptations make them especially difficult to swallow.

There are no indications that tropic-birds feed at night, but from observations on their diurnal rhythms, several observers have concluded that they obtain most of their food in the period immediately after daybreak (see Murphy 1936; Gibson-Hill 1947).

We know of no published information on the feeding habits of $P$. nativitatis (it seems possible that Anderson [1954] did not distinguish P. pacificus and $P$. nativitatis). However, there are a number of accounts of the feeding of other members of the genus Puffinus. They either Feed at Surface, or make Surface Dives, or fly low over the water (sometimes Pattering with their feet), and then Plunge to Surface or make Air Dives with the wings partly open. While swimming under water they use their wings as well as their feet. During the Pacific Ocean Biological Survey Program of the Smithsonian Institution, P. pacificus have also been observed to chase and catch flying fish in mid-air (Gould, pers. comm.).

The various species of Puffinus differ in the extent of their adaptations for swimming and diving, and $P$. nativitatis is among the species most highly adapted for aquatic life (Kuroda 1954). However, all of them contrast with Pterodroma spp., which have quite different adaptations. The bill of $P$. nativitatis is a little longer and less deep than that of Pt. alba, and the terminal hook characteristic of all Procellariiformes is less developed. However, the bill of $P$. nativitatis is actually more like those of Pterodroma species than are the bills of most other members of the genus Puffinus. The legs and feet of $P$. nativitatis show the adaptations for fast swimming emphasized by Kuroda; the tarsometatarsus is robust but well streamlined (min. lat. width $2.8 \mathrm{~mm}$., ant.-post. $7.3 \mathrm{~mm}$.), while the long toes encompass a large area of webbing (Table 8), but fold into a narrow lateral space for the forward stroke. As in other diving shearwaters (Kuroda 1954), the plumage of $P$. nativitatis is extremely compact, helping to give the bird the high specific gravity necessary in birds which need to be able to submerge easily (Storer 1960).

$P t$. alba lacks these specializations for feeding by high-speed underwater swimming. Most conspicuous is the difference in the legs and feet. The tarsi are slender and not streamlined (min. lat. width $3.3 \mathrm{~mm}$., ant.-post. $4.5 \mathrm{~mm}$.), while the toes are widespread and do not fold easily into a streamlined form. However, the webs are well developed and are doubtless important in take-off, and probably also in holding the body off the water during feeding by Hovering. The bill is short, deep, and powerful, while the tip of the upper mandible is sharply decurved into a massive hook. As might be expected from the form of the bill, Pt. alba can exert considerable force at the bill tip. This species thus appears to be adapted especially for cutting and tearing its food, and this may explain the appearance in our samples of several arms and eye lenses from 
squid larger than the bird could possibly eat whole. It is conceivable-though improbable-that the arms were cut off living squid, but the large eye lenses were doubtless obtained from dead or moribund animals. It is worth mentioning that Pt. alba (and other members of the genus) have exceptionally soft and loose plumage, which could perhaps be useful in making it difficult for living squid to get a grip on the bird.

It is clear from a number of accounts in the literature that large dead or dying squid are sometimes available in the open ocean. For instance, Murphy (1936: 487) wrote that "Both the shearwaters and the Pterodroma petrels occasionally 'stand' on the water, sustained by rapidly beating wings, while they feed upon large and heavy objects such as the bodies of squids or fish." Similarly Collins (1899) mentioned the occurrence of dead giant squid in the North Atlantic in 1875 , and said that the tentacles were usually eaten by Great Shearwaters (Puffinus gravis). Voss and Voss (1962) have described a new species of squid in the genus Calliteuthis on the basis of a series of specimens found floating on the surface-either dead or dying - over a period of many years: all were also mutilated, showing signs of having been fed upon by predators. Furthermore, Malcolm R. Clarke informed us (pers. comm.) that he has seen dead squid floating at the surface on a number of occasions during oceanographic cruises. The fairly frequent occurrence of dead or dying squid on beaches (see section on food size under Pt. alba in the Species Accounts), also suggests that they may be available with some regularity far from land. Relevant in this context is the work on Loligo opalescens by Fields (1965), who assembled impressive evidence that in this species of squid both sexes die after spawning, and quotes observations of large numbers of sea birds (Puffinus sp. and Larus sp.) in Monterey Bay feeding on concentrations of squid debilitated by the spawning process. If a significant number of other species of squid also die after spawning, this would largely explain the occurrence of dead or dying squid at sea, and would suggest that such squid must provide an important food source for sea birds. Among the species which we studied, however, only Pt. alba showed evidence of feeding on dead or dying squid. That Pterodroma spp. also sometimes feed on large dead fish is indicated both by Murphy's statement, quoted above, and by Kuroda's (1955) observation of two Pt. inexpectata feeding on the carcass of a dead pollack in the North Pacific. However, we detected no evidence of this in the regurgitations from Pt. alba, which were generally largely digested.

Nevertheless, it must not be forgotten that gadfly petrels also eat many small fish and squid which they must catch alive, while Pt. alba also obtains substantial numbers of marine water striders. There seem to be no accounts in the literature of the feeding of Pt. alba, but the staff of the Pacific Ocean Biological Survey Program have observed the feeding of some other gadfly petrels (especially $P t$. externa); Gould (pers. comm.) said that "they are much more prone to 'Contact Dipping' [Fig. 7] than the shearwaters and spend much less time in contact with the water; like the shearwaters, they have been observed to chase and catch flying-fish in mid-air [Air Dipping] and they spend a great deal of time in pursuit of such prey." The available evidence (see Kuroda 1954) indicates that the gadfly petrels are extremely. efficient fliers, their high-aspect-ratio wings making them well adapted to traveling long distances with a minimum of 
effort (Savile 1957). This flight efficiency, together with great skill in Dipping, probably accounts for the fact that it is evidently economic for Pt. alba to catch such minute prey as Halobates, which are not utilized by the terns of comparable size. At the same time, however, their economic flight (and strong cutting bills) enables Pterodroma spp. to employ another specialized kind of foraging behavior, discussed above, searching for and eating large floating objects such as dead squid, which are very thinly scattered over the surface of the ocean.

Although we have no direct evidence, it may well be that Pt. alba, like some other tubinares (cf. Murphy 1936: 486) feeds to some extent at night or just before dawn. It may be relevant that the Galápagos Swallow-tailed Gull (Larus furcatus), which feeds at night (Hailman 1964), resembles Pt. alba in feeding very largely on squid, and-also like Pt. alba-is recorded as taking marine water striders (Murphy 1936: 1088).

Little detailed information is available on the feeding methods of the five tern species, but the general accounts in the literature (e.g., Murphy 1936; Ascension Island papers in Ibis 103b, 1962-63; Anderson 1954; Moul 1954), together with our own observations on some species, permit certain comparisons to be made. As far as we are aware none of these terns normally submerge completely, so that prey animals are available only if they are within a few inches of the sea surface. Prey may be caught when they have jumped clear of the water in attempts to escape marine predators, or they may be taken at the surface or just below it. It appears that the various terns under consideration use the methods of Air Dipping, Contact Dipping, Pattering, Hovering, and Plunging to Surface with different frequencies, although probably none of them use one method to the exclusion of the others.

As would be predicted from the general similarity of the feeding methods of these five terns, their bills show a number of common features (Fig. 6 and Table 8). All are slender, more or less straight, and laterally compressed, especially near the tip, in a manner which must minimize water resistance when the bill penetrates the surface in the process of fishing by Contact Dipping. Furthermore, the bills of four out of the five species are of very similar length; this is considered further in the Discussion.

The literature suggests that $S$. fuscata most often feed by Dipping (summary in Ashmole 1963b). Probably both Air Dipping and Contact Dipping are used, but it is so difficult to distinguish these actions in the field that very critical observations will be needed to determine which is the more frequent. Watson and Lashley (1915) mentioned only one observation of Plunging to Surface by $S$. fuscata, Dipping being the normal feeding method, but during the Pacific Ocean Biological Survey Program Plunging to Surface has also often been observed (Gould, pers. comm.). However, there is no evidence that this species ever uses its feet to maintain distance from the surface; this is consistent with the fact that the webbing on the feet has an enormously smaller area than in the noddies, which use their feet extensively during feeding (Table 8). Also of interest in this connection is Watson and Lashley's (1915) experimental proof that while $A$. stolidus can rest on the sea overnight without harm, $S$. fuscata become waterlogged in as little as 25 minutes. It is unexpected to find that a sea bird 
which is adapted to feeding in the open ocean and which can remain away from land for months on end (Ashmole 1963b) should lack the waterproofing adaptations which would enable it to rest on the sea. However, it is very possible that the risk of predation by fish when resting on the sea is sufficient to make aerial resting preferable for a species which can evolve the capability.

The available data thus indicate that $S$. fuscata feed on prey either in the air or right at the surface, a situation which during the day is most commonly achieved when predatory fish, especially tunas, chase small fish or squid to the surface, where they sometimes even jump out of the water. However, S. fuscata evidently also feed during twilight periods and sometimes even at night. Bruyns and Voous (1965) recorded that an individual captured at sea in the eastern Pacific regurgitated about six fresh Vinciguerria cf. lucetia (Garman) -family Gonostomatidae-three hours after sunset. However, Gould (in press) records what is apparently the first actual observation of $S$. fuscata feeding at night. He encountered-and observed with the aid of a flood light-a feeding flock of this species mixed with Puffinus pacificus, in the central Pacific; it was just before midnight and there was a full moon.

A. stolidus apparently feed both by Dipping and Plunging to Surface, and like the previous species, depend largely on the presence of predatory fish to scare their prey to the surface. On Onotoa Atoll (Gilbert Islands) both $A$. stoli$d u$ and $A$. tenuirostris were frequently seen feeding on an ebbing tide where "They hovered low over the reef, darting about, dropping to pick their food from the surface of the water or just below the surface, not diving and submerging. . . " (Moul 1954). Off Oahu (Hawaii) N.P.A. observed A. stolidus feeding over tuna schools in mixed flocks with $A$. tenuirostris and Puffinus pacificus. On one occasion $A$. stolidus were fishing by Contact Dipping, attempting to catch fish just below the surface, but on another occasion by Plunging to Surface. Watson (1908) said that $A$. stolidus catch fish actually in the air (Air Dipping), and they doubtless sometimes do this. Watson and Lashley (1915) also mentioned that "The noddy [A. stolidus] steps on the water often, sometimes strikes it with the breast, not in diving movements, but in those of pursuit." It is thus clear that $A$. stolidus uses its feet in the way $A$. tenuirostris and $P r$. cerulea do, to keep the body up off the surface during fishing; the extensive webbing of the feet (Table 8) would be of value in this and also in take-off after Plunging to Surface; in fact Watson (in Watson and Lashley 1915) remarked on the ease with which $A$. stolidus gets off the surface. This species, apparently alone among the terns studied, sometimes Feeds on Surface: Audubon (1835: 265) said that in the Gulf of Mexico it "not only frequently alights on the sea, but swims about on floating patches of the Gulf Weed, seizing on the small fry and little crabs that are found among the branches of that plant, or immediately beneath them." The staff of the Pacific Ocean Biological Survey Program have also observed this species sitting on the water and dabbling beneath the surface (Gould, pers. comm.). The indications are that $A$. stolidus is primarily-if not exclusively-a diurnal feeder; the main arrival of birds at the colony seems always to be at dusk, and we know of no observations of nocturnal fishing.

G. alba, considered at this stage because it is next in size, presents a contrast with the following species-A. tenuirostris—since although it is very similar in 
size, it differs in its coloration and the form of the bill and feet. Both the culmen and the lower edge of the mandible are unusually straight, and the base of the bill is rather deep. The feet are specialized for perching on branches and not for swimming or pushing off from the water; they have long claws and very little webbing, and the tarsi are very short (Table 8).

A few G. alba were sometimes seen with feeding flocks of $A$. tenuirostris and Pr. cerulea just offshore from Christmas Island. Although there were no opportunities to watch their feeding behavior at close range, it was noted on one occasion that while flying over a fish school they kept well above the noddies for most of the time. Dorward (1963), describing G. alba fishing off Ascension Island, said they "swooped very fast from a height of about 20 feet and seemed to pick things from just above the surface without touching the water." These birds were evidently feeding by Air Dipping, which agrees with Murphy's (1936) statement that the species "feeds not by diving but by the amazingly rapid and precise technique of catching little fishes in mid-air as they leap out." GibsonHill (1951) recorded that on the Cocos-Keeling Islands (Indian Ocean) G. alba feeding on Stolephorus sp. (Engraulidae) obtain them "either by hovering over still water and picking them from the surface, or by catching them when they are driven into the air by the attacks of larger fish. I never saw the White Tern dive properly." Baker (1951: 181) made the statement that G. alba "almost certainly obtain food also on the islands as indicated by the presence of insects in stomach contents; this is not surprising since the birds frequent woodland habitats." Baker gave no identification of the insects, and they might have been marine water striders, but it is also possible that $G$. alba sometimes hawk for insects where these are abundant close to their breeding sites.

Several times during watches from the seaward side of Cook Island soon after first light, G. alba were seen close to the limit of visibility (probably more than one mile offshore), apparently fishing; they were not flocking closely together, as feeding noddies generally do, but were working as individuals or loose groups, suggesting that they might not be feeding in association with a tuna school. The timing of this activity is of great interest; although it was barely light enough to read at 0700 (local time), by $0720 \mathrm{G}$. alba had already begun flying in from the sea, some of them carrying food. $S$. fuscata could also be seen coming in between 0700 and 0800 , but the $A$. stolidus and $A$. tenuirostris seen during this period were nearly all going out. The data on the occurrence of fish and squid in samples obtained from G. alba at different times of day (Table 9) suggest that early morning fishing may be largely for squid, while mid-day samples produce mainly fish. Samples collected in the early part of the night again show a preponderance of squid, and many of these were in excellent condition, suggesting that they had been caught at dusk. In addition, Myctophidae and Gonostomatidae-fish which are generally present at the surface only at night (see section on the environment)-are more important in the diet of G. alba than in those of the other terns. Although most were obtained from G. alba in the early morning or at night, myctophids were also found (in good condition) in samples collected at 1445 and 1700, and gonostomatids in one sample obtained at 1145. Two other families of fish which are normally at considerable depths during the day were represented-each by one individual-in the sam- 
TABLE 9. Frequency of occurrence of fish and squid obtained from Gygis alba adults at different times of day

\begin{tabular}{lrrrrrr}
\hline \hline & \multicolumn{7}{c}{ LOCAL TIME } \\
& 0700 & 0800 & 0900 & 1200 & 1800 & 2030 \\
& -0800 & -0900 & -1200 & -1800 & -1930 & -2400 \\
\hline Samples containing fish & 2 & 4 & 22 & 15 & 14 & 15 \\
Samples containing squid & 5 & 0 & 3 & 3 & 3 & 25 \\
\hline
\end{tabular}

NOTES FOR TABLE 9:

Samples collected before September 1963 are not included since the time of collection was not always recorded.

Separation of the data according to whether the food was carried in the bill or regurgitated has no appreciable effect on the relative frequency of fish and squid.

No samples were obtained between 1930 and 2030.

ples from G. alba: a member of the Astronesthidae was collected at 1830 (early dusk) and a rather dried-up member of the Paralepididae at 2215. Similarly, Dorward (1963) obtained a hatchet-fish (Sternoptyx, Sternoptychidae) and a myctophid (Lampanyctus) from G. alba within about an hour of first light. Comments by Strasburg (pers. comm.) on the habits of two members of the Blenniidae (Aspidontus filamentosus and Runula tapeinosoma) which formed part of the diet of G. alba but not of that of $A$. tenuirostris (see Species Accounts) suggest that they too are more likely to be available at the surface at night than during the day. Whereas $A$. filamentosus is usually and $R$. tapeinosoma sometimes taken around nightlights at the surface, in the daytime the former is generally found beneath floating objects, while the latter, although it is a reef-dweller commonly seen by day, "does not live near the surface, but hovers in midwater or near the bottom ..." (Strasburg, pers. comm.). However, some individuals of both species were obtained from G. alba during the middle of the day, although they might have been caught in the early morning.

It may thus be said that although G. alba certainly feeds during the middle of the day, there is some evidence that it also feeds extensively in the half light of dawn and dusk, exploiting some prey species that are not available to the noddies. If fishing at this time is done without the intervention of tunas or other predatory fish, as is suggested by the behavior of the birds, it could provide an explanation of the difference in the color of the dark noddies and of G. alba. G. C. Phillips (quoted by Tinbergen 1964) has obtained experimental evidence that the white plumage of sea birds hunting fish from the air helps them to approach their prey more closely than if they were dark. It is reasonable to suppose that selection for inconspicuousness from below will be more intense in a species which sometimes hunts undisturbed prey, than in those like the noddies which feed almost exclusively on animals which are already fleeing marine predators, and so are in less of a position to take avoiding action when attacked from the air. The pure white plumage of $G$. alba, and its extraordinarily translucent wings and tail, appear to be very efficient in rendering it inconspicuous against the sky in dim light. An experimental comparison of the reactions of 
fish to G. alba and to A. tenuirostris under different light conditions would be of great interest.

In $G$. alba, the total absence of melanins from all parts of the remiges, which is unusual even in species with generally white plumage, suggests that strong selection is operating, since unpigmented feathers become abraded more rapidly than pigmented ones. However, the unusual molt sequence of G. alba (Dorward 1963, and Ashmole, in press) ensures that the old feathers in the wings are always dispersed among the newer ones, thus minimizing the effects of abrasion. Although we do not fully understand why the noddies have dark plumage, its greater resistance to abrasion may well be significant, and there may also be selection favoring coloration which renders an individual inconspicuous to other sea birds-especially members of its own species-which are likely to compete with it for available prey. Since the tropical ocean is normally very dark blue, dark-colored birds are inconspicuous against it (Royce and Otsu 1955), though conspicuous from it against the sky.

The evidence suggests that the fishing methods of $A$. tenuirostris are almost identical to those of $A$. stolidus (see, for instance, Anderson 1954, Moul 1954, Morris 1963, and sources given in Ashmole 1962). Morris gave an interesting account of the behavior of noddies in the Gilbert Islands, saying that large flocks, mainly of $A$. minutus ( $=A$. tenuirostris), were seen over shoals of fish: "When small fish, put up by tunny or barracuda, rise thickly, the noddies pack closely just above the water, the whole black mass pattering and dipping almost like storm petrels." A. tenuirostris was frequently seen off Christmas Island, where it generally fished in company with Pr. cerulea, while off Oahu it was observed fishing with $A$. stolidus. Although the flocks varied greatly in size, density, and behavior, A. tenuirostris were sometimes seen feeding in such tight groups that they were clearly competing for jumping or surfacing fish. The methods used were Dipping and Plunging to Surface. When the birds were Dipping it was generally not possible to see whether the prey was out of the water or merely at the surface, but sometimes it seemed certain that the birds were taking prey from the water. Sometimes the noddies would Dip almost into the splash made by a large fish breaking the surface, and probably the two animals were often aiming at the same prey. When Plunging to Surface, although the body is normally nothing like submerged, the bird is doubtless able to catch prey further below the surface than when Dipping. A. tenuirostris generally put down their feet when they come very close to the surface during fishing, but do not normally remain long enough close to the water for this to develop into Pattering, as it does in Pr. cerulea. However, the very fully webbed feet and moderately long tarsi of $A$. tenuirostris (Table 8) are clearly of great importance in maintaining distance from the surface. Like $A$. stolidus, both $A$. tenuirostris and Pr. cerulea sometimes rest on the water for appreciable periods. The bill of $A$. tenuirostris, though long, is very slender (Fig. 6), this presumably being related to the fact that the species catches mainly very small food items (see Discussion).

Like $A$. stolidus, $A$. tenuirostris is probably a diurnal feeder. Murphy (1936) believes that it also feeds extensively at night, but there seems to be no direct evidence for this. Cullen and Ashmole (1963) suspected that at Ascension Island some $A$. tenuirostris might be absent from the island at night, but both there and 
on Christmas Island, as in other parts of the world, it is clear that the main departures from the colonies are in the early mornings and the main arrivals in the evenings.

Pr. cerulea was regularly observed feeding-usually in mixed flocks with $A$. tenuirostris - within a few miles of the shore during trips on a fishing boat near the western end of Christmas Island. Pr. cerulea were seen Dipping and Plunging to Surface in the same way as $A$. tenuirostris, but it was noticed that they used their feet more often than the latter species. For instance, on one occasion a flock were seen over a school of Yellowfin, flying into the wind between $\mathbf{0}$ and $\mathbf{5}$ feet above the water, always putting down their feet as they approached the surface, and Pattering with them; at intervals they pecked at the surface, but it was not possible to see if they were catching anything. Similarly, Hindwood (1940), describing the feeding of this species on Lord Howe Island, said that "they fluttered above the water with their feet drooping and would drop down and pick up what appeared to be shrimps or very small fish which were being chased to the surface by kingfish. Occasionally they would momentarily touch the water, paddling with their webbed feet." During the Pacific Ocean Biological Survey Program it has been noted that this species spends more time Hovering than any of the other species, although the two larger noddies do Hover at times (Gould, pers. comm.).

The importance of the legs and feet in enabling Pr. cerulea to maintain the most economic distance from the water is reflected in the fact that the tarsi are relatively much longer than in the two Anous species, and in the very large area of webbing on the feet (Table 8). However, Pr. cerulea has a bill absolutely and relatively much shorter than $A$. tenuirostris. In all these features-long tarsi, extensive webbing and relatively short bill, and also in its small size-Pr. cerulea resembles some of the storm petrels (Hydrobatidae), and it is clear that there is a similarity also in the feeding methods and in the food eaten. However, it appears that Pr. cerulea eats more active prey than most storm petrels, and is largely dependent on the presence of predatory fish to make this part of its diet available.

Pr. cerulea seem to leave the colony in the morning well after first light, and they return to it in large numbers at dusk; we have no evidence that they ever feed at night. 


\section{SEASONAL CONSIDERATIONS}

\section{SEAsonal Variation in the ENVIRONMENT}

Seasonal changes are much less pronounced in the Central Equatorial Pacific than in most oceanic areas. The climatology of the region has been discussed by Hutchinson (1950), while Riehl (1954) and Barkley (1962) also gave some relevant information. Murphy and Shomura (manuscript) give a fuller analysis of the winds of the region, and also give monthly mean surface water temperatures for latitudes $0^{\circ}-5^{\circ} \mathrm{N}$. (see also Roden 1963, Wyrtki 1965). At the longitude of Christmas Island the monthly means range from about $79^{\circ} \mathrm{F}$. to about $81.5^{\circ} \mathrm{F}$., with lowest temperatures in December through February and highest temperatures in about June. However, Murphy and Shomura point out that although there are climatological seasons at the Equator, "these may frequently be altered or obscured by short-term changes to the extent that during a given year the 'seasons' may not materialize." Since oceanographic conditions are closely related to the preceding climatological conditions (especially through the effect of winds on the equatorial upwelling), the result of irregular variation in the equatorial weather can be seen in both short-term changes and trends extending over several years in the characteristics of the surface waters, especially within five degrees of the Equator. Some of these non-seasonal effects are shown in Barkley's data on surface salinities and temperatures at Christmas Island over a period of several years. Nevertheless, the data do show a seasonal pattern, and the abundance of zooplankton in the area, which is primarily controlled by upwelling at the Equator, probably also varies in a fairly regular seasonal pattern. The plankton sampling which has been carried out in the area (King and Demond 1953, King and Hida 1957) was limited to short periods spread over several years, probably resulting in blurring of seasonal trends by differences between the years, and it was not possible to demonstrate significant differences between seasons. However, there was a suggestion that both in the South Equatorial Current and the Countercurrent zooplankton abundance is lower in the first quarter of the year than at other times.

For the sea birds, the important variable is the availability of forage animals at the surface, which, as already discussed, is more directly related to the abundance of surface-feeding schools of tunas (and so perhaps to the occurrence of fronts) than to the general abundance of zooplankton. The most relevant data are those of Murphy and Ikehara (1955), since Waldron (1964) did not separate oceanic sightings of bird flocks and fish schools from those closer to islands. These data show that in oceanic areas fish schools were seen at average rates of about one per day in the period September-November, about 0.5 per day in December-February and June-August, and less than 0.2 per day in March-May. Variation in sightings of bird flocks was similar, and may in fact have been largely responsible for the apparent variation in the abundance of fish schools, since most schools were detected by sighting accompanying birds. Interpretation 
of the observed seasonal pattern is made even more difficult by the fact that the observations were spread unequally over three different current systems, among which there was important variation in the abundance of fish schools.

It may therefore be concluded that the data presently available do not permit assessment of the seasonal variation in the availability of food for the sea birds. Nevertheless, it must not be forgotten that if there were-in the area under consideration-seasonal changes approaching in magnitude those which occur in many other areas, they could undoubtedly be detected from the data now available. It is therefore reasonable to assume that seasonal changes in the availability of food for the birds are relatively slight.

\section{Seasonal Variation in the Food of the Birds}

Our only other information on seasonal variation in the food supply comes from the composition of the food obtained by the various bird species at different times. The data are not sufficient for a detailed seasonal analysis, but the available relevant information is summarized in Figures 8-10. Fig. 8 shows that considering the composition of the food by volume, the relative abundance of the major food classes (fish, squid and other invertebrates) in the samples obtained varies considerably in most species from month to month, but without showing consistent seasonal trends. Furthermore, there is little tendency for the variations that do occur to be parallel in the different species. In spite of the small number of samples involved, striking seasonal trends in the composition of the food would probably have been reflected in our data. However, it is very likely that analysis of more extensive data, gathered over a period of several years, would bring to light some subtle seasonal tendencies.

On the other hand, there is evidence that real short-term changes in the availability of the different foods do occur. For instance in S. fuscata, for which relatively large numbers of samples are available, the proportion of squid in the food given to chicks during March 1963 (in a colony on the main island) was far higher than in August and rather higher than in September (on Cook Island). However, the situation in February 1964 was more similar to August and September 1963 than to the previous March, arguing against the possibility that the winter breeding season (with laying mainly in December) is timed in relation to a seasonal peak in the availability of squid for feeding the young.

Similarly, the importance of short-term and perhaps randomly occurring changes in availability of different foods is well shown by the difference in the samples obtained from G. alba in the first three weeks of January 1964 and the first week of February 1964. In the first period food was apparently in short supply-since several large chicks were extremely light in weight-and fish made up a large proportion of the diet (Fig. 8). But in the first week of February food was clearly abundant (since almost every bird handled at night regurgitated) and consisted almost entirely of squid of extremely uniform size (see later); presumably these squid had just moved into the area.

Figure 9 gives information on the seasonal variation in the size of the fish and squid taken. Data are presented only for P. nativitatis, S. fuscata, G. alba and $A$. tenuirostris, since in the other species there were few periods with adequate sampling. Similarly, the data on squid in the diet of $A$. tenuirostris are not worth 
PHAETHON RUBRICAUDA

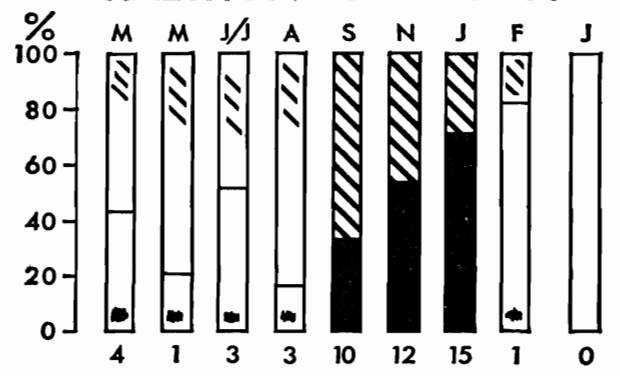

PUFFINUS NATIVITATIS

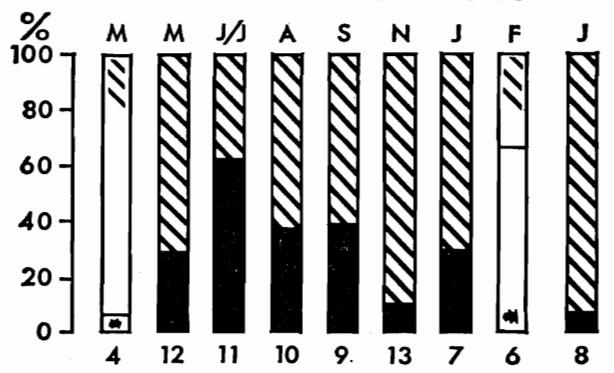

PTERODROMA ALBA

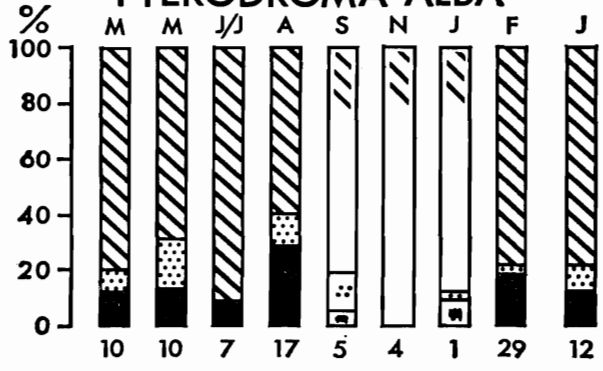

STERNA FUSCATA

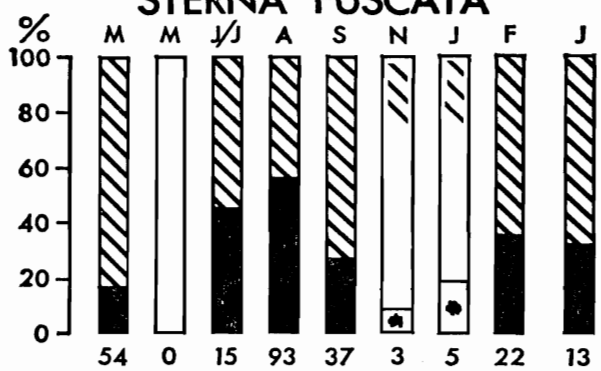

FISH
ANOUS STOLIDUS
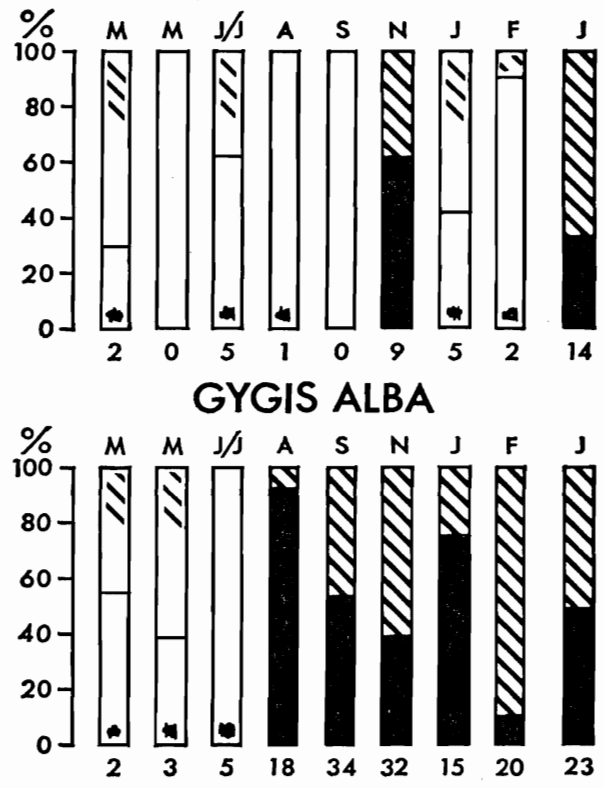

ANOUS TENUIROSTRIS

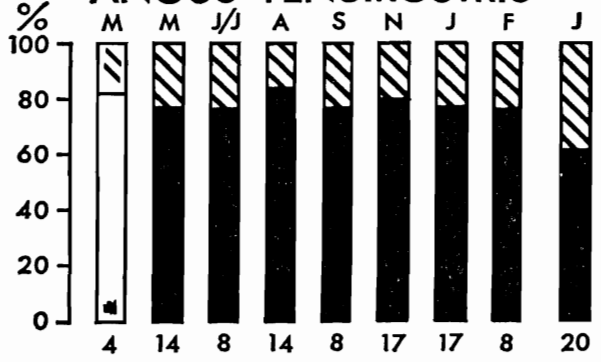

PROCELSTERNA CERULEA

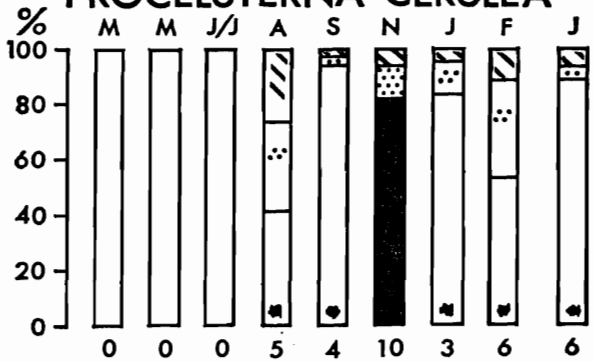

圆 OTHER INVERTEBRATES

FIGURE 8. Seasonal variation in the proportions (by volume) of the major food classes in the diets of the birds.

The figures below the columns indicate the number of samples obtained in each period: full shading is used only when there were at least 7 samples. Details of the sampling periods (designated here by initial letters of the months concerned) are given in Fig. 1. 


\section{PUFFINUS NATIVITATIS}
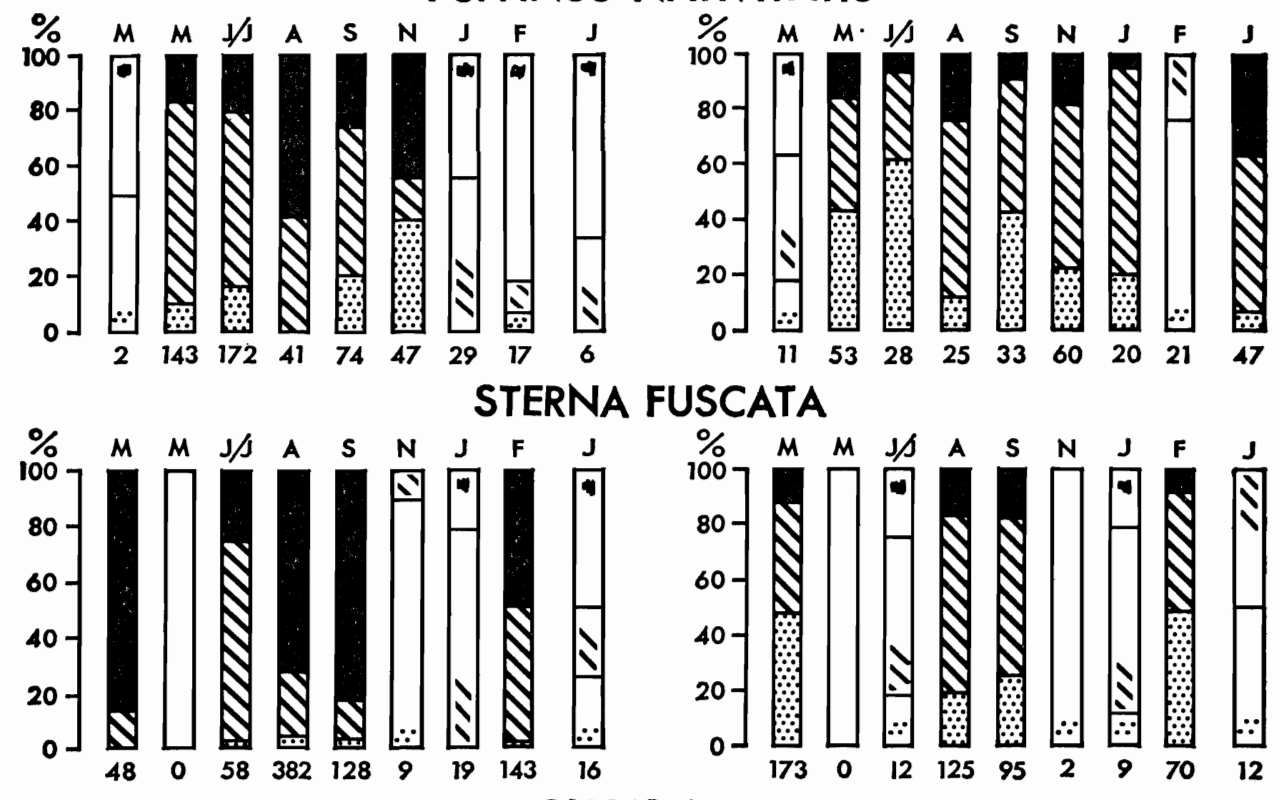

\section{GYGIS ALBA}

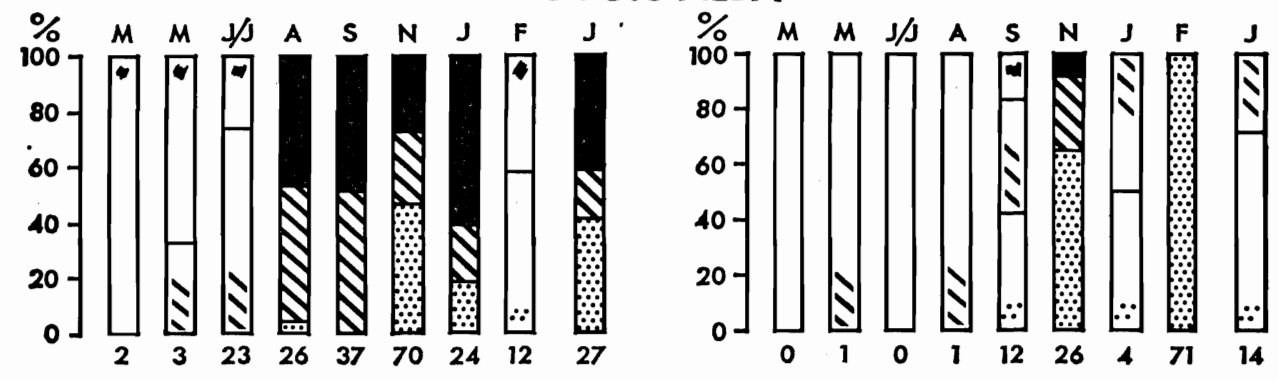

ANOUS TENUIROSTRIS

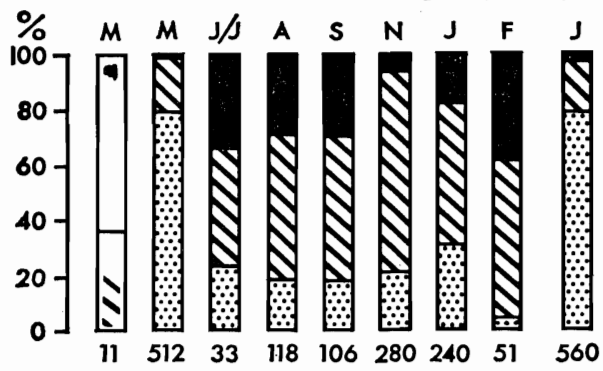

$\square \mathrm{FISH}>4 \mathrm{CM}, \mathrm{SQUID}>6 \mathrm{CM}$

D FISH 2-4 CM,SQUID 4-6 CM

圈 FISH 0-2 CM,SQUID 0-4 CM

FIGURE 9. Seasonal variation in the size of the fish and squid in the diets of four bird species.

The figures below the columns indicate the number of measurable fish (or squid) which were available in each sampling period. Full shading is used only when these numbers are 20 or higher, and at least 7 samples contained some fish (or squid). 

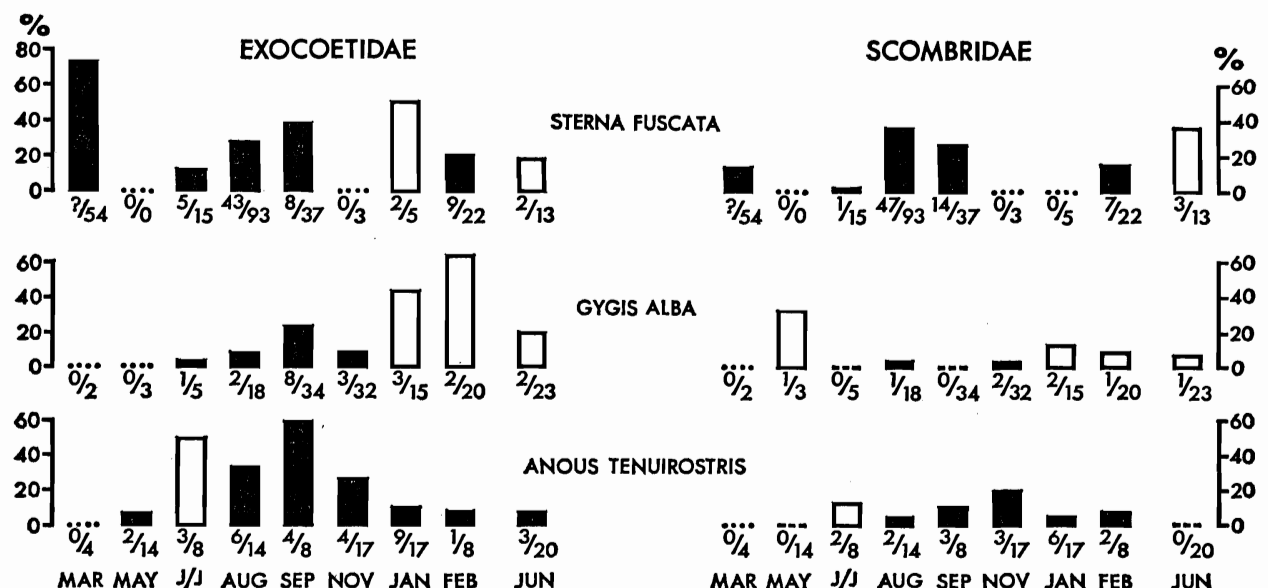

ANOUS TENUIROSTRIS
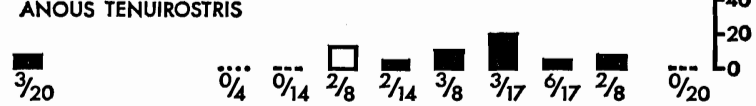

MAR MAY J/J AUG SEP NOV JAN FEB

JUN

MAR MAY J/J AUG SEP NOV JAN FEB

JUN
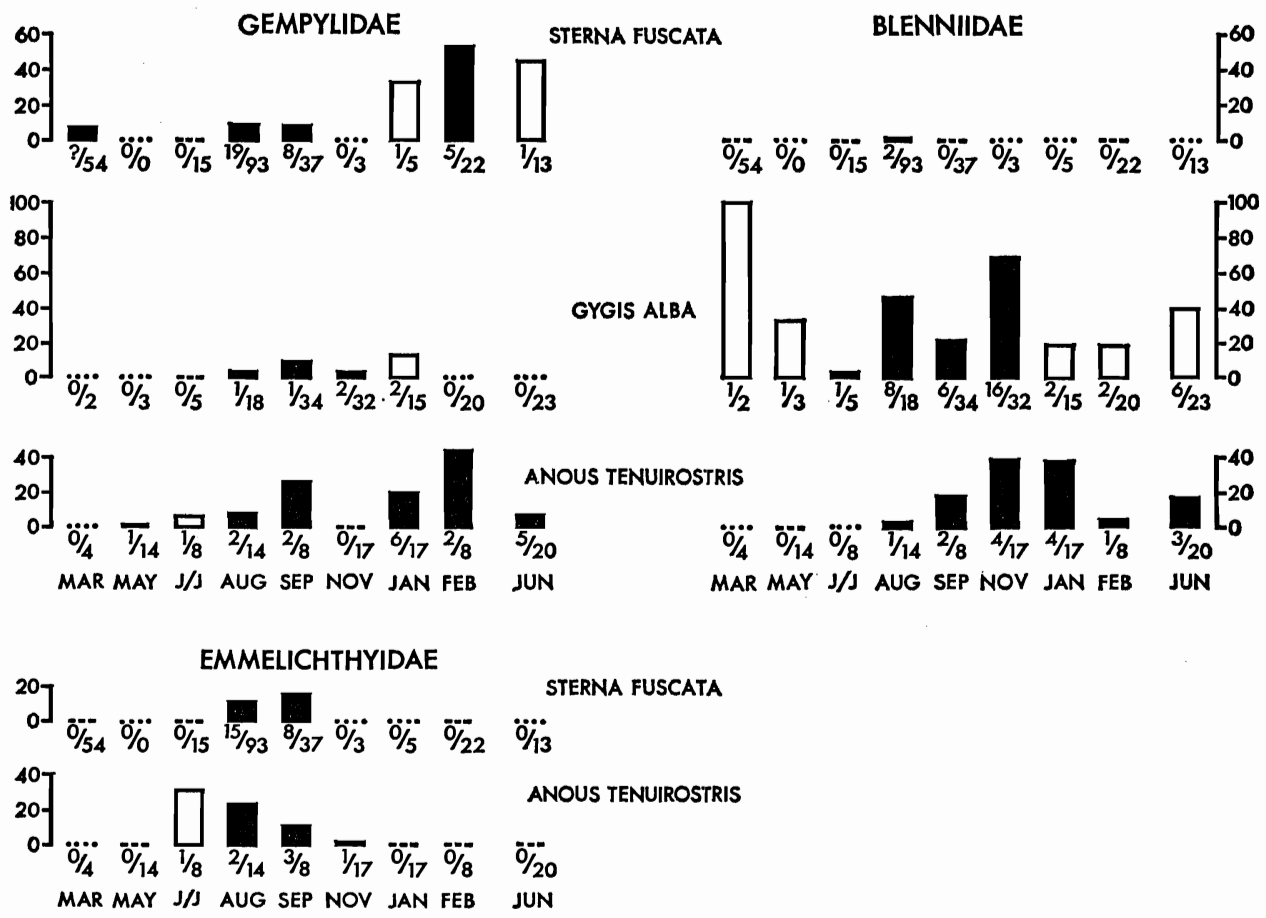

FIGURE 10. Seasonal variation in the representation (by number) of some important fish families in the diets of Sterna fuscata, Gygis alba, and Anous tenuirostris.

The five fish families are considered separately. Each histogram shows, for a bird species, variation in the percentage of the identified fish which belonged to the relevant fish family. Solid black columns (or dashed zero lines) indicate that at least 20 fish obtained from the bird species in that sampling period were identified (i.e., when $100 \%$ represents at least 20 fish): in the other periods open columns or dotted zero lines are used. The figures below the columns are frequencies of occurrence: the first figure is the number of samples in which members of the relevant fish family were found; the second figure is the total number of samples obtained from the bird in that sampling period. 
presenting, but are available in Appendix 2, together with the fish and squid data for the other four species. The numbers of measurable fish and squid obtained in each sampling period are given in the figure, while information on the number of samples containing fish and squid in each period is available in Appendix 1. It is thus possible to obtain an idea of the reliability of the observed differences between periods, so long as it is remembered that each item cannot be considered as necessarily being obtained independently of others in the same sample, since the birds may fish for considerable periods over a single school of prey.

Examining the fish data first, the only dramatic seasonal effect is found in the diet of A. tenuirostris, which in both May 1963 and June 1964 included $79 \%$ of fish less than $2 \mathrm{~cm}$ long. In none of the other periods did the proportion of small fish approach this level, the highest being $32 \%$ in January 1964 . Thus the diet of $A$. tenuirostris showed an enormous swing in favor of small fish in the early summer of both years. In 1963 the sampling period in which many small fish were obtained was from 29 April to 9 May, while the regurgitations obtained in the next period, between 19 June and 5 July, contained a much lower proportion of small fish. In 1964 it was sampling between 30 May and 11 June which produced a high percentage of small fish. It is thus possible that the period of abundance of small fish was slightly later in 1964 than in 1963. The peak of breeding occurred at about the same time in the two years, and in both the tiny fish were used extensively in feeding chicks. However, it was clear that the high proportion of small fish obtained at these times did not result merely from their selection by birds which were feeding chicks, since they were regurgitated also by birds which did not yet have eggs and by birds which were incubating. Because of this, it does not seem plausible to suggest that small fish are equally available at all times of year but are selected by $A$. tenuirostris especially when breeding. It is more probable that they become much more abundant at roughly the same time in each year, and that this abundance has been an important factor influencing the evolution of the observed breeding season.

In this case, one might expect to find the seasonal abundance of small fish reflected in the diets of the other species. The data available for comparison are not sufficient to be sure, but it seems that neither $P$. nativitatis, $S$. fuscata, nor G. alba took an unusually high proportion of fish less than $2 \mathrm{~cm}$ long at the times when $A$. tenuirostris was catching so many. However, at least $P$. nativitatis and $S$. fuscata, and probably $G$. alba, feed further out to sea than $A$. tenuirostris, while the data for G. alba are complicated by a bias in favor of large fish in samples carried in the bill. Unfortunately, the majority of the tiny fish obtained from $A$. tenuirostris could not be identified, so we do not know how many different kinds of fish were involved in the peak of their abundance. However, it appeared that only a few different species were of major importance.

In S. fuscata the large young in March and September 1963 were fed mainly on fish more than $4 \mathrm{~cm}$ long (Fig. 9). The food given to the slightly smaller young in August had a similar size composition, but at a slightly earlier stage in the following breeding season (February 1964) more fish in the $2-4 \mathrm{~cm}$ class were present in the samples. The representation of this class was even greater in June/ July 1963, when many of the samples were obtained from adults which had 
chicks a few days old. However, the number of samples from June/July is rather small (11 containing fish), so that this difference may not be meaningful.

The available data thus suggest that there was an early summer peak in the abundance of small fish in inshore waters, but no well-marked seasonal cycle in the size of the fish taken by the birds feeding further from the island. The lack of any consistent seasonal pattern, and the rather large variation from one sampling period to the next, may be in part a reflection of the fact that most of the species studied fed on a wide variety of fish. There are doubtless wellmarked trends in the size-frequency distribution of the separate fish species, but in the area well away from the island it appears that these trends do not run parallel to one another, and so do not result in conspicuous trends in the size distributions of the taxonomically diverse samples taken by the birds.

In contrast to the fish, the squid taken by the various bird species were almost entirely of one family and genus (Ommastrephidae-Symplectoteuthis) and thus might be expected to show more clear-cut seasonal size variation. Large samples are available for rather few bird species and sampling periods (Fig. 9), but in $S$. fuscata, where the sampling is best, there are indications of a seasonal pattern. In March 1963 and in February 1964 the proportion of squid less than $4 \mathrm{~cm}$ in mantle length was considerably higher than in the large samples from $\mathrm{Au}$ gust and September 1963. However, evidence from several more years would be needed to prove that this indicated a regular annual cycle in size. The abundance of squid less than $4 \mathrm{~cm}$ long in February 1964 is shown more dramatically in G. alba, in which the 71 squid obtained in this period were all in the $2-4 \mathrm{~cm}$ size class. This abundance of small squid seems to be reflected also in the small sample from $P$. nativitatis (Fig. 9), but $P t$. alba did not take a specially high proportion of small individuals at this time (Appendix 2b).

Another possibility for seasonal variation is that members of the various fish families might be available to different extents at different times of year. Fig. 10 gives our data for some of the more abundant fish families and the bird species from which the largest numbers of identifiable fish were available, spread fairly evenly throughout the period of study. However, a number of biases are involved and the data should be interpreted with care. The sampling should be sufficient to demonstrate any drastic seasonal changes in availability, but the situation is made complex by the large number of kinds of fish eaten by most of the bird species, so that subtle changes would not be apparent. In fact, few consistent trends emerge from the analysis, suggesting that seasonal changes are relatively slight.

Exocoetidae, which were important in the diets of nearly all the birds, were clearly available in all the sampling periods. One feature of interest is that in March 1963, a period in which the diet of $S$. fuscata consisted largely of squid (Fig. 8), an unusually high proportion (73\%) of the identified fish were Exocoetidae. This suggests that other fish were less abundant than usual at this time. In August and September 1963, when S. fuscata were again feeding large chicks, relatively fewer Exocoetidae, and more Scombridae, were obtained. In February 1964 Gempylidae provided a higher percentage of the fish taken by S. fuscata than either Exocoetidae or Scombridae, but the frequencies of occurrence of the two latter families were higher. Scombridae were eaten in small numbers by 
A. tenuirostris in all sampling periods except May 1963 and June 1964, the two periods when this species was eating many very small fish.

The occurrence of Blenniidae has already been discussed in the Species Account for G. alba, since they were the most important family in the diet of this species. Fig. 10 shows that Blenniidae were obtained by G. alba at all times of year. However, Cirripectus sp., which were the only blennies taken by any of the other bird species, were obtained from G. alba only in November; even in this period they comprised only one third of the blennies taken. $A$. tenuirostris took Cirripectus sp. in six different periods, but they were most important in November and January.

Finally, members of the family Emmelichthyidae were obtained by $S$. fuscata in considerable numbers, and with some regularity, in August and September 1963, but not at all at other times. This family also featured prominently in the diet of $A$. tenuirostris at about the same time, while they were present in two samples from $P$. nativitatis and one from $A$. stolidus between June/July and September, but at no other time. It therefore seems probable that there was a real peak in the availability of members of this family during the late summer of 1963.

It will be clear from the above discussion of seasonal variation in the food of the various bird species that our evidence is largely negative; that is to say, few well-marked seasonal changes were detected in the present study. Although this failure may partly be ascribed to the inadequacy of the data, it should be emphasized that if strong seasonal trends had existed, they would have been detected. Our results imply either that no consistent seasonal trends exist, ormore likely-that subtle ones are present, but are overshadowed by short-term fluctuations in availability, and by sampling errors. It should be pointed out that this conclusion implies that the environment is an unusual one; in the majority of oceanic areas less intensive sampling would have detected more striking seasonal changes in the environment.

\section{Seasonal Variation in Breeding Actrivities}

Our interpretation of the oceanic environment of Christmas Island as being one of the most nearly seasonless of any oceanic area is supported by the relatively slight seasonal variation in breeding activity shown by most of the sea birds. Even before the start of the present study, the evidence indicated that the breeding regimes of several species did not involve the usual well-marked peaks in breeding activity at a particular season in each year (Gallagher 1960); this picture has been confirmed by the investigations during 1963-64 (Fig. 1).

The initial object of the work on Christmas island was to document the breeding schedules of individual birds, especially of $S$. fuscata and G. alba. Individual $S$. fuscata were shown to breed either at six-month or at twelve-month intervals, according to their success in the previous breeding period (Ashmole 1965); breeding seasons start each year in May-June and November-December, and there are only two or three months in the year in which members of the species are not breeding on the island. In contrast, individual G. alba finished their breeding activities, underwent a complete molt, and then immediately returned to breed, apparently irrespective of the season (Ashmole, in press). 
There was a peak in breeding activity during the early summer, but the reasons for this were not determined; neither is it certain that the peak occurs at the same time in each year. Other species, for instance $A$. tenuirostris and Pr. cerulea, showed straightforward annual cycles and definite-though extendedbreeding seasons once each year.

Looking at the breeding periods in 1963-64 of all the birds whose food was investigated (Fig. 1), the most striking feature is that at any time of year a large proportion of the species can be found at some stage of their breeding activities. Furthermore, it is difficult even to say which are the peak breeding periods and which have least breeding activity. Giving equal weight to all the species studied, the modal periods for eggs in 1963-64 were May through July and December-January, and the least popular months were November and February. For chicks the pattern is even less sharp, but more species had chicks during January through March and June through October, than in April-May and November-December.

However, Fig. 1 shows graphically only the data for the eight species studied in detail; information on the breeding periods of the other species which breed on Christmas Island is given in the note to the figure. This information shows that among the Pelecaniformes of Christmas Island (including Ph. rubricauda) there is a tendency for breeding to occur during the northern summer, as it does also in the Hawaiian chain (Richardson 1957). However, in Sula dactylatra and S. sula on Christmas Island some laying may occur at any time of year, and in the other species except Fregata ariel there is a considerable spread in laying dates. Puffinus pacificus also has a definite summer breeding season, in contrast with the two Procellariiformes included in the present study. It may well be that the food of the Pelecaniformes, which consists mainly of larger prey animals than were taken regularly by any of the non-pelecaniform species studied, does show an annual peak of abundance which makes it advantageous for these species to breed at roughly the same time in each year. However, the selective pressures involved clearly do not necessitate closely synchronized breeding, except perhaps in the case of Fregata ariel. One may speculate that in this species, which obtains part of its food by piracy, apparently largely on terns (personal observations), selection has favored laying at such a time that the young are being fed at the same time as the young of $S$. fuscata in their summer breeding season.

$S$. fuscata overshadows in number and biomass all the other terns and petrels combined; thus the times when this species is feeding large young, especially during August-September and February-March, are perhaps those when the demand on the total food supply of the area is greatest. There is no apparent general tendency for these periods to be avoided as breeding times by the other species. One possible exception is $\boldsymbol{A}$. tenuirostris, the second most numerous species on the island, whose main breeding season overlaps to only a small extent with the time when $S$. fuscata have chicks. However, A. tenuirostris takes mainly smaller prey than $S$. fuscata and feeds much closer to shore, and it seems more likely that the timing of its breeding season is related to the season of abundance of small fish which are not important to $S$. fuscata, than that it is related directly to a need to minimize competition with the more numerous species. 
Of interest in this connection is the fact that many adults and apparently all juvenile $A$. tenuirostris leave the island after the breeding season; this could imply that for this species Christmas Island is a particularly favorable place for breeding (for instance, because of the abundance of nest sites), but that at other times of year feeding conditions are better elsewhere, either because there is less competition for food or for some other reason.

Figure 1 also demonstrates the almost total lack of overlap between the breeding seasons of $A$. tenuirostris and Pr. cerulea, two species which both feed mainly close inshore, often in mixed flocks, and whose diets are similar in consisting largely of fish less than $4 \mathrm{~cm}$ in length (Figs. 3 and 4 and Table 5). If, as suggested in the previous section, there is a peak in the abundance of the small fish taken by $A$. tenuirostris in early summer, it is necessary to explain why $P r$. cerulea lays mainly in autumn (Fig. 1 and Gallagher 1960). It could be argued that the breeding season is timed so as to minimize competition for food with $A$. tenuirostris, and this possibility cannot be entirely excluded. However, it should be pointed out that there are important differences between the diets of the two species, which must tend to reduce competition between them, and which might also result in selection favoring breeding at different times, irrespective of the presence of the other species. One important difference is that the fish family Gempylidae is of outstanding importance in the diet of Pr. cerulea, while in $A$. tenuirostris it is only one of ten important fish families. It is thus possiblethough quite unproven-that the winter breeding season of Pr. cerulea has evolved as a result of selection favoring breeding in the period when small Gempylidae are especially abundant, and that this is the main reason why breeding occurs at such different times in the two species. This is not to say, of course, that the difference in food preferences is not itself an evolutionary consequence of competition between the species. 


\section{DISCUSSION}

The main interest in the present study lies in the fact that it includes data on the food of nearly all the smaller members of the sea bird community of an oceanic island, in an equatorial region where seasonal influences are minimal. Since all the species studied obtain their food just above, on, or just below the surface of the ocean around Christmas Island, it is worth considering the competitive relations between them.

First, it is necessary to assess the probability that the species are limited in numbers by some resource other than food. Reasons for thinking that populations of many tropical oceanic birds may be limited primarily by competition for food were presented in an earlier paper (Ashmole 1963a). However, it was recognized that certain sea bird populations might be limited by the availability of nest sites, and this possibility has since been further discussed by Rowan (1965) in relation to the Great Shearwater (Puffinus gravis). She suggested that in this and perhaps some other Procellariiformes, since there is no form of land tenure apart from defence of the burrow itself, birds which do not own burrows can nevertheless make unsuccessful attempts to nest on the surface in colonies which are already overcrowded, rather than being forced to breed in other, less crowded colonies nearby, or to found new colonies. Similarly, Robertson (1964), in his discussion of the populations of $S$. fuscata and A. stolidus in the Dry Tortugas, presented arguments that these populations may at present be limited by the tendency for birds which cannot obtain optimal sites within the colony to attempt to breed in suboptimal sites in the same area, rather than to establish new colonies elsewhere. A similar tendency in A. tenuirostris on Ascension Island was discussed previously (Ashmole 1962: 236).

Such situations raise the problem of why these colonial birds have not evolved greater readiness to establish new colonies. Three factors may be important. First, potential colonists will generally be young birds, which have to form pairs before they can breed; individuals which spend the courting period in an established colony may have a higher chance of obtaining mates than those which go elsewhere. Second, it is probable that colonial species depend rather largely on responsiveness to the behavior of other members of the colony to ensure that they breed close to the optimum time (Brown and Baird 1965). One or a few pairs establishing a new colony, especially if they were young birds, would be likely to breed later than the main colony, and therefore to have lower breeding success. Finally, if one assumes that before man became a significant factor in their environment the populations of most sea birds were relatively stable, the normal situation would be for there to be established colonies in all the places suitable for breeding. Thus, for colonial species in reasonably stable environments, the best indication that a particular place was suitable for breeding would be the presence of a colony there (cf. Crook 1965). This fact would clearly have an important influence on the evolution of behavioral mechanisms for breeding-site selection in the species. Man's intermittent disturbance of the habitats 
of many colonial sea birds has largely vitiated this mechanism of breeding-site selection and may be largely responsible for the inadaptiveness-in certain present-day circumstances - of the reluctance to establish new colonies. However, it is clear that this same characteristic must hinder range expansion in response to changing ecological conditions. Salomonsen (1965) argued that the recent spread of the Fulmar (Fulmarus glacialis) in the boreal zone became possible only when members of a certain population overcame-possibly through genotypic alterations-the strong adherence to the traditional breeding place which is normal in this species (but see also Fisher 1966).

We are now of the opinion that although most populations of tropical sea birds probably are limited mainly by the effects of competition for food, additional density-dependent effects, differing widely in importance in different populations, may often be exerted by competition for optimal nest sites, even when an excess of suboptimal sites is available within the colony.

It is to be expected that since birds possess well developed behavioral mechanisms for selection of an appropriate nest site, a higher proportion of individuals will obtain optimal nest sites when a population is small than when it is large. This effect will be most important in species with specialized nesting requirements, and in areas where large numbers of equally favorable sites are not available. For example, it seems certain that in a cliff-nesting species the most secure sites will on average be occupied first in an expanding colony, while in colonies of petrels nesting underground the chance of breeding failure through burrow collapse doubtless increases slightly with the density of the colony. Similarly, Robertson (1964) points out that in certain species nests outside the area of the normal colony may be more exposed to weather than those in the preferred area.

Behavioral interactions between members of a population may have the same kind of effect. For instance, Cullen and Ashmole (1963: 440-443) frequently observed $A$. tenuirostris chicks on Ascension Island being pecked by displaying adults which visited their ledges, and considered that some chicks were killed in this way. It seems probable that such intrusions would be less frequent in colonies in which an excess of good nesting sites were available, and observations on Christmas Island, where A. tenuirostris build nests in trees, tend to confirm this view. Similarly, Snow (1965), in a paper on the Red-billed Tropic-bird (Phaethon aethereus) in the Galápagos Islands, described intense intraspecific competition for nesting sites on one island, and a high rate of nesting failure which was attributed to the competition, although there was a much less crowded —and more successful — colony on a different island only 16 miles away.

Another real possibility is that predation sometimes acts density-dependently by causing higher mortality in birds in suboptimal sites than optimal ones. With large populations the proportion of birds in suboptimal sites will be greater, so that the overall rate of predation might be higher than it would be when the population was small. This effect must certainly sometimes occur, and Robertson (1964: 43) cited a possible example in S. fuscata. A different type of example-perhaps as yet unproven-is provided by the many species of petrels which are subject to predation by gulls or birds of prey. In these, the chance of survival of chicks and adults is probably inversely related to the distance be- 
tween the burrow entrance and a place (for instance, a steep slope or cliff top) from which they can take off.

Since effects of these kinds may be expected to exert some density-dependent influence on breeding success, even when not all the possible nest sites are occupied, one must be cautious in claiming that competition for nest sites cannot be contributing to the regulation of a given population. However, the nesting requirements of most of the Christmas Island sea birds are very unspecialized; of the species studied, Ph. rubricauda, P. nativitatis, Pt. alba, S. fuscata, A. stolidus and Pr. cerulea all breed in scrapes on the surface of the ground. Nevertheless, most of these species seem to prefer sites sheltered to some extent by vegetation, and it was suspected that in Pt. alba during the midsummer breeding season, when vegetation was generally thin, adults at exposed sites sometimes left the nests during the hottest part of the day, exposing their eggs to lethal temperatures. If this phenomenon could be confirmed it would clearly provide an example of a subtle density-dependent effect of competition for optimal sites. However, in none of the other ground-nesting species were there any obvious indications that similar effects were operating. It should also be mentioned that in the three species of boobies, two species of frigate-birds and two species of terns which were not included in the present study, it seemed most improbable that competition for nest sites could exert important density-dependent effects.

The two remaining species whose food was studied, G. alba and A. tenuirostris, have slightly more specialized nest-site requirements. $G$. alba, which on Christmas Island places its egg mainly in crevices on the branches of Messerschmidia argentea, probably utilized a high proportion of the best of such sites, as well as many suboptimal ones. Furthermore, some eggs on Cook Island were placed on coral blocks in the open, where they may have been generally less successful; however, the biases involved in estimating breeding success made it impossible to be sure of this. A. tenuirostris was far more abundant than G. alba, but since it can build nests in almost any fork of a Messerschmidia tree, there did not seem to be a lack of potential sites.

The possibility that predation might exert a significant control on the bird populations of Christmas Island can probably be excluded at once for all the species except $S$. fuscata. Chicks of the latter species in some of the mainland colonies are taken in large numbers by the Great Frigate-bird (Fregata minor). However, it was rare to see a frigate-bird hunting over Cook Island. In the enormous mainland colonies a much higher proportion of nests were in places accessible to frigate-birds, and therefore suboptimal from the viewpoint of predation. An increase in numbers might raise this proportion still further, and so perhaps increase the overall rate of predation slightly, but the densitydependent effect would be rather small. Furthermore, since small chicks of $S$. fuscata are available for such short periods (about one month, twice a year), it is unlikely that an increase in the numbers of chicks would cause an equivalent increase in the population of Fregata minor. Thus an increase in the numbers of $S$. fuscata might even result in a decrease in the proportion of chicks predated.

It may therefore be provisionally concluded that shortage of optimal nest sites may exert some density-dependent control on the breeding success of the populations of Pt. alba and G. alba, but is unlikely to be of great importance in 
the other species, including $S$. fuscata, which is by far the most numerous species on the island.

However, another possibility which must be borne in mind when considering the results of the present study is that the populations of some of the species may not be in equilibrium at the present time. Whereas in most bird species with high reproductive and mortality rates any divergence from equilibrium caused by man's activities is likely to be quickly succeeded by a new equilibrium, this is not necessarily true of populations of long-lived birds with low reproductive potential.

Although Christmas Island had no indigenous human population, it has been the scene of a wide variety of human activity (King 1955, Gallagher 1960), culminating in the explosion of nuclear weapons at the east end of the main island during 1958-59. The latter caused heavy mortality of Red-footed Boobies (Sula sula), but probably had relatively small effects on the other bird species, which are concentrated at the opposite end of the island. However, the population of Ph. rubricauda may also not be in equilibrium at the present time, since this species is subject to sporadic illegal slaughter by Gilbert and Ellice islanders, who apparently consider it a delicacy. The complex history of Christmas Island makes it difficult to judge to what extent the populations of the other birds have been affected by man, but there is no evidence that the species composition has altered since the early visits to the island, and S. fuscata has clearly always been enormously abundant (King 1955).

It therefore seems reasonable to consider the sea birds of Christmas Island as a group of species fully adapted both to their environment and to the presence of each other, even though the situation at present probably does not represent exactly the natural equilibrium. Furthermore, in an earlier paper (Ashmole 1963a) general arguments were presented to support the hypothesis that competition for food determines the size of many populations of tropical sea birds, and exerts an important influence on the evolution of many aspects of their biology. If we may conclude from the first part of the present discussion that most of the Christmas Island sea birds are not primarily limited by shortage of nest sites (although this may exert certain density-dependent effects), it seems most likely that the main control is exerted-or at least was originally exerted-by competition for food. The situation on Christmas Island thus provides an opportunity to consider the ways in which the species in a simple bird community are able to occupy distinct feeding niches in an exceptionally uniform and seasonally constant environment.

Lack (1944), although initially doubting the universal applicability to wild bird populations of the principle of competitive exclusion, collected evidence which suggested that sympatric species of birds always differ appreciably in their ecology. As pointed out by Dixon (1961), subsequent work on many different groups has generally confirmed the lack of exceptions to the principle. MacArthur (1958), in his important study of the competitive relations among five species of warblers (Parulidae), presented a concise discussion of the problems of coexistence of similar species. In a population controlled by density-dependent events, the presence of many members of the species makes the environment less suitable for other individuals of that species. Similarly, when several species are 
sympatric, interspecific competition occurs if the presence of individuals of one species makes the environment less suitable also for members of a different species. Populations of sympatric species must always be limited by factors which are sufficiently different that each species inhibits its own increase more than it inhibits that of the others. This formulation by MacArthur implies that interspecific competition will be common among sympatric species, but that its intensity will always be less than that of intraspecific competition. In other words, for each of the competing species, a member of any of the other species must be a less serious competitor than another member of the same species, if all of them are to coexist.

If the species under consideration are limited by the availability of food, one must expect that their feeding ecology will differ significantly. Huxley (1942) and Lack $(1944,1945,1946,1947)$, after consideration of a variety of avian examples, concluded that the most important kinds of ways in which ecological separation is achieved are habitat differences, size differences (especially of the bill), and differences in feeding methods associated with differences in the food. More recently MacArthur (1958) has made an essentially similar statement, saying that "Two species may eat different foods for only three reasons: 1 . They may feed in different places or at different times of day; 2. They may feed in such a manner as to find different foods; 3. They may accept different kinds of food from among those to which they are exposed. (Of course, a combination of these reasons is also possible.)" However, it must be remembered that these behavioral differencesespecially that involving choice among a number of available foods-will not by themselves permit coexistence of two species on an evolutionary time-scale. Unless each species is more efficient than the other in utilizing the food which it chooses, there will be no selective pressure favoring the maintenance of the behavioral differences; one or both species will become more general feeders, and one of them will be excluded from the habitat. On the other hand, indefinite coexistence will be possible if each species is also structurally or physiologically adapted to its own particular feeding niche (cf. Hinde 1966: 445). The extent of this specialization must be sufficient to ensure that when circumstances are critical (i.e., when density-dependent limiting factors are actually operating) each species can occupy its own feeding niche more efficiently than any of the other sympatric species (cf. MacArthur and Levins 1964). Recher (1966) emphasized the importance of morphological divergence in achieving ecological segregation among shorebird species in which spatial segregation is often not possible. However, as he pointed out, morphological divergence is also characteristic of adaptation to "different spatial segments of the environment" (i.e., habitats).

Perhaps the most striking feature of the ecology of Christmas Island is that seven species of terns breed on the island, and that all may be found on or near the island at any time of year. We shall show that like the four species of terns studied by A. N. Formosov (quoted by Gause 1934) on the island of Jorilgatch in the Black Sea, the terns of Christmas Island all show differences in their feeding ecology.

Food samples were obtained from only five of the tern species. One of the others, Thalasseus bergii, is obviously ecologically separated from all the other species, since it was seen feeding only close to beaches within the lagoon and 
along the coast, while none of the species studied fed in these areas to a significant extent. It is unfortunate that transportation problems made it impracticable to obtain food samples from the other tern species, Sterna lunata, a close relative of $S$. fuscata which is only a little smaller; this species probably feeds mainly at sea, but also within the lagoon and at brackish water holes (Gallagher 1960).

Many ecologists, in investigating the application of the principle of competitive exclusion, have concentrated their attention on congeneric species, on the grounds that these are the most likely to compete seriously with each other. Such a procedure would be unjustified in the present case, since although the five species of terns are placed in four genera, some competition clearly occurs even between those which are members of different genera. ${ }^{5}$ More important than the taxonomic situation is the fact that all five species catch their food exclusively within a few inches of the plane of the surface of the sea.

Among the five species of terns, the greatest similarities in diet were between the two largest species, $S$. fuscata and $A$. stolidus. They took very similar proportions of fish and squid, although fish were perhaps slightly more important in $A$. stolidus. The mean size of the items obtained from the two species was almost the same, and the small differences in the size-frequency distributions probably result partly from sampling errors. The only definite difference between the diets of the species was in the representation of certain fish families, and even this was not dramatic. In both species Exocoetidae were the most important family, Scombridae ranked second and Gempylidae third. However, in $S$. fuscata Scombridae were almost equal in importance to Exocoetidae, while in $A$. stolidus there was a much larger difference between the two families.

Both these large terns are dependent largely or entirely on the presence of schools of large predatory fish (mainly tunas) to drive their prey to the surface and so make it available. Since tuna schools have only a low overall density in the tropical Pacific, the numbers of birds feeding over each school are often high. Thus there may be severe competition for available food, even though the total stock of potential prey is very large relative to the number of avian predators (Ashmole 1963a: 473). If it is intraspecific competition of this kind which limits the numbers of each of these species, it is remarkable to find that they take prey of the same kinds and the same size, and yet coexist on so many tropical islands.

Available information on the biology of these two species suggests that the most important difference between them is that they feed largely in different zones (see Section 6), A. stolidus being found mainly close to the breeding colonies (within about 50 miles), but $S$. fuscata ranging much further into the open ocean. It can be no coincidence that $S$. fuscata is undoubtedly the most abundant of all tropical sea birds; it clearly owes its success to unspecialized nest-site requirements and the ability to exploit food made available by schools of predatory fish hundreds of miles from land, even while it is breeding. This is

5 Although Peters (1934) and Murphy (1936) maintain the genera Gygis and Procelsterna, Moynihan (1959) merged both with Anous. While agreeing that Procelsterna should probably be considered as congeneric with Anous stolidus and A. tenuirostris, we feel that there are ample grounds for retaining Gygis as a monotypic genus. 
made obvious by considering the situation which would ensue if the whole population of $S$. fuscata on Christmas Island, consisting of probably more than one million birds, tried to feed over the small number of fish schools (perhaps about a dozen) which are present within about ten miles of the island at a given time. Clearly there would be such intense competition for the limited number of prey individuals which came to the surface that none of the birds could survive. In fact, $S$. fuscata was not seen feeding close to shore around Christmas Island, but $A$. tenuirostris did feed largely in this zone, and although its total population is of the order of one hundredth the size of that of $S$. fuscata (Table 1), the numbers of individuals present over fish schools were often so high that it seemed certain that there was appreciable competition for available prey (Fig. 11).

The adaptations which confer on S. fuscata the ability to feed far from the colony even when breeding, and in which this tern is convergent with many Procellariiformes, include the exceptional length of the incubation shifts, and the ability of the chick to survive for several days without food, even when it is very small, but to accept an enormous meal rapidly when a parent returns. There may also be an ability to delay digestion of food intended for the chick, but this has not yet been investigated. Similarly, although it is certain that $S$. fuscata can remain airborne for indefinite periods (Ashmole 1963b), the aerodynamic, behavioral and physiological adaptations involved have not yet been worked out. Although no proof is yet available, it seems unlikely that $\boldsymbol{A}$. stolidus has this ability to remain airborne for long periods, and it is probable that it normally returns to land at night. However, unlike $S$. fuscata, it can rest easily on the surface of the water (Watson 1910, Watson and Lashley 1915), and it also makes use of floating objects as perches (Murphy 1936).

The fact that $S$. fuscata frequently feed at great distances from shore even while they are breeding implies that they must often fly past feeding flocks of noddies, including $A$. stolidus, to reach their oceanic foraging areas; personal observations near Hawaii confirm that they sometimes do this, although mixed feeding flocks certainly also occur. The results of the present study, showing that the diets of $S$. fuscata and $A$. stolidus are very similar both in general composition and in the size of food items, indicate that food suitable for S. fuscata is available in the areas where $A$. stolidus feed. The situation seems to be most easily explained on the basis that the competition for available prey close to shore makes it advantageous for $S$. fuscata to do a large part of their fishing outside the normal range of $A$. stolidus. However, since $S$. fuscata can forage further from the breeding island, it is clear that $A$. stolidus-if its populations are foodlimited-must be at some advantage when feeding close to the island, or the two species could not coexist.

Although the nature of this advantage is not definitely known, it seems clear that the more extensively webbed feet and longer legs of $A$. stolidus (Table 8 ), and its swimming ability, enable this species to use a greater variety of feeding methods than $S$. fuscata. Furthermore, there are indications that $A$. stolidus, which does not require the capability of regularly traveling great distances, has been able to evolve greater maneuverability in flight than $S$. fuscata. Although we have not analysed in detail the aerodynamic characteris- 

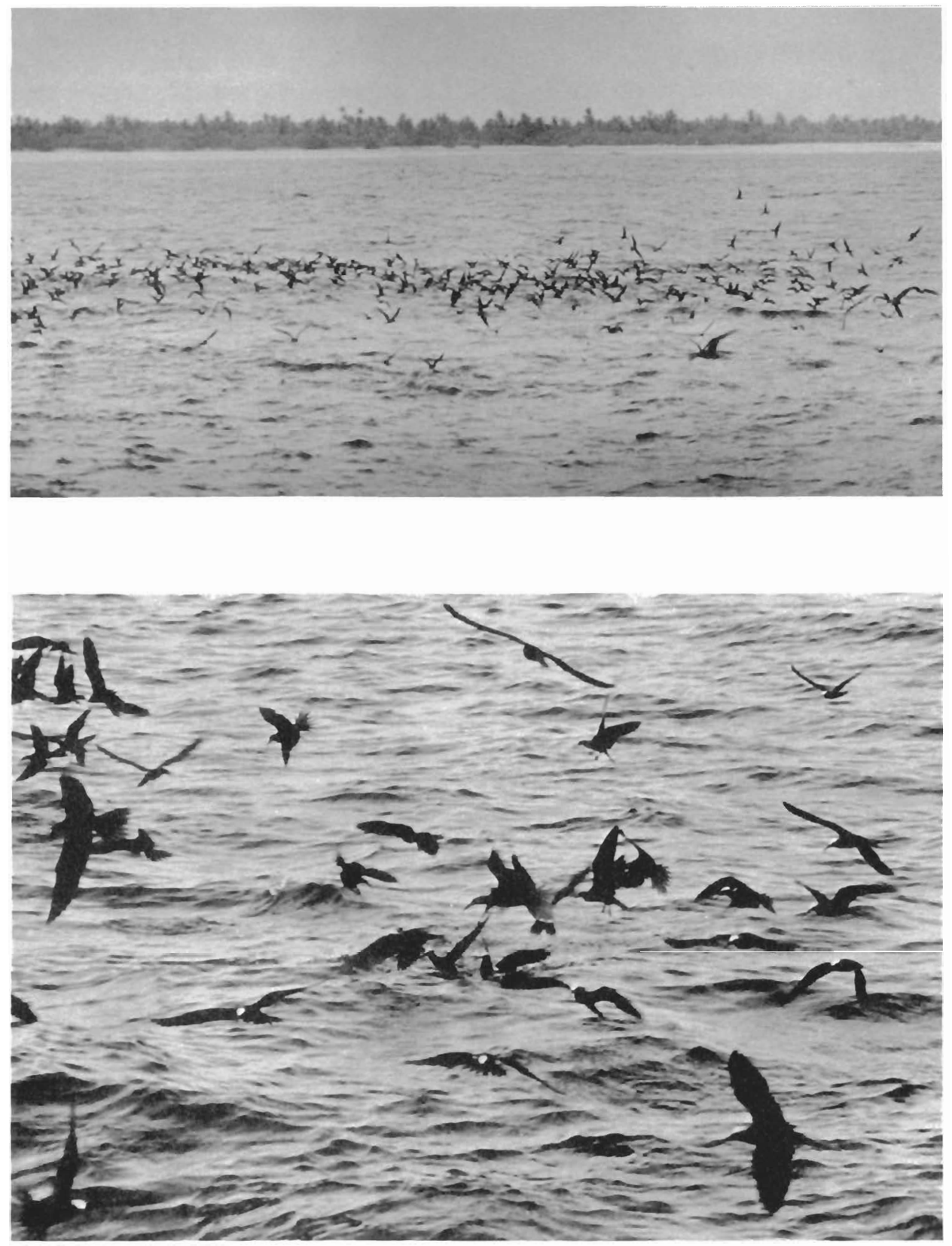

FIGURE 11. Two views of a dense flock of Anous tenuirostris feeding over a tuna school close to the western end of Christmas Island. 
tics of the two species, measurements on relaxed museum skins show that in individuals with the same 'wing length' the area of the distal part of the wing (including all the primaries and secondaries) is much larger in $A$. stolidus than $S$. fuscata (in the specimens measured the areas were 242 sq. cm and 198 sq. $\mathrm{cm}$ respectively, giving a ratio of $1.2: 1$ ). Since in the Christmas Island populations both the mean weights and the mean wing lengths are the same in the two species (Table 8), it is clear that there is a substantial difference in wing loading, while the area of the tail is also greater in $A$. stolidus. The difference in wing area results mainly from the greater length of the secondaries and inner primaries in $A$. stolidus, which makes its wing much broader. It is thus evident that while $S$. fuscata has a well developed high-speed wing (see Savile 1957), that of $\boldsymbol{A}$. stolidus should give greater maneuverability.

Before leaving the subject of the relations between $S$. fuscata and $A$. stoli$d u s$, it is of interest to consider the situation in the Dry Tortugas, which is apparently different from that in most other colonies. Watson (1908) and Watson and Lashley (1915) imply that around the Tortugas the two species feed together, and they apparently do not normally go more than 17 or 18 miles from the colony to obtain their food; Watson was of the opinion that both returned to the island each night. The data already quoted, showing that $S$. fuscata have much shorter incubation shifts on the Tortugas than on Ascension and Christmas Islands, support the conclusion that the feeding ranges of this species are remarkably different in the different areas. Considering also the evidence that chicks in the Tortugas populations develop more rapidly than those on Ascension (Watson 1908, Ashmole 1963b, Robertson 1964), it seems reasonable to conclude, as did Robertson, that the Tortugas population of S. fuscata is not limited by competition for food in the breeding season. If this conclusion is correct, and if-as Robertson believes-the population of A. stolidus in the Tortugas is also limited by factors other than competition for food, the lack of separation of the feeding zones of the two species in this area is just what might have been expected.

The next largest tern species, G. alba, is a little larger than A. tenuirostris but much smaller than $S$. fuscata and $A$. stolidus. Its diet is similar in general composition to those of the latter two species, but differentiated by the larger proportion of small food items, and also by the very different representation of various fish families. Although G. alba may well stay at sea during the nonbreeding period, it does not spend such long periods away from the colony while breeding as does S. fuscata. There are certain indications, already discussed, that the specialty of this species is its ability to feed in the half light of dawn and dusk, when there is more opportunity of catching organisms which come close to the surface at night. If this supposition is correct, it is clear that G. alba might be less dependent than the other species of terns on the presence of tuna schools, and so could avoid undue competition with the other species even though it feeds in the same zones as some of them. The importance in the diet of G. alba of three species of Blenniidae which are known to occur in open waters rather than close to coral reefs, but which were not represented in the diets of the other species, supports the idea that G. alba is able to exploit a source of food which is not available to the other birds, and is consistent with 
the idea that it does much of its feeding at times which are less utilized by the other terns. However, it should also be remembered that the size-frequency distribution of the items obtained from G. alba, though subject to certain biases, is intermediate between that for A. tenuirostris and those for the two larger terns; this will also tend to reduce competition among the tern species.

$A$. tenuirostris, which is similar in size to G. alba but much smaller than $\boldsymbol{A}$. stolidus, is very like the latter species in its morphology (except size) and behavior, including feeding methods. Although the two species were not seen feeding together off Christmas Island, they do so in other areas, and it seems that the main distinctions between them are those related to size. The sizefrequency diagrams (Fig. 4) show the extent of the differences in the lengths of the animals eaten. Although there is a considerable area of overlap, it must be remembered that for $A$. stolidus the smaller prey are of relatively little volumetric importance, so that the great bulk of its food comprises items larger than are taken in appreciable numbers by $A$. tenuirostris.

A. tenuirostris and Pr. cerulea were the two terns most commonly seen feeding within a few miles of the coast during the day, and they often occurred in mixed flocks. Both eat mainly small fish and some squid, but Pr. cerulea also takes a substantial number of small crustaceans and insects. The representation of the fish families is also different in the two species, tiny Gempylidae being of outstanding importance in the diet of Pr. cerulea. Since these two species feed together using very similar methods, but differ so much in body weight and bill size (Table 8), it seems likely that the most fundamental difference in their feeding ecology lies in the size of item that they are best adapted to catch; the difference in representation of the various fish families could follow directly from this. However, Pr. cerulea also exploits two food sources -marine water striders and small planktonic crustaceans-which are not utilized by any of the other terns. It seems probable that the feeding action required for collecting food of this kind is impossible or uneconomic for larger species. It is of interest in this connection that although Pr. cerulea is so much the smallest of the terns of Christmas Island, the mean volume of the items which it ate, and also the volume of the largest items, were much smaller relative to body weight than in the other species. This was reflected also in the fact that although the regurgitations were small in relation to body weight, they contained, on average, far more items than those of the larger terns. It thus appears that although Pr. cerulea is exploiting the smallest prey available to sea birds in the area of Christmas Island, its body size is rather larger than might have been expected. In fact, there are few sea birds smaller than Pr. cerulea, and it may be that certain characteristics of their environment make extremely small size uneconomic for sea birds.

This discussion has been restricted so far to the five species of terns whose diets were studied, since their coexistence on a single island is of special interest. However, it is worthwhile to consider briefly the other three species for which we have data. Ph. rubricauda needs little comment, since its diet, and probably also its method of feeding, are very different from those of the other species. A high proportion of the fish and squid which it obtains are effectively outside the size range of prey of any other species studied, while the representation of 
fish families and of squid species is distinct from that in the other birds; it seems probable that Ph. rubricauda feeds largely on dispersed fish and squid and is relatively independent of the predatory activity of fish schools to make its prey available. This conclusion is reasonable in the light of the observations of Jespersen (1929), who found that scattered tropic-birds (Ph. lepturus) were the characteristic birds of the Sargasso Sea. This area is very poor in zooplankton and presumably also in forage animals, and very few other birds were seen there. For species feeding on scarce, dispersed prey, the ability-possessed by tropic-birds-to exploit prey of a very wide range of sizes may be a critical adaptation; such species cannot afford to be food specialists (cf. MacArthur and Levins 1964). Ph. rubricauda probably does not compete appreciably with any of the terns, or with either of the two petrels which were studied; however, a comparison of its diet with those of the boobies of Christmas Island would be of interest.

Some of the shearwaters (Puffinus spp.) share with tropic-birds and boobies the ability to catch prey well below the surface of the water (Kuroda 1954). They thus contrast with the tropical terns, which probably never obtain prey more than a few inches below the surface. Of the two shearwaters occurring on Christmas Island, samples were obtained only from $P$. nativitatis. Although no observations could be made on its feeding habits, it is highly adapted for swimming (Kuroda 1954), and doubtless obtains much of its food below the surface. The way in which competition for food between the tropical terns and shearwaters is minimized is immediately suggested by a personal observation on a mixed flock of noddies (Anous spp.) and $P$. pacificus near Hawaii. On that occasion a school of tunas was clearly present, but the tunas were not feeding actively at the surface, and no prey animals were seen jumping. The noddies (mainly $A$. stolidus) were not fishing to any extent, and were evidently waiting for prey to become more available, but the shearwaters were diving from the air, sometimes remaining submerged for several seconds. Shearwaters are doubtless largely dependent on tuna schools to make their prey available, but for the diving species it is not essential that the prey be actually at the surface. Therefore, provided that the total numbers of the prey are limited mainly by factors other than predation by birds, there is no reason to suppose that diving shearwaters compete significantly with terns.

Nevertheless, since shearwaters and terns often flock together over the same tuna schools, one may expect their diets to be very similar in composition. In the present study, there was a close similarity in the proportions of fish, squid and other items, and in the representation of the various fish families, between $P$. nativitatis and the two large terns, $S$. fuscata and $A$. stolidus. However, $P$. nativitatis, in spite of its greater body weight, took a much larger proportion of small fish than the large terns. This suggests that $P$. nativitatis is adapted to catching-under water-fish smaller than $S$. fuscata and A. stolidus can economically obtain at the surface. However the size-distribution of the squid eaten was almost identical in the two large terns and in P. nativitatis and Pt. alba.

$P t$. alba has a rather different diet, and evidently employs feeding methods different from both the terns and $P$. nativitatis. It does not swim under water like the latter species, and probably obtains most of its food-including many 
very small items-by Dipping. However, as pointed out earlier, its economic flight and its powerful cutting bill enable it also to exploit the presence in the ocean - at very low density - of floating objects such as dead squid and fish.

It appears from this discussion of the feeding ecology of the sea birds studied, that four main types of differences are important in reducing interspecific competition between them to the level at which they can all coexist. First, there is difference in the time of day at which most feeding occurs; although we have few relevant data, it appears to be one of the factors important in separating G. alba and $A$. tenuirostris, two species which take food rather similar in size.

Second, there is difference in feeding zone, in relation to the position of the island on which breeding (and in some cases roosting) occurs; this is probably critical in separating $S$. fuscata and $A$. stolidus and may be significant also between G. alba and A. tenuirostris. A difference in feeding zones is not quite equivalent to a difference in habitat in terrestrial birds, since the sea birds may be feeding on the same kinds of food and catching them in areas which are very similar except in their distance from land. The ability to feed very far from the breeding colony requires special adaptations, but the species feeding closer to the colony must have some advantage there. We have suggested that $A$. stolidus is more maneuverable than $S$. fuscata and more versatile in its feeding behavior, thus probably exploiting the resources in its feeding zone more efficiently than the latter species.

Differences in feeding methods, accompanied by structural specialization and resulting in the exploitation of significantly different food sources, is the third way in which ecological segregation is achieved. Feeding methods and structural adaptations are generally similar in congeneric species, so one may expect differences in feeding methods to be important in reducing interspecific competition mainly among less closely related species. Thus, whereas all the terns studied obtain their prey by diving from above and catching it at the surface, $P$. nativitatis has the ability to catch active prey by pursuing them when they are well below the surface. In Pt. alba different food sources are made available by adaptations of the bill and by exceptionally efficient flight, while Ph. rubricauda probably specializes in catching large, dispersed fish and squid swimming below the surface.

Finally, there is separation by differences in size of body and of bill, accompanied by choice of food items of different sizes. It has been recognized for about 25 years that size differences in food are often important in permitting the coexistence of species with otherwise similar ecology (Huxley 1942, Lack 1944, and other references in Schoener 1965). Hutchinson (1959) in an attempt to place quantitative limits on the extent of such differences which are necessary to permit coexistence of two species, presented data on the ratios of the culmen lengths of pairs of congeneric bird species in areas of sympatry. Since then, culmen length ratios of large numbers of pairs of species have been used in general discussions of "niche size" (Klopfer and MacArthur 1961, Klopfer 1962, Schoener 1965). Schoener has pointed out that Klopfer and MacArthur's preliminary conclusion that culmen length ratios among pairs of tropical species are lower than those of temperate zone species is not confirmed by a more extensive compilation of data. Schoener considered that differences in ratios be- 
tween different groups of species are most closely related to the kinds of food which they eat. However, at this stage it seems worthwhile to re-emphasize the fact that although culmen length is a convenient characteristic related to feeding, it is a very unreliable index to the feeding ecology of a species. Our data for the two species of Anous illustrate the danger: the smaller species has a slightly longer culmen, but eats much smaller food items. Probably any naturalist looking at the birds in the flesh (or the photographs in Fig. 6) would predict correctly the relative sizes of their prey, but comparison of culmen lengths alone would suggest that they ate prey of very similar size. We do not want to deny the usefulness of culmen length ratios in comparing large numbers of pairs of species, but merely to point out the necessity for caution in interpreting the results, and the need for detailed studies of the overall feeding ecology of critical groups of birds.

It is of interest to note that although the five tern species fall into three groups in terms of body weight and also of size of prey (S. fuscata and $A$. stolidus; G. alba and A. tenuirostris; and Pr. cerulea), the bill lengths of the first four species (and also of Sterna lunata, which was not studied) are very similar to each other (Table 8). Since these four species all catch their prey when it becomes available momentarily at or above the surface, the speed with which the bill can be closed on the prey will be of great importance. As pointed out by Beecher (1962), a long bill is capable of greater speed at the tip than a shorter, more powerful one. Furthermore, the greater reach conferred by a long bill may help in catching prey a little below the surface. However, considerable force is required to retain a grip on a struggling prey animal, and-other things being equal-the force which a bird can apply near the tip of its bill is inversely related to the length of the bill. Thus the observed bill length of each species must represent a critical compromise, which could be understood completely only by a full functional analysis of the skull architecture and musculature (see, for instance, Bowman 1961, Beecher 1962, Zusi 1962, Bock 1966). However, viewing the situation in its simplest terms, it appears that to evolve the ability to exploit larger prey, without a sacrifice in bill length, a tern must increase the force of the mechanical system for closing the bill. This will normally involve an increase in the mass of the muscles and bones involved, while a stronger (and therefore heavier) bill will also be required. Changes of this kind will create mechanical and aerodynamic problems whose solution will usually result in an increase in general body size. Furthermore, increase in size with increase in size of prey may also tend to result from the fact that sea birds such as terns which normally swallow their prey in flight (probably because of the danger of settling on the surface where large fish are feeding), need to be able to lift their prey from the surface in their bills.

We have included in Table 8 some dimensional relationships relevant to consideration of the structural adaptations associated with exploitation of prey of different sizes. It can be seen that $S$. fuscata and $A$. stolidus have evolved very similar relationships between body size and bill size, and this is reflected in the generally similar size of their prey. (The slightly stouter bill of $A$. stolidus suggests that it may be able to tackle fish and squid a little bigger than $S$. fuscata, and our data give some support to this possibility: Table 4 and Fig. 4.) 
It is of interest to compare the dimensions of these two species with those of Larosterna inca (Lesson), the Inca Tern, which is endemic to the Humboldt Current region. It is a close relative of the noddies (Anous spp.), and has a wing length almost the same as $A$. stolidus and $S$. fuscata (mean of 11 adults $280 \mathrm{~mm}$ ), but it is about $20 \%$ heavier (mean of 13 adults $209 \mathrm{~g}$ ). The bill is a little longer (mean of 11 adults $45.2 \mathrm{~mm}$ ), and is also substantially stouter than those of $\boldsymbol{A}$. stolidus and $S$. fuscata: its cross-section area at the proximal end of the gonys is estimated as 31.0 sq.mm; the square root of this divided by culmen length gives a figure of .123 (cf. .110 and .100 for A. stolidus and S. fuscataTable 8). It seems likely that the heavier weight and stouter bill of Larosterna inca than of the two tropical oceanic terns are adaptations related to the fact that by far the most abundant fish in its habitat is the Peruvian Anchovy (Engraulis ringens), which commonly reaches lengths of 15 or $16 \mathrm{~cm}$ : it would clearly be disadvantageous for Larosterna inca not to be able to exploit fish of a size which at certain times form a high proportion of the total fish population of the area. Fish more than $12 \mathrm{~cm}$ long are exceptional in the diet of $S$. fuscata, and in our samples they were almost all long but thin fish; A. stolidus also obtained very few fish between 12 and $16 \mathrm{~cm}$ long. Larosterna inca, on the other hand, does take anchovies 14-16 cm long when they are available (N. P. Ashmole, unpublished).

$A$. tenuirostris, which is little more than half the weight of $A$. stolidus, but has a slightly longer bill, has apparently gone far in the direction of maintaining reach, and speed at the bill tip, at the cost of force. In such a species the maximum size of the prey will be limited by the force which the bird can exert near the tip of its bill; our data show that A. tenuirostris is indeed a specialist in catching small prey. Since fish are more muscular than squid, it is possibly significant that there is apparently a greater difference in the size of the biggest fish taken by $\boldsymbol{A}$. stolidus and by $\boldsymbol{A}$. tenuirostris than there is in the size of the biggest squid (Fig. 4 and Table 4). This line of reasoning makes it clear why $A$. tenuirostris has such a slender bill (Fig. 6 and Table 8). The maximum size of its prey is low because of the length of the bill, and additional strength of the bill beyond the minimum necessary to avoid undue risk of breakage would merely add unnecessary weight. G. alba is a little heavier than A. tenuirostris, and has a slightly shorter and stouter bill; these factors, and perhaps also differences in its jaw mechanics, may account for the ability of $G$. alba to catch some fish substantially larger than any taken by $\boldsymbol{A}$. tenuirostris.

Small size, especially when associated with a relatively long bill, severely limits the size of active prey which can be captured. However, it also confers certain advantages. For instance, it is clear that the energy expenditure involved in hunting by Dipping to the surface and returning to a height will be so great as to make this feeding method uneconomic if the potential prey is below a certain size. However, most terns cannot stay near the surface continuously while hunting, because reflections at the surface must prevent a bird from seeing potential prey below the surface except in the area more or less vertically below it: the higher the bird, the greater is the area in which visibility will be adequate. Thus for a bird searching for fairly large and relatively scarce prey, it is generally best to fly a few meters above the surface, swoop- 
ing very rapidly when prey is sighted. Pr. cerulea, on the other hand, reduces the energy expended in feeding by remaining close to the surface, using its feet to push off from the water. There it can feed on numerous but small prey, and it has doubtless evolved its small body size as an adaptation for minimizing total food requirements. Furthermore, since it is almost certain that within a group of similar species agility is inversely related to size, Pr. cerulea is probably better adapted than its larger relatives for catching small, highly mobile prey animals. Members of the Pacific Ocean Biological Survey Program have specifically noted that it is more maneuverable than the larger noddies (Gould, pers. comm.), and it may be this which enables it to catch water striders, which are not taken by any of the other terns. However, being so small, Pr. cerulea cannot afford a very long bill because this would not provide adequate force at the tip.

It may thus be concluded that it is primarily by reaching different morphological compromises related to differences in size, and by evolving appropriate differences in feeding behavior, that the three species of noddies-A. stolidus, A. tenuirostris and Pr. cerulea - are able to coexist in an area where prey animals of a wide variety of sizes are available at the surface. 


\section{SUMMARY}

(The numbered sections correspond with the sections of the paper)

1. During nine visits to Christmas Island (Equatorial Pacific Ocean) between March 1963 and June 1964, 800 food samples (mainly regurgitations) were obtained from eight species of sea birds: Phaethon rubricauda, Puffinus nativitatis, Pterodroma alba, Sterna fuscata, Anous stolidus, Gygis alba, Anous tenuirostris and Procelsterna cerulea. These included all the most abundant of the smaller members of the sea bird community, which totals 17 species.

2. Methods used in previous studies of the food of birds (and fish) are discussed, and it is concluded that as well as analysis by number, by volume, and by frequency of occurrence of the various food classes, the sizes of the food items should be determined whenever possible. In the present study the food items from each of the preserved samples were sorted into three main classes-fish, squid, and other invertebrates-and identified as far as possible. Volumes were determined individually for all items, and the lengths of the fish and squid were measured or estimated.

3. In the Species Accounts each bird species is considered under the headings of Status, General description and condition of samples, Quantitative composition of samples, Size of food items, and Identifications of food items. The previous literature on the food of each species is briefly reviewed.

4. Fish and squid formed the bulk of the food of all the species. Fish were especially important in A. tenuirostris and Pr. cerulea, and squid in Pt. alba and $P$. nativitatis. The remaining four species took roughly equal volumes of fish and squid, but the individual fish were on average smaller than the squid, except in Ph. rubricauda. Only Pr. cerulea and Pt. alba took many other invertebrates (mainly water striders and Crustacea), and they were mostly very small.

$P h$. rubricauda took some fish and squid much larger than any eaten by the other birds. The fish and squid obtained from $P$. nativitatis were very similar in size to those from Pt. alba (although Pt. alba also ate parts of much larger squid), and both these species took fewer large fish than $S$. fuscata and $A$. stolidus, which are smaller birds. Among the smaller terns, which ate generally smaller items, G. alba took more large fish than $A$. tenuirostris, which took many very small ones, while the diet of $P r$. cerulea contained an even higher proportion of tiny items.

Representatives of 33 fish families were found in the samples, but only 12 of these constituted more than $1 \%$ by number of all the identified fish. 
Exocoetidae (including halfbeaks) were the most important single family, ranking first in five of the bird species: however, in G. alba Blenniidae barely ranked higher, in Pr. cerulea Gempylidae were far more important, while there are no data for Pt. alba. Among the species in which Exocoetidae were predominant, the rest of the fish portion of the diet was made up mainly of the same few families in $P$. nativitatis, $S$. fuscata and $A$. stolidus, while in $A$. tenuirostris more families were important, and $P h$. rubricauda exploited-in addition to Exocoetidae-three families not much eaten by the other birds.

The vast majority of the cephalopods taken by the birds were Ommastrephidae of the genus Symplectoteuthis, but a species of Abralia (Enoploteuthidae) was of some importance in G. alba, and a number of additional squid families were represented in the diet of Pt. alba.

5. Analysis of data on the food of Yellowfin Tuna caught at the surface close to Christmas Island and other islands in the same area, showed large differences between the diets of these fish and the birds, although a large proportion of the items eaten by the birds are made available at the surface only by the feeding activities of tunas. Fewer squid and more other invertebrates are eaten, and the representation of the various fish families is very different. The differences probably arise mainly because certain kinds of prey do not come to the surface even when pursued by tunas, while other kinds (e.g., Exocoetidae) are especially subject to avian predation while escaping from tunas.

6. Available information on the tropical marine environment of the birds is discussed. Localized concentrations of plankton and nekton produced by convergence and sinking of surface waters at "fronts," which have been suggested as exerting important effects on the distribution of surface schools of tunas in the open ocean, may also provide favorable feeding grounds for many oceanic birds. Concentrations of tunas and birds in inshore waters are produced by rather different factors, although eddies near islands may share some properties with oceanic fronts. For those bird species which are capable of feeding under conditions of low light intensity, the vertical migration of forage animals to the surface at night may be an important additional feature of the environment.

In assessing the feeding zones of the different species, use is made both of direct evidence and of deductions from the length of the incubation shifts and the proportions of reef-originating fish in the diets. Of the birds studied, Pr. cerulea and $A$. tenuirostris fish largely within a few miles of the island, while $A$. stolidus probably ranges somewhat further out to sea; $G$. alba sometimes fishes close inshore, but is capable of feeding far from the island. Probably all the other species regularly feed up to hundreds of miles away, perhaps especially in the Equatorial Countercurrent: their long incubation shifts and the fact that their chicks do not need frequent feeding help to make this possible. It is not yet known whether any of these species can delay digestion of food brought back to the young, but the secretion of 
stomach oil by many species of petrels is viewed as an alternative adaptation, which permits them to forage at great distances from the colony, even when they are breeding.

All the birds studied catch their prey above, at, or within a short distance below the surface of the water. However, their feeding methods (defined in Fig. 7) differ considerably, as do the associated morphological adaptations. Ph. rubricauda, which feeds by Air Diving, exploits prey furthest below the surface, but $P$. nativitatis also catches some prey below the surface, although it doubtless also Feeds at Surface, and perhaps also by Plunging to Surface or Dipping. Pt. alba evidently sometimes Feeds at Surface, but Dipping may be more important. All five species of terns feed primarily by Dipping and Plunging to Surface, the most fundamental difference being the utilization by the noddies (Pr. cerulea, A. tenuirostris, and $A$. stolidus) of their extensively webbed feet to keep them just above the water surface when feeding, which is a habit not shared by $S$. fuscata and G. alba, whose feet are much smaller in area. The noddies probably do not feed much at night, but the two petrels and $S$. fuscata almost certainly sometimes do so, and G. alba feeds actively at dawn, and perhaps also at dusk.

7. Seasonal changes in the Central Equatorial Pacific are certainly not as pronounced as in most marine areas, but there are still too few data to determine the existence or extent of regular seasonal changes in the availability of food for the sea birds of the region.

Data on the food of the birds in the different sampling periods suggests that seasonal changes in the availability of different kinds or sizes of food are not of great importance for most of the species. However, $A$. tenuirostris took a far greater proportion of small fish in May 1963 and June 1964 than in the other sampling periods, suggesting an early summer peak in the numbers of small fish in inshore waters.

At all times of year several species of sea birds may be found breeding on Christmas Island. The species (including A. tenuirostris) with a single, more or less definite, breeding season mostly have it in summer, but $P r$. cerulea breeds in autumn. The most numerous species (S. fuscata) has sharp breeding seasons in both summer and winter, while some species can be found breeding at any time, though not always in the same numbers.

8. It is argued that although there may be a shortage of optimal nest sites on Christmas Island for certain of the bird species, populations of most of them were probably controlled primarily by competition for available food, before the advent of man. Thus although the populations may not all be in equilibrium at the present time, it is of interest to consider the differences in the feeding ecology of the various species which have permitted them to coexist.

It is concluded that among the species which are not closely related, competition is reduced mainly by differences in feeding methods, permitting 
different species to exploit different types of food, or allowing members of one species to capture prey unavailable at that moment to another species. Also significant are the ability of at least one species to hunt under conditions of low light intensity, and adaptations which enable some species to feed at great distances from the colony, even when breeding. Among the most closely related species, differences in body size, and in the other morphological characteristics determining the size of prey which each species can exploit most efficiently, are of critical importance in reducing interspecific competition to the level at which coexistence is possible.

\section{ACKNOWLEDGMENTS}

The field work on Christmas Island was undertaken while N.P.A. was the holder of a Yale/Bishop Museum Fellowship. We are most grateful to S. Dillon Ripley and H. Laurence Achilles, who made this arrangement possible, and to Roland W. Force, who gave us both niches in the Bishop Museum, and enabled M.J.A. to do the main part of the analysis there. For help with transportation and for generous hospitality, we gratefully acknowledge the Royal Air Force and the members of the R.A.F. Officers' Mess, Christmas Island, and also Percy Roberts, District Commissioner. Philip Helfrich kindly arranged for the loan of a small boat from the Hawaii Marine Laboratory.

Without the help of Gareth J. Nelson, James W. Atz and Donald W. Strasburg, the task of identifying the fish would have been formidable; they gave us much of their time and it is a pleasure to thank them here. Malcolm R. Clarke identified a large number of squid for us; we are most grateful for his assistance, which was indispensable with this difficult group. In addition, we received help over various problems of identification from Georgiana B. Deevey, Willard D. Hartman, Robert T. B. Iversen, Giles W. Mead and Robert L. Usinger.

We are deeply indebted to Garth I. Murphy and Richard S. Shomura, who allowed us to make extensive use of their manuscript "The abundance of tunas in the Central Equatorial Pacific in relation to the environment" in advance of publication; John J. Magnuson gave us access to data on the food of Yellowfin Tuna, from the records of the Bureau of Commercial Fisheries Biological Laboratory, Honolulu. Through the kindness of Philip S. Humphrey and Patrick J. Gould, we have been able to use data on bird numbers on Christmas Island collected by the Pacific Ocean Biological Survey Program of the Smithsonian Institution, and to quote a number of unpublished observations on feeding habits. In addition, we have benefited from discussion or correspondence with Roger S. Bailey, John R. Brooks, G. Evelyn Hutchinson, Joseph R. King, Charles G. Sibley and George E. Watson.

Dean Amadon allowed us to measure specimens in the collection of the American Museum of Natural History. Tony Garcia helped extensively with the laboratory analysis, while John Howard and Carl Wester showed great skill in the preparation of the illustrations.

We are exceedingly grateful to all these people, and it is a pleasure to thank them here. 


\section{LITERATURE CITED}

Anderson, William G., 1954. Notes on food habits of sea birds of the Pacific. Elepaio 14: 80-84.

Arata, George F., 1954. A note on the flying behavior of certain squids. Nautilus 68: 1-3. Arimoto, K., 1962. The role of marine and fresh-water foods in the Japanese diet, p. 361-375. In Georg Borgstrom [ed.] Fish as food, 2. Academic Press, New York and London.

Ashmole, N. P., 1961. The biology of certain terns. D. Phil.thesis, Oxford University. , 1962. The Black Noddy Anous tenuirostris on Ascension Island. Part 1. General biology. Ibis 103b: 235-273.

, 1963a. The regulation of numbers of tropical oceanic birds. Ibis 103b: 458-473.

- 1963b. The biology of the Wideawake or Sooty Tern Sterna fuscata on Ascension Island. Ibis 103b: 297-364.

Ashmole, N. Philip, 1965. Adaptive variation in the breeding regime of a tropical sea bird. Nat. Acad. Sci., Proc. 53: 311-318.

. In press. Breeding and molt in the White Tern (Gygis alba) on Christmas Island, Pacific Ocean. Condor.

Audubon, John James, 1835. Ornithological biography, or an account of the habits of the birds of the United States of America. Adam \& Charles Black, Edinburgh. Vol. 3.

Austin, Thomas S., 1960. Oceanography of the east central equatorial Pacific as observed during expedition Eastropic. U.S. Fish and Wildlife Serv., Fish. Bull. 60 (168): 257-282.

Bailey, R. S., 1965. Cruise of R.R.S. Discovery in the Indian Ocean. Sea Swallow 17: 52-56.

Bailey, Roger, 1966. The sea-birds of the southeast coast of Arabia. Ibis 108: 224-264.

Baker, A. de C., 1960. Observations of squid at the surface in the NE Atlantic. Deep-Sea Research 6: 206-210.

Baker, Rollin H., 1947. Observations on the birds of the North Atlantic. Auk 64: 245-259. , 1948. Report on collections of birds made by United States Naval Medical Research Unit No. 2 in the Pacific war area. Smithsonian Misc. Coll. 107, No. 15. $74 \mathrm{p}$.

— 1951. The avifauna of Micronesia, its origin, evolution, and distribution. Univ. Kansas Mus. Nat. Hist., Publ. 3(1). 359 p.

Barkley, Richard A., 1962. A review of the oceanography of the Central Pacific Ocean in the vicinity of the Line Islands. Multilithed by the Biological Laboratory, Honolulu, of the Bureau of Commercial Fisheries, U.S. Fish and Wildlife Service.

Bates, Donald H., 1950. Tuna trolling in the Line Islands in the late spring of 1950. U.S. Fish and Wildlife Serv., Fishery Leaflet 351.32 p.

Beebe, William, 1926. The Arcturus adventure. G. P. Putnam's Sons, New York. 439 p.

Beecher, William J., 1962. The bio-mechanics of the bird skull. Chicago Acad. Sci., Bull. 11 (2): 10-33.

Belopol'skili, L[ev] O[sipovich], 1957. Ecology of sea colony birds of the Barents Sea. (Translation 1961, by Israel Program for Scientific Translations.) Acad. Sci. USSR, Karelian Branch. 346 p. 
Bock, Walter, 1966. An approach to the functional analysis of bill shape. Auk 83: 10-51. Bourne, W. R. P., 1957. The Sooty Petrel of Latham, Fregetta fuliginosa (Gmelin). Brit. Orn. Club, Bull. 77: 40-42.

$\longrightarrow, 1959$. Notes on sea reports received 1958-59. Sea Swallow 12: 6-17.

- 1963. A review of oceanic studies of the biology of seabirds. Proc. XIII Intern. Ornithol. Congr.: 831-854.

- 1965. Comment [on paper by Bruyns 1965]. Sea Swallow 17: 65-66.

Bowmaker, A. P., 1963. Cormorant predation on two central African lakes. Ostrich 34: 2-26.

Bowman, Robert I., 1961. Morphological differentiation and adaptation in the Galápagos finches. Univ. Calif. Publ. Zoöl. 58. 326 p.

Brooks, S. C., 1934. Oceanic currents and the migration of pelagic birds. Condor 36: 185-190.

Brown, R. G. B., and D. E. Baird, 1965. Social factors as possible regulators of Puffinus gravis numbers. Ibis 107: 249-251.

Bruyns, W. F. J. Mörzer, 1965. Birds seen during west to east trans-Pacific crossing along Equatorial Counter-current around latitude $7^{\circ} \mathrm{N}$. in the autumn of 1960 . Sea Swallow 17: 57-65.

—, and K. H. Voous, 1965. Night-feeding by Sooty Tern (Sterna fuscata). Ardea 53: 79.

Carrick, R., 1959. The food and feeding habits of the Straw-necked Ibis, Threskiornis spinicollis (Jameson), and the White Ibis, T. molucca (Cuvier), in Australia. CSIRO Wildl. Res. 4: 69-92.

Carter, Charlie Lyons, and John Malcolm, 1927. Observations on the biochemistry of "mutton bird" oil. Biochemical J. 21: 484-493.

Clarke, M. R., 1965. Large light organs on the dorsal surfaces of the squids Ommastrephes pteropus, 'Symplectoteuthis oualaniensis' and 'Dosidicus gigas.' Malacol. Soc. Lond., Proc. 36: 319-321.

Clarke, Malcolm R., 1966. A review of the systematics and ecology of oceanic squids. Adv. Mar. Biol. 4: 91-300.

Collins, J. W., 1899. The shearwaters and Fulmar as birds and bait. Osprey 4: 35-42.

Cromwell, Townsend, 1953. Circulation in a meridional plane in the Central Equatorial Pacific. J. Mar. Res. 12: 196-213.

-, and Joseph L. Reid, 1956. A study of oceanic fronts. Tellus 8: 94-101.

Crook, John Hurrell, 1965. The adaptive significance of avian social organizations. Zool. Soc. Lond., Symp. 14: 181-218.

Cullen, J. M., and N. P. Ashmole, 1963. The Black Noddy Anous tenuirostris on Ascension Island. Part 2. Behaviour. Ibis 103b: 423-446.

David, P. M., 1965. The Neuston net: a device for sampling the surface fauna of the ocean. J. Mar. Biol. Ass. U.K. 45: 313-320.

Davies, P. W., and D. W. Snow, 1965. Territory and food of the Song Thrush. Brit. Birds 58: 161-175.

Davis, Peter, 1957. The breeding of the Storm Petrel. Brit. Birds 50: 85-101, 371-384.

Dixon, Keith L, 1961. Habitat distribution and niche relationships in North American species of Parus, p. 179-216. In W. Frank Blair [ed.] Vertebrate speciation. University of Texas Press, Austin.

Dobben, W. H. Van, 1952. The food of the Cormorant in the Netherlands. Ardea 40: 1-63.

Dorward, D. F., 1962. Comparative biology of the White Booby and the Brown Booby Sula spp. at Ascension. Ibis 103b: 174-220. 1963. The Fairy Tern Gygis alba on Ascension Island. Ibis 103b: 365-378. 
and N. P. Ashmole, 1963. Notes on the biology of the Brown Noddy Anous stolidus on Ascension Island. Ibis 103b: 447-457.

Eisenmann, Eugene, 1955. The species of Middle American birds. Linn. Soc. N. Y., Trans. 7. $128 \mathrm{p}$.

Falla, R. A., 1934. The distribution and breeding habits of petrels in Northern New Zealand. Auckland Inst. Mus., Rec. 1: 245-260.

Fields, W. Gordon, 1965. The structure, development, food relations, reproduction, and life history of the squid Loligo opalescens Berry. Calif. Dept. Fish and Game, Fish Bull. 131. 108 p.

Fisher, James, 1952. The Fulmar. Collins, London. 496 p.

—, 1966. The Fulmar population of Britain and Ireland, 1959. Bird Study 13: 5-76.

Fisher, Walter K., 1906. Birds of Laysan and the Leeward Islands, Hawaiian group. U.S. Fish Commission, Bull. 23 (1903): 767-807.

Frith, H. J., 1959. The ecology of wild ducks in inland New South Wales. III. Food habits. CSIRO Wildl. Res. 4: 131-155.

Gallagher, M. D., 1960. Bird notes from Christmas Island, Pacific Ocean. Ibis 102: 489-502.

Gause, G. F., 1934. The struggle for existence. Williams and Wilkins Co., Baltimore. $163 \mathrm{p}$.

Gibb, J. A., and Monica M. Betts, 1963. Food and food supply of nestling tits (Paridae) in Breckland pine. J. Anim. Ecol. 32: 489-533.

Gibson-Hill, C. A., 1947. The normal food of tropic-birds (Phaëthon spp.). Ibis 89: 658-661.

, 1950. Notes on the birds of the Cocos-Keeling Islands. Raffles Mus., Bull. 22: 212-270.

- 1951. Notes on the nesting habits of seven representative tropical sea birds. Bombay Nat. His. Soc., J. 48: 214-235.

Gould, Patrick J. In press. Nocturnal feeding of Sterna fuscata and Puffinus pacificus. Condor.

Greenwood, P. Humphry, Donn E. Rosen, Stanley H. Weitzman, and George S. Myers, 1966. Phyletic studies of teleostean fishes, with a provisional classification of living forms. Amer. Mus. Nat. Hist., Bull. 131 (4): 339-456.

Hailman, Jack P., 1964. The Galápagos Swallow-tailed Gull is nocturnal. Wilson Bull. 76: 347-354.

Hardy, A. C., 1928. The work of the Royal Research Ship "Discovery" in the Dependencies of the Falkland Islands. Geogr. J. 72: 209-234.

Harris, M. P., 1965. The food of some Larus gulls. Ibis 107: 43-53.

Hartley, P. H. T., 1948. The assessment of the food of birds. Ibis 90: 361-381.

Hedgpeth, Joel W., 1957. Classification of marine environments, p. 17-27. In Joel W. Hedgpeth [ed.] Treatise on marine ecology and paleoecology. Geol. Soc. Amer., Mem. 67 (1). 1296 p.

Hersey, J. B., and R. H. Backus, 1962. Sound scattering by marine organisms, p. 498-539. In M. N. Hill [ed.] The sea, 1. Interscience, New York.

Heyerdahl, Thor, 1950. The Kon-Tiki expedition. George Allen and Unwin Ltd., London. 235 p.

Hinde, Robert A., 1966. Animal behaviour: a synthesis of ethology and comparative psychology. McGraw-Hill, New York. 534 p.

Hindwood, K. A., 1940. The birds of Lord Howe Island. Emu 40: 1-86.

Hutchinson, George Evelyn, 1950. The biogeochemistry of vertebrate excretion. Amer. Mus. Nat. Hist., Bull. 96. 554 p.

Hutchinson, G. E., 1959. Homage to Santa Rosalia or Why are there so many kinds of animals? Amer. Nat. 93: 145-159. 
Huxley, Julian, 1942. Evolution. The modern synthesis. Harper and Brothers, New York and London. $645 \mathrm{p}$.

Ikehara, Isaac I., 1953. Live-bait fishing for tuna in the central Pacific. U.S. Fish and Wildlife Serv., Spec. Sci. Rep., Fisheries 107. 20 p.

Jespersen, P., 1929. On the frequency of birds over the High Atlantic Ocean. Verh. VI Intern. Orn. Kongr., Kopenhagen 1926: 163-172.

Kahl, M. Philip, 1964. Food ecology of the Wood Stork (Mycteria americana) in Florida. Ecol. Monogr. 34: 97-117.

King, Joseph E., 1955. Annotated list of birds observed on Christmas Island, October to December 1953. Pacif. Sci. 9: 42-48.

, and Joan Demond, 1953. Zooplankton abundance in the Central Pacific. U.S. Fish and Wildlife Serv., Fish Bull. 54 (82): 111-144.

, and Thomas S. Hida, 1957. Zooplankton abundance in the Central Pacific, Part

II. U.S. Fish and Wildlife Serv., Fish. Bull. 57 (118): 365-395.

, and Isaac I. Ikehara, 1956. Comparative study of food of Bigeye and Yellowfin tuna in the Central Pacific. U.S. Fish and Wildlife Serv., Fish. Bull. 57 (108): $61-85$.

, and Robert T. B. Iversen, 1962. Midwater trawling for forage organisms in the Central Pacific 1951-1956. U.S. Fish and Wildlife Serv., Fish. Bull. 62 (210): 271321.

—, and Robert L. Pyle, 1957. Observations on sea birds in the tropical Pacific. Condor 59: 27-39.

Klopfer, Peter H., 1962. Behavioral aspects of ecology. Prentice-Hall, New Jersey. 166 p.

$\longrightarrow$, and R. H. MacArthur, 1961. On the causes of tropical species diversity: niche overlap. Amer. Nat. 45: 223-226.

Knauss, John A., 1957. An observation of an oceanic front. Tellus 9: 234-237.

Kritzler, Henry, 1948. Observations on behavior in captive fulmars. Condor 50: 5-15.

Kuroda, Nagahisa, 1954. On the classification and phylogeny of the Order Tubinares, particularly the shearwaters (Puffinus), with special considerations on their osteology and habit differentiation. Herald Co. Ltd., Tokyo. 179 p.

- 1955. Observations on pelagic birds of the Northwest Pacific. Condor 57: 290-300.

Lack, David, 1944. Ecological aspects of species-formation in passerine birds. Ibis 86: 260-286.

- 1945. The ecology of closely related species with special reference to Cormorant Phalacrocorax carbo and Shag $P$. aristotelis. J. Anim. Ecol. 14: 12-16.

, 1946. Competition for food by birds of prey. J. Anim. Ecol 15: 123-129.

$\longrightarrow$, 1947. Darwin's finches. Cambridge University Press. 208 p.

Lane, Frank W., 1957. Kingdom of the octopus. Jarrolds, London. 287 p.

Lewis, R. W., 1966. Studies of the glyceryl ethers of the stomach oil of Leach's Petrel Oceanodroma leucorhoa (Viellot). Comp. Biochem. Physiol. 19: 363-377.

Loomis, Leverett Mills, 1918. A review of the albatrosses, petrels, and diving petrels. Calif. Acad. Sci., Proc. 2 (2), No. 12: 1-187.

MacArthur, Robert H., 1958. Population ecology of some warblers of northeastern coniferous forests. Ecology 39: 599-619.

MacArthur, Robert H., and Richard Levins, 1964. Competition, habitat selection, and character displacement in a patchy environment. Nat. Acad. Sci., Proc. 51: 1207. 1210.

McGary, James W., 1955. Mid-Pacific oceanography, Part VI, Hawaiian offshore waters, December 1949-November 1951. U.S. Fish and Wildlife Serv., Spec. Sci. Rep., Fisheries 152. 138 p. 
Madsen, F. Jensenius, 1957. On the food habits of some fish-eating birds in Denmark. Danish Rev. Game Biol. 3: 19-83.

Madsen, F. Jensenius, and R. Spärck, 1950. On the feeding habits of the Southern Cormorant (Phalacrocorax carbo sinensis Shaw) in Denmark. Danish Rev. Game Biol. 1: 45-76.

Marshall, N. B., 1960. Swimbladder structure of deep-sea fishes in relation to their systematics and biology. Discovery Reps. 31: 1-122.

Matthews, L. Harrison, 1949. The origin of stomach oil in the petrels, with comparative observations on the avian proventriculus. Ibis 91: 373-392.

Mayr, Ernst, 1945. Birds of the Southwest Pacific. Macmillan, New York. 316 p.

Morris, R. O., 1963. The birds of the Gilbert Islands. Sea Swallow 16: 79-82.

Moul, E. T., 1954. Preliminary report on land animals at Onotoa Atoll, Gilbert Islands. Atoll Res. Bull. 28. 28 p.

Moynihan, Martin, 1959. A revision of the family Laridae (Aves). Amer. Mus. Novit. 1928. $42 \mathrm{p}$.

Murphy, Garth I., and Isaac I. Ikehara, 1955. A summary of sightings of fish schools and bird flocks and of trolling in the central Pacific. U.S. Fish and Wildlife Serv., Spec. Sci. Rep., Fisheries 154.19 p.

-, and Richard S. Shomura. The abundance of tunas in the Central Equatorial Pacific in relation to the environment. Unpublished manuscript.

Murphy, Robert Cushman, 1936. Oceanic birds of South America. American Museum of Natural History, New York. 2 vols.

Alfred M. Bailey, and Robert J. Niedrach, 1954. Canton Island. Denver Mus. Nat. Hist., Mus. Pict. 10. 78 p.

Nakamura, Eugene L., 1965. Food and feeding habits of Skipjack Tuna (Katsuwonus pelamis) from the Marquesas and Tuamotu Islands. Amer. Fish. Soc., Trans. 94: 236-242.

Oliver, W. R. B., 1930. New Zealand birds. A. H. and A. W. Reed, Wellington. 661 p.

Olney, P. J. S., 1964. The food of Mallard Anas platyrhynchos collected from coastal and estuarine areas. Zool. Soc. Lond., Proc. 142: 397-418.

Palmer, Ralph S. [ed.] 1962. Handbook of North American birds. 1. Loons through flamingos. Yale University Press, New Haven and London. 567 p.

Pearcy, William G., 1964. Some distributional features of mesopelagic fishes off Oregon. J. Mar. Res. 22: 83-102.

—_, and R. M. Laurs, 1966. Vertical migration and distribution of mesopelagic fishes off Oregon. Deep-Sea Res. 13: 153-165.

Peters, James Lee, 1931, 1934. Check-list of birds of the world, Vol. 1 and Vol. 2. Harvard University Press, Cambridge.

Ragotzkie, Robert A., and R. A. Bryson, 1953. Correlation of currents with the distribution of adult Daphnia in Lake Mendota. J. Mar. Res. 12: 157-172.

Recher, Harry F., 1966. Some aspects of the ecology of migrant shorebirds. Ecology 47: 393-407.

Reintjes, John W., and Joseph E. King, 1953. Food of Yellowfin Tuna in the Central Pacific. U.S. Fish and Wildlife Serv., Fishery Bull. 54 (81): 91-110.

Rice, Dale W., and Karl W. Kenyon, 1962. Breeding cycles and behavior of Laysan and Black-footed Albatrosses. Auk 79: 517-567.

Richardson, Frank, 1957. The breeding cycles of Hawaiian sea birds. B. P. Bishop Mus., Bull. 218. 41 p.

Richdale, L. E., 1945. The nestling of the Sooty Shearwater. Condor 47: 45-62.

Ridley, M. W., and Lord Richard Percy, 1958. The exploitation of sea birds in Seychelles. Colonial Research Studies No. 25. H. M. Stationery Office, London. 78 p. 
Riehl, Herbert, 1954. Tropical meteorology. McGraw-Hill Book Co., New York. 392 p.

Robertson, William B., 1964. The terns of the Dry Tortugas. Florida State Mus., Bull. 8: 1-94.

Robertson, William B., Jr., Dennis R. Paulson, and C. Russell Mason, 1961. A tern new to the United States. Auk 78: 423-425.

Roden, Gunnar I., 1963. On sea level, temperature, and salinity variations in the central tropical Pacific and on Pacific Ocean islands. J. Geophys. Res. 68: 455-472.

Rowan, M. K., 1965. Regulation of sea-bird numbers. Ibis 107: 54-59.

Royce, William F., and Tamio Otsu, 1955. Observation of Skipjack schools in Hawaiian waters, 1953. U.S. Fish and Wildlife Serv., Spec. Sci. Rep., Fisheries 147. 31 p.

Ryther, J. H., 1963. Geographic variations in productivity, p. 347-380. In M. N. Hill [ed.] The sea, 2. Interscience, New York.

Salomonsen, Finn, 1965. The geographical variation of the Fulmar (Fulmarus glacialis) and the zones of marine environment in the North Atlantic. Auk 82: 327-355.

Savile, D. B. O., 1957. Adaptive evolution in the avian wing. Evolution 11: 212-224.

Schoener, Thomas W., 1965. The evolution of bill size differences among sympatric congeneric species of birds. Evolution 19: 189-213.

Sette, Oscar E., 1955. Consideration of midocean fish production as related to oceanic circulatory systems. J. Mar. Res. 14: 398-414.

Skokova, N. N., 1963. A quantitative study of the diet of fish-eating birds [in Russian]. Ornitologiya 4: 288-296.

Snow, David W., 1965. The breeding of the Red-billed Tropic Bird in the Galápagos Islands. Condor 67: 210-214.

Stonehouse, Bernard, 1962a. Ascension Island and the British Ornithologists' Union Centenary Expedition 1957-59. Ibis 103b: 107-123.

- 1962b. The tropic birds (genus Phaethon) of Ascension Island. Ibis 103b: 124-161.

Storer, Robert W., 1960. Evolution in the diving birds. Proc. XII Intern. Ornithol. Congr.: 694-707.

Tickell, W. L. N., 1964. Feeding preferences of the albatrosses Diomedea melanophris and D. chrysostoma at South Georgia, p. 383-387. In Biologie antarctique. Premier symposium organisé par le S.C.A.R., Paris, 2-8 Septembre 1962. Hermann, Paris.

Tinbergen, N., 1964. On adaptive radiation in gulls (Tribe Larini). Zool. Mededel. 39: 209-223.

Trautman, Carl G., 1952. Pheasant food habits in South Dakota. S. Dak. Dept. Game, Fish., Parks, Tech. Bull. No. 1. 89 p.

Uda, M., 1938. Researches on "Siome" or Current Rip in the seas and oceans. Geophys. Mag. 11: 307-372.

Uda, Michitaka, 1953. On the convergence and divergence in the NW Pacific in relation to the fishing grounds and productivity. Japanese Soc. Sci. Fish., Bull. 19: 435-438.

- 1954. Studies of the relation between the whaling grounds and the hydrographical conditions (I). Whales Res. Inst., Sci. Reps. 9: 179-187.

Vogt, William, 1964. Informe sobre las aves guaneras [in Spanish]. Bol. Corporación Nacional de Fertilizantes 2, $2^{a}$ Epocha, (8): 9-28; (9): 6-48; (10): 5-40.

Voorhis, A. D., and J. B. Hersey, 1964. Oceanic thermal fronts in the Sargasso Sea. J. Geophys. Res. 69: 3809-3814.

Voss, Nancy A., and Gilbert L. Voss, 1962. Two new species of squids of the genus Calliteuthis from the Western Atlantic with a redescription of Calliteuthis reversa Verrill. Bull. Mar. Sci. Gulf and Carribbean 12: 169-200.

Waldron, Kenneth D., 1964. Fish schools and bird flocks in the Central Pacific Ocean, 1950-1961. U.S. Fish and Wildlife Serv., Spec. Sci. Rep., Fisheries 464. 20 p.

-, and Joseph E. King, 1962. Food of Skipjack in the Central Pacific. World sci- 
entific meeting on the biology of tunas and related species. Section No. 5, Experience Paper 26. 28 p.

Warham, J., 1964. Breeding behaviour in Procellariiformes, p. 389-394. In Biologie antarctique. Premier symposium organisé par le S.C.A.R., Paris, 2-8 Septembre 1962. Hermann, Paris.

Watson, John B., 1908. The behavior of Noddy and Sooty Terns. Carnegie Inst. Washington, Tortugas Lab., Pap. 2: 187-255.

- 1910. Further data on the homing sense of Noddy and Sooty Terns. Science, N.S., 32: $470-473$.

and K. S. Lashley, 1915. An historical and experimental study of homing. Carnegie Inst. Washington, Dept. Mar. Biol., Pap. 7: 7-60.

Wiens, Herold J., 1962. Atoll environment and ecology. Yale Univ. Press, New Haven and London. $532 \mathrm{p}$.

Wyrtki, Klaus, 1965. The annual and semiannual variation of sea surface temperature in the North Pacific Ocean. Limnol. Oceanog. 10: 307-313.

Zusi, Richard L., 1962. Structural adaptations of the head and neck in the Black Skimmer Rynchops nigra Linnaeus. Nuttall Ornithol. Club, Publ. 3. 101 p. 
Appendix 1. Composition of Food Samples: Basic Data

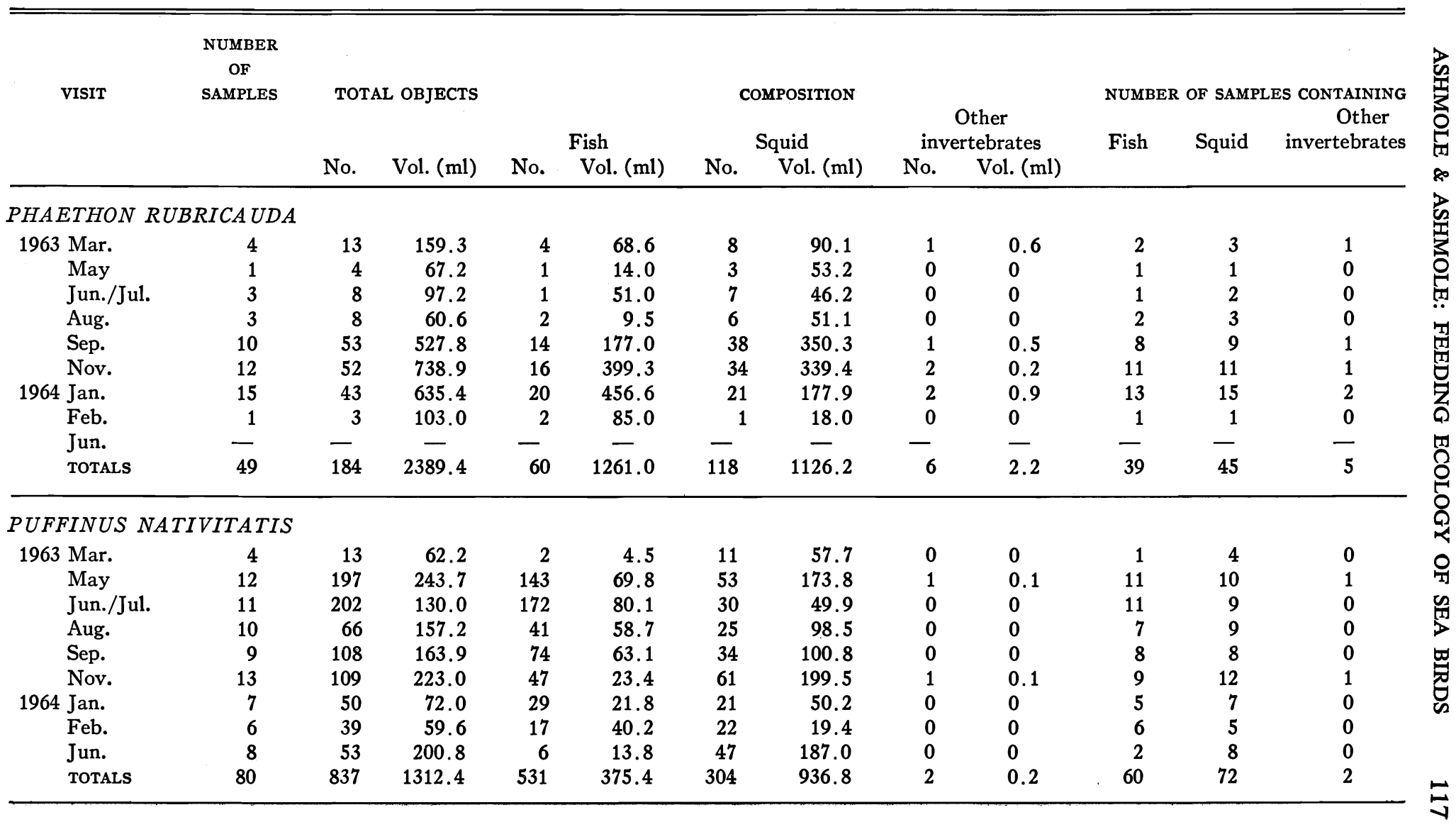


APPENDIX 1 (continued)

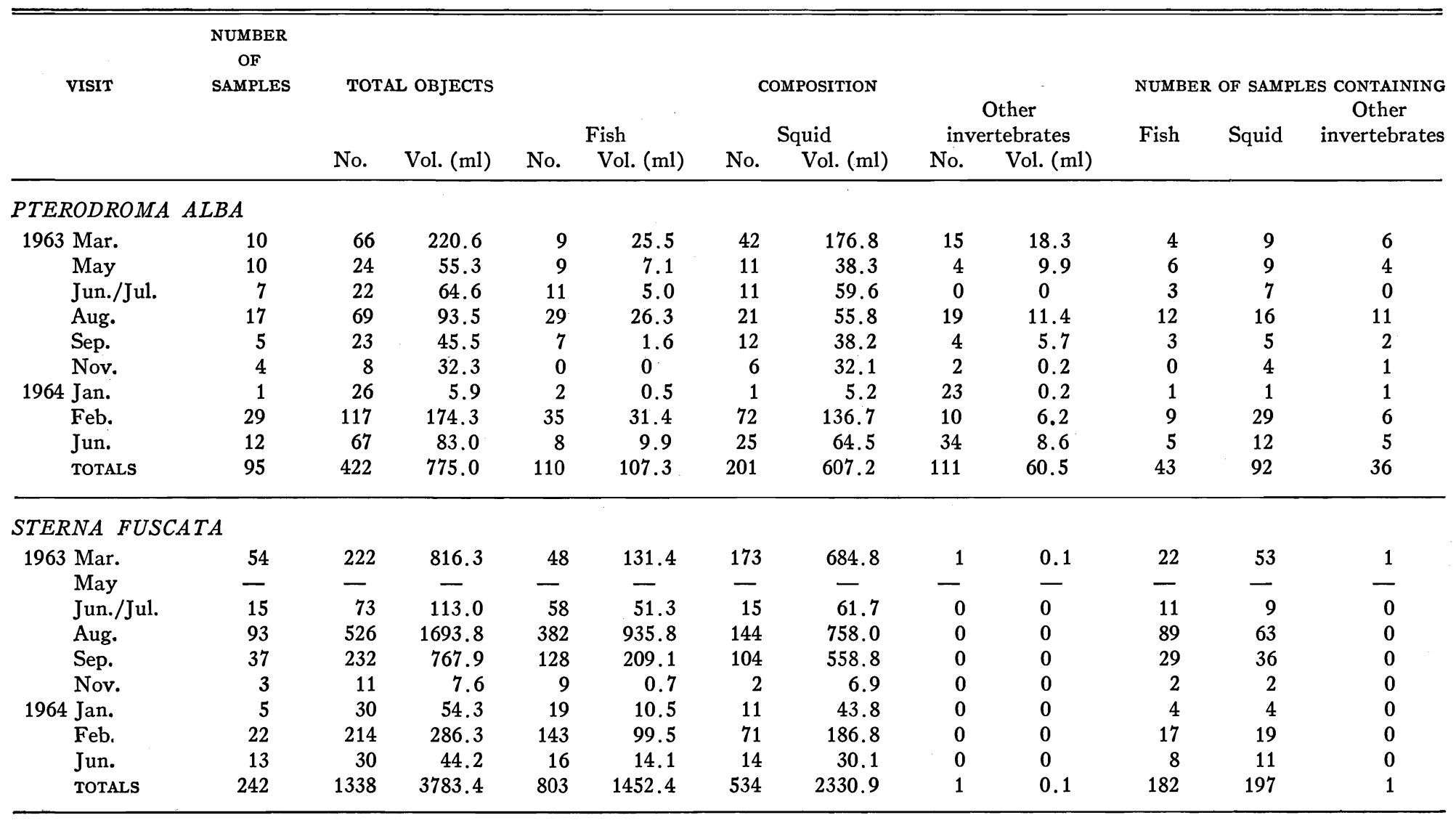


0100100000

N 1 no 0 n

$\sim \ln \mid \operatorname{anm} \rightarrow \infty$

0100100000

0100,00000

$m$ a $0.7 m$ m ฉं |

m 1 - a 음은

n. ㅇ. 00 th m

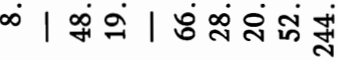

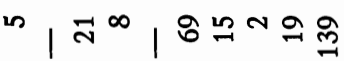

$\infty$ o. 0 .

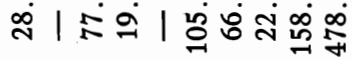

$\infty$ |

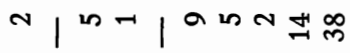

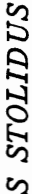

ก

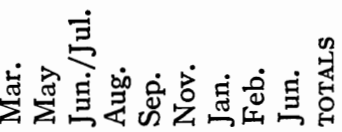

总
$000000-007$

サー0円ヘ

-

$000000 \ddot{0} 00 \overrightarrow{0}$

$000000-001$

o in $\rightarrow$ mo mo tho ง

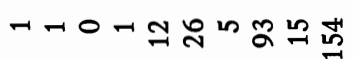

H in 0 o n 겅ํำ

ง

HoO 0090090

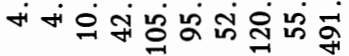

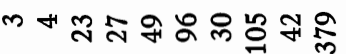

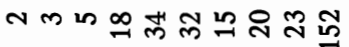

奛 莺

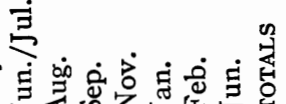

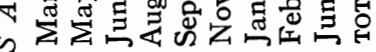

प⿺辶大

ఫั 


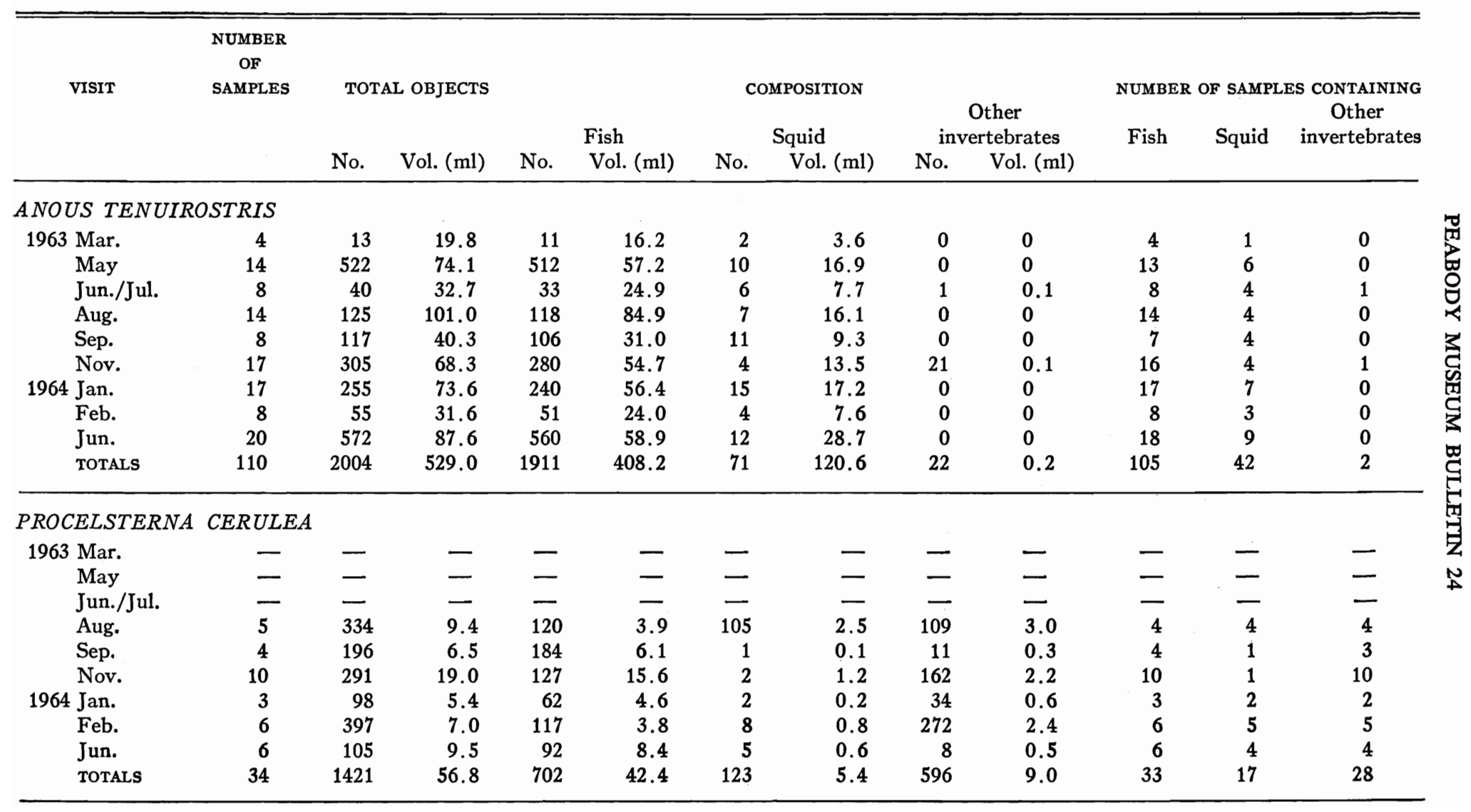


Appendix 2A. Seasonal Data on Fish Lengths

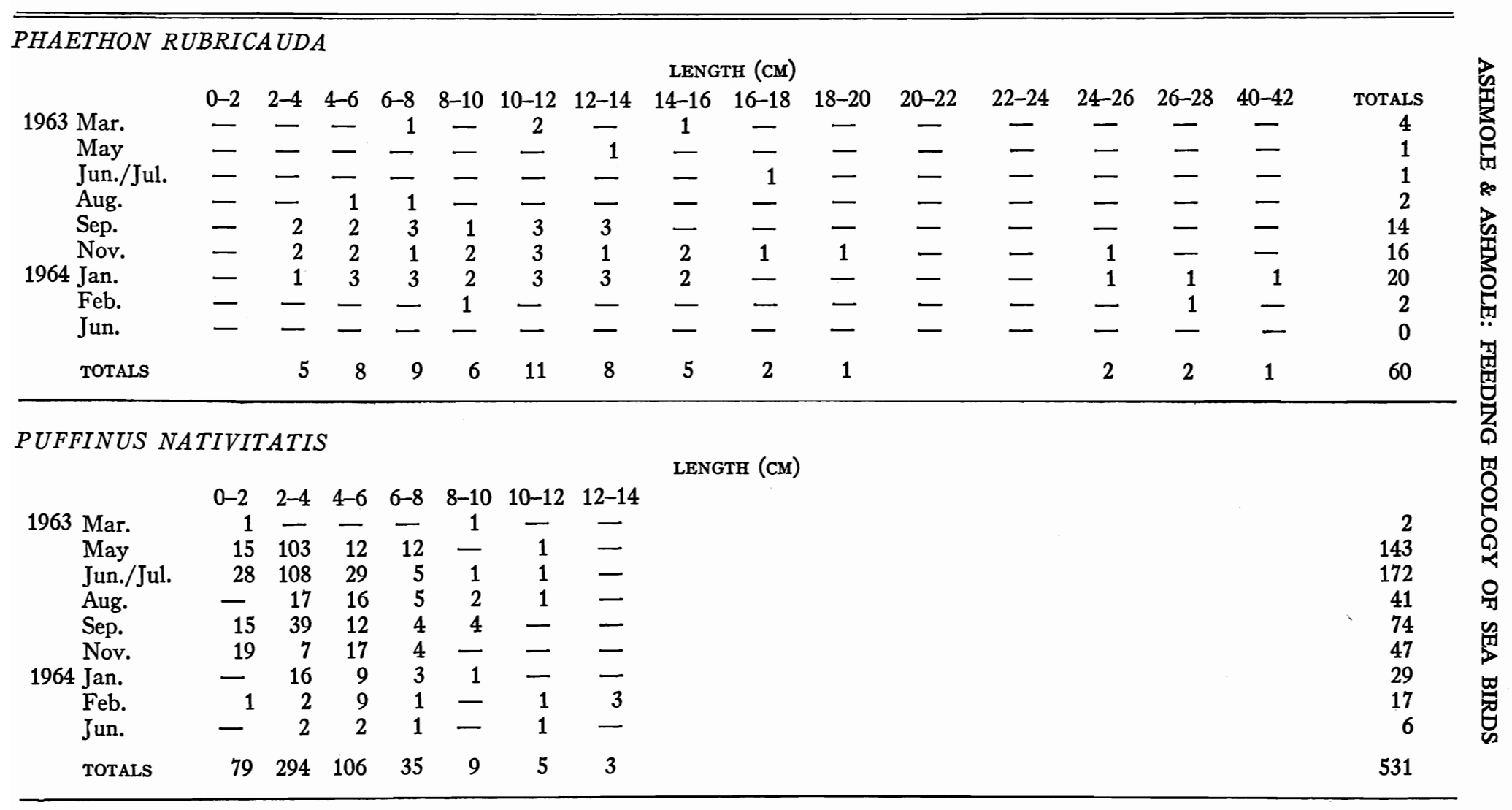


APPENDIX 2a (continued)

\begin{tabular}{|c|c|c|c|c|c|c|c|c|c|c|c|c|}
\hline \multicolumn{13}{|c|}{ PTERODROMA ALBA } \\
\hline & $0-2$ & $2-4$ & $4-6$ & $6-8$ & $8-10$ & $10-12$ & $12-14$ & $14-16$ & $16-18$ & $18-20$ & $20-22$ & Tот \\
\hline 1963 Mar. & - & 6 & - & 1 & 2 & - & - & - & - & - & - & $\begin{array}{l}901 \mathrm{ALS} \\
9\end{array}$ \\
\hline May & - & 9 & - & - & - & - & - & - & - & - & - & 9 \\
\hline Jun./Jul. & - & 8 & 2 & 1 & - & - & - & - & - & - & - & 11 \\
\hline Aug. & 3 & 18 & 6 & 2 & - & - & - & 一 & - & 一 & 一 & 29 \\
\hline Sep. & 2 & 5 & - & - & - & - & - & - & 一 & - & - & 7 \\
\hline Nov. & - & - & - & - & - & - & - & - & - & - & - & 0 \\
\hline 1964 Jan. & - & 2 & - & - & - & - & - & - & - & - & - & 2 \\
\hline Feb. & 3 & 17 & 13 & - & - & - & 1 & 一 & - & - & 1 & 35 \\
\hline Jun. & - & 2 & 5 & - & 1 & - & - & - & - & - & - & 8 \\
\hline TOTALS & 8 & 67 & 26 & 4 & 3 & - & 1 & - & - & - & 1 & 110 \\
\hline \multicolumn{13}{|c|}{ STERNA FUSCATA } \\
\hline \multicolumn{13}{|c|}{ LENGTH (CM) } \\
\hline & $0-2$ & $2-4$ & $4-6$ & $6-8$ & $8-10$ & $10-12$ & $12-14$ & $14-16$ & $16-18$ & & & \\
\hline 1963 Mar. & - & 6 & 12 & 15 & 11 & 4 & - & - & - & & & 48 \\
\hline May & - & - & - & - & - & - & - & - & - & & & 0 \\
\hline Jun./Jul. & 1 & 42 & 6 & 6 & 2 & 1 & - & - & - & & & 58 \\
\hline Aug. & 11 & 92 & 101 & 119 & 38 & 15 & 5 & 一 & 1 & & & 382 \\
\hline Sep. & 3 & 18 & 61 & 35 & 8 & 2 & - & 1 & 二 & & & 128 \\
\hline Nov. & 8 & 1 & - & - & - & 二 & - & $二$ & 一 & & & 9 \\
\hline 1964 Jan. & - & 15 & 3 & 1 & - & - & 一 & - & - & & & 19 \\
\hline Feb. & 2 & 70 & 51 & 14 & 5 & - & 1 & - & - & & & 143 \\
\hline Jun. & 4 & 4 & 5 & 3 & - & - & - & - & - & & & 16 \\
\hline TOTALS & 29 & 248 & 239 & 193 & 64 & 22 & 6 & 1 & 1 & & & 803 \\
\hline
\end{tabular}


APPENDIX 2a (continued)

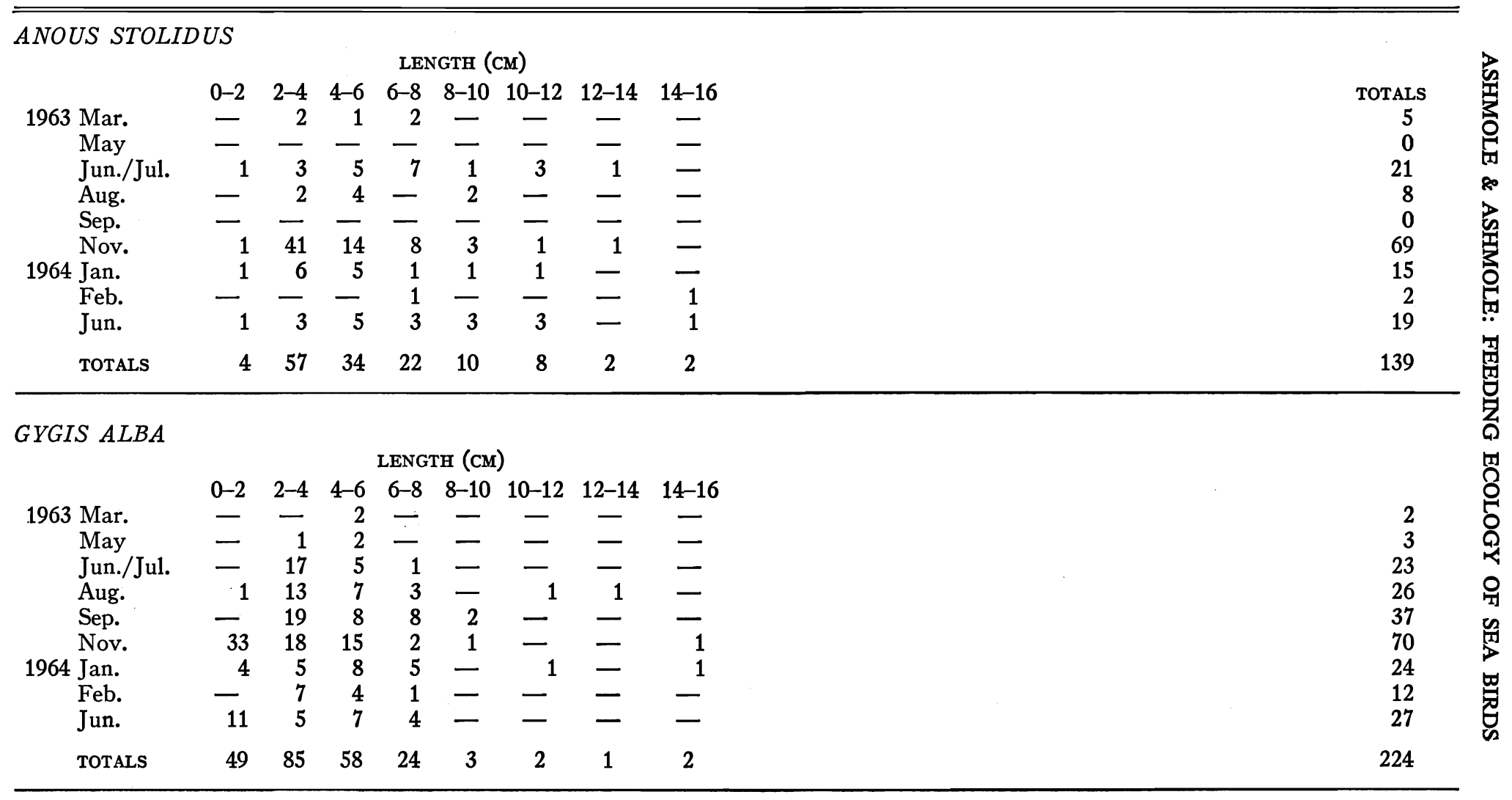




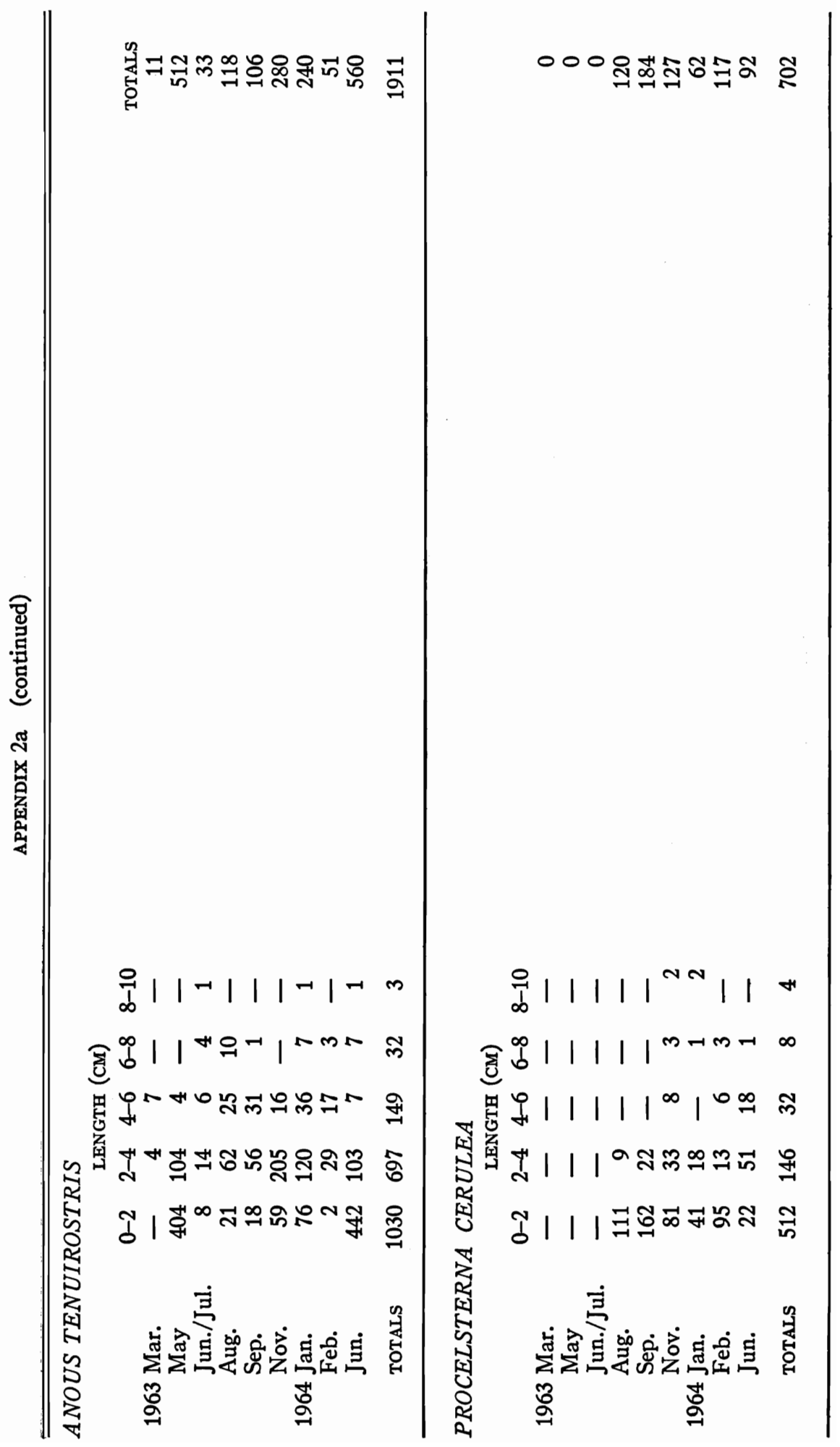


Appendix 2b. Seasonal Data on Squid Mantle Lengths

Figures in parentheses refer to additional squid represented by remains onlysee Techniques section.

\begin{tabular}{|c|c|c|c|c|c|c|c|}
\hline \multicolumn{8}{|c|}{ PHAETHON RUBRICAUDA } \\
\hline & $0-2$ & $2-4$ & $4-6$ & $6-8$ & $8-10$ & $10-12$ & TOTALS \\
\hline 1963 Mar. & - & 1 & - & 5 & 1 & 1 & 8 \\
\hline May & - & 一 & 一 & 1 & 2 & 一 & 3 \\
\hline Jun./Jul. & - & - & 1 & 6 & - & - & 7 \\
\hline Aug. & - & 一 & - & 1 & 2 & 一 & $3(+3)$ \\
\hline Sep. & - & 8 & 11 & 11 & 7 & 1 & 38 \\
\hline Nov. & - & 8 & 4 & 10 & 10 & 1 & $33(+1)$ \\
\hline 1964 Jan. & 一 & 1 & 7 & 6 & 1 & 2 & $17(+4)$ \\
\hline Feb. & 一 & 一 & 一 & - & 1 & 一 & 1 \\
\hline Jun. & - & 一 & 一 & 一 & - & 一 & 0 \\
\hline TOTALS & & 18 & 23 & 40 & 24 & 5 & $110(+8)=118$ \\
\hline
\end{tabular}

PUFFINUS NATIVITATIS

\begin{tabular}{lrrrrrl} 
& \multicolumn{7}{c}{ LENGTH (CM) } \\
& $0-2$ & $2-4$ & $4-6$ & $6-8$ & $8-10$ & \multicolumn{1}{c}{ TOTALS } \\
1963 Mar. & - & 2 & 5 & 4 & - & 11 \\
May & - & 23 & 21 & 8 & 1 & 53 \\
Jun./Jul. & 1 & 16 & 9 & 2 & - & $28(+2)$ \\
Aug. & - & 3 & 16 & 6 & - & 25 \\
Sep. & - & 14 & 16 & 2 & 1 & $60(+1)$ \\
Nov. & - & 14 & 35 & 10 & 1 & $20(+1)$ \\
1964 Jan. & - & 4 & 15 & 1 & - & $21(+1)$ \\
Feb. & - & 16 & 5 & - & - & 47 \\
Jun. & 1 & 2 & 27 & 17 & - & $298(+6)=304$ \\
Totals & 2 & 94 & 149 & 50 & 3 & \\
\hline
\end{tabular}

PTERODROMA ALBA

\begin{tabular}{lrrrrrr} 
& \multicolumn{7}{c}{ LENGTH (CM) } \\
1963 Mar. & $0-2$ & $2-4$ & $4-6$ & $6-8$ & $8-10$ & TOTALs \\
May & - & 18 & 14 & 2 & 2 & $39(+3)$ \\
Jun./Jul. & - & 2 & - & - & 1 & $3(+8)$ \\
Aug. & - & 1 & 4 & 2 & 1 & $8(+3)$ \\
Sep. & - & 6 & 2 & 3 & - & $11(+10)$ \\
Nov. & - & - & 1 & 2 & 1 & $11(+1)$ \\
1964 Jan. & - & - & - & - & - & $0(+2)$ \\
Feb. & - & 13 & 33 & 10 & - & $56(+16)$ \\
Jun. & - & 4 & 12 & 3 & 2 & $21(+4)$ \\
Totals & 3 & 45 & 75 & 23 & 7 & $153(+48)=201$ \\
\hline
\end{tabular}


APPENDIX 2b (continued)

\begin{tabular}{|c|c|c|c|c|c|c|}
\hline \multicolumn{7}{|c|}{$S T E R N A$ FUSCATA } \\
\hline \multicolumn{7}{|c|}{ LENGTH (CM) } \\
\hline & $0-2$ & $2-4$ & $4-6$ & $6-8$ & $8-10$ & TOTALS \\
\hline 1963 Mar. & 3 & 79 & 68 & 23 & - & 173 \\
\hline May & - & - & - & - & 一 & 0 \\
\hline Jun./Jul. & 一 & 2 & 7 & 3 & - & $12(+3)$ \\
\hline Aug. & 1 & 22 & 81 & 19 & 2 & $125(+19)$ \\
\hline Sep. & 1 & 23 & 54 & 17 & - & $95(+9)$ \\
\hline Nov. & 一 & 2 & - & - & - & 2 \\
\hline 1964 Jan. & 一 & $\overline{1}$ & 6 & 2 & - & $9(+2)$ \\
\hline Feb. & 2 & 32 & 30 & 6 & - & $70(+1)$ \\
\hline Jun. & 1 & 5 & 6 & - & 一 & $12(+2)$ \\
\hline TOTALS & 8 & 166 & 252 & 70 & 2 & $498(+36)=534$ \\
\hline
\end{tabular}

ANOUS STOLIDUS

\begin{tabular}{lrrrrrr} 
& \multicolumn{7}{c}{ LENGTH (CM) } \\
1963 Mar. & $0-2$ & $2-4$ & $4-6$ & $6-8$ & \multicolumn{1}{c}{ TOtals } \\
May & - & - & 1 & 1 & 3 \\
Jun./Jul. & - & - & - & - & 0 \\
Aug. & - & - & - & - & $6(+1)$ \\
Sep. & - & - & - & - & 0 \\
Nov. & - & 2 & 7 & - & 9 \\
1964 Jan. & - & 9 & 4 & 2 & $15(+1)$ \\
Feb. & - & 1 & - & - & $1(+1)$ \\
Jun. & - & 3 & 7 & 6 & $16(+3)$ \\
Totals & 1 & 16 & 22 & 11 & $50(+6)=56$ \\
\hline
\end{tabular}

GYGIS ALBA

\begin{tabular}{|c|c|c|c|c|c|}
\hline \multicolumn{6}{|c|}{ LENGTH (CM) } \\
\hline & $0-2$ & $2-4$ & 4-6 & $6-8$ & TOTALS \\
\hline 1963 Mar. & 一 & - & - & 一 & $0(+1)$ \\
\hline May & - & - & 1 & - & 1 \\
\hline Jun./Jul. & - & - & - & - & 0 \\
\hline Aug. & - & - & 1 & - & 1 \\
\hline Sep. & - & 5 & 5 & 2 & 12 \\
\hline Nov. & 2 & 15 & 7 & 2 & 26 \\
\hline 1964 Jan. & - & 2 & 2 & - & $4(+1)$ \\
\hline Feb. & - & 71 & - & - & $71(+22)$ \\
\hline Jun. & 3 & 7 & 4 & - & $14(+1)$ \\
\hline TOTALS & 5 & 100 & 20 & 4 & $129(+25)=154$ \\
\hline
\end{tabular}


APPENDIX $2 b$ (continued)

\begin{tabular}{|c|c|c|c|c|c|}
\hline \multicolumn{6}{|c|}{ ANOUS TENUIROSTRIS } \\
\hline \multicolumn{6}{|c|}{ LENGTH (CM) } \\
\hline & $0-2$ & $2-4$ & $4-6$ & $6-8$ & TOTALS \\
\hline 1963 Mar. & - & 1 & 1 & - & 2 \\
\hline May & 1 & 4 & 3 & - & $8(+2)$ \\
\hline Jun./Jul. & 1 & 2 & 1 & - & $4(+2)$ \\
\hline Aug. & 1 & 2 & 2 & 1 & $6(+1)$ \\
\hline Sep. & 1 & 7 & - & - & $8(+3)$ \\
\hline Nov. & 1 & - & 2 & - & $3(+1)$ \\
\hline 1964 Jan. & - & 10 & 4 & - & $14(+1)$ \\
\hline Feb. & - & 2 & 2 & - & 4 \\
\hline Jun. & 1 & 3 & 2 & 3 & $9(+3)$ \\
\hline TOTALS & 6 & 31 & 17 & 4 & $58(+13)=71$ \\
\hline \multicolumn{6}{|c|}{ PROCELSTERNA CERULEA } \\
\hline \multicolumn{6}{|c|}{ LENGTH (CM) } \\
\hline & $0-2$ & $2-4$ & & & TOTALS \\
\hline 1963 Mar. & - & - & & & 0 \\
\hline May & 一 & - & & & $\mathbf{0}$ \\
\hline Jun./Jul. & 一 & - & & & 0 \\
\hline Aug. & 104 & 1 & & & 105 \\
\hline Sep. & 1 & - & & & 1 \\
\hline Nov. & 1 & - & & & $1(+1)$ \\
\hline 1964 Jan. & - & 一 & & & $0(+2)$ \\
\hline Feb. & 5 & 一 & & & $5(+3)$ \\
\hline Jun. & 5 & 一 & & & 5 \\
\hline TOTALS & 116 & 1 & & & $117(+6)=123$ \\
\hline
\end{tabular}


$\dagger$ Names of fish families, and their sequence and limits, follow Greenwood et al. (1966).

* Families marked with an asterisk are considered to be primarily reef-originating (see text); Tetraodontidae, Diodontidae and Type $\mathrm{X}$ are not assigned

to either the reef-originating or the pelagic category; among the Blenniidae Cirripectus sp. are considered reef-originating, while the others are not assigned.

1. Including 1 Psenes sp.

2. Including 1 Myctophus sp. ?, 1 Diaphus sp.

3. Approximately 70 Exocoetus volitans Linnaeus, 45 halfbeaks ("Hemiramphidae"), 1 Prognichthys sp., many of the remainder being Oxyporhamphus micropterus (Cuvier and Valenciennes).

4. Including 10 Holocentrus sp., 3 Holocentrus lacteoguttatus Cuvier, 3 Myrapristis sp.

5. Including 2 Anthias sp.

6. Including 4 Priacanthus cruentatus (Lacépède), 2 Priacanthus sp.

7. $\operatorname{Caranx} \mathrm{sp}$.

8. Coryphaena sp.

9. Caristium japonicus Gill and Smith.

10. Tholichthys larvae.

11. Sphyrna sp.

12. 4 Halichoeres trimaculatus (Quoy and Gaimard), 2 Cymolutes praetextatus (Quoy and Gaimard).

13. 146 Cirripectus sp., 23 Petroscirtes mitratus Rüppell, 30 Aspidontus filamentosus (Cuvier and Valenciennes), 15 Runula tapeinosoma (Bleeker).

14. Including 4 Acronurus larvae.

15. Probably all Gempylus serpens Cuvier and Valenciennes.

16. Most Katsuwonus pelamis (Linnaeus); few Neothunnus macropterus (Temminck and Schlegel), Thunnus germo (Lacépède) and Acanthocybium solandri (Cuvier).

17. Including 1 Lycocephalus sp.

18. Including 3 Diodon sp.

19. Type $\mathrm{X}$ were a distinct group of small fish whose identity has still not been determined. 
Appendix 4. Cephalopods in the Diets of the Birds

\begin{tabular}{|c|c|c|c|c|c|c|}
\hline \multirow[t]{2}{*}{$\begin{array}{c}\text { BIRD } \\
\text { SPECIES } \\
\end{array}$} & \multirow[t]{2}{*}{$\begin{array}{l}\text { NUMBER OF } \\
\text { SQUID } \\
\text { EXAMINED } \\
\end{array}$} & \multicolumn{2}{|c|}{$\begin{array}{l}\text { IDENTIFIED TO } \\
\text { FAMILY }\end{array}$} & \multirow{2}{*}{$\begin{array}{c}\text { OMMASTREPHIDAE } \\
\text { IDENTIFIED TO } \\
\text { GENUS }\end{array}$} & \multicolumn{2}{|c|}{$\begin{array}{l}\text { OMMASTREPHIDAE } \\
\text { IDENTIFIED TO } \\
\text { SPECIES }\end{array}$} \\
\hline & & Ommastrephidae & $\begin{array}{l}\text { Other } \\
\text { families }\end{array}$ & & $\begin{array}{l}\text { Symple } \\
\text { sp. A }\end{array}$ & $\begin{array}{l}\text { toteuthis } \\
\text { sp. B }\end{array}$ \\
\hline $\begin{array}{l}\text { Phaethon } \\
\quad \text { rubricauda }\end{array}$ & 54 & 53 & $1^{d}$ & $\begin{array}{c}34 \\
(47)\end{array}$ & $\begin{array}{c}4 \\
(15)\end{array}$ & $\begin{array}{c}3 \\
(10)\end{array}$ \\
\hline $\begin{array}{l}\text { Puffinus } \\
\text { nativitatis }\end{array}$ & 150 & $\begin{array}{c}93 \\
(134)\end{array}$ & 0 & $\begin{array}{c}32 \\
(43)\end{array}$ & $\begin{array}{c}19 \\
(24)\end{array}$ & $\begin{array}{c}1 \\
(2)\end{array}$ \\
\hline $\begin{array}{l}\text { Pterodroma } \\
\quad \text { alba }\end{array}$ & $71^{\circ}$ & $\begin{array}{c}17 \\
(48)\end{array}$ & 0 & 5 & 4 & 0 \\
\hline $\begin{array}{l}\text { Sterna } \\
\quad \text { fuscata }\end{array}$ & $430^{4}$ & $\begin{array}{c}379 \\
(419)\end{array}$ & 0 & $\begin{array}{c}300 \\
(337)\end{array}$ & $\begin{array}{c}186 \\
(277)\end{array}$ & $\begin{array}{c}16 \\
(17)\end{array}$ \\
\hline $\begin{array}{l}\text { Anous } \\
\text { stolidus }\end{array}$ & 10 & 10 & 0 & $\stackrel{4}{4}$ & 3 & 1 \\
\hline $\begin{array}{l}\text { Gygis } \\
\text { alba }\end{array}$ & 15 & 14 & 18 & 13 & 13 & 0 \\
\hline $\begin{array}{l}\text { Anous } \\
\quad \text { tenuirostris }\end{array}$ & 34 & $\begin{array}{c}24 \\
(32)\end{array}$ & $\mathbf{0}$ & $\begin{array}{c}12 \\
(20)\end{array}$ & 8 & 0 \\
\hline $\begin{array}{l}\text { Procelsterna } \\
\text { cerulea }\end{array}$ & 105 & $76^{h}$ & $2^{i}$ & 0 & 0 & 0 \\
\hline TOTALS & 869 & $\begin{array}{c}666 \\
(786)\end{array}$ & 4 & $\begin{array}{r}400 \\
(472)\end{array}$ & $\begin{array}{c}237 \\
(344)\end{array}$ & $\begin{array}{c}21 \\
(30)\end{array}$ \\
\hline
\end{tabular}

NOTES:

a. This table is based on the squid collected in the period March through September 1963. The identifications were made by Dr. Malcolm Clarke, of the National Institute of Oceanography, England. The figures in parentheses include those squid which were only tentatively identified.

b. Only squid represented by mantle and/or head are included in the table; isolated lenses, beaks, arms or pens are omitted.

c. For discussion of Symplectoteuthis species A and species B see Species Accounts: Phaethon rubricauda.

d. Histioteuthidae?

e. In addition, some remains of other cephalopods were found in samples from Pterodroma alba: see Species Accounts.

f. In addition, one small Argonauta sp. (Octopoda) was found.

g. Abralia sp. (Enoploteuthidae).

h. Of these 53 (from a single sample) were Rhynchoteuthis larvae, probably of one of the Symplectoteuthis species.

i. Loligo sp. (Loliginidae). 
Appendix 5. Detalls of the Stomach Contents of 191 Yellowfin Tuna

(NeOthunNus macropterus), CaUght by SURFaCe-Trolling

Within 10 Miles of Christmas, JaRvis, Washington aNd FANNING IsLaNDS (Line IsLands)

\begin{tabular}{|c|c|c|c|}
\hline & NUMBER & VOLUME (ml) & $\begin{array}{l}\text { NUMBER OF SAMPLES } \\
\text { CONTAINING }\end{array}$ \\
\hline \multicolumn{4}{|l|}{ OVERALL COMPOSITION } \\
\hline Fish & 1161 & 3774.2 & 151 \\
\hline Squid $\dagger$ & 324 & 586.0 & 91 \\
\hline Other invertebrates & 34768 & 6806.5 & 161 \\
\hline \multicolumn{4}{|l|}{ FISH } \\
\hline *Congridae & 5 & 2.2 & 3 \\
\hline *Synodontidae & 1 & 2.0 & 1 \\
\hline Myctophidae & 16 & 47.0 & 6 \\
\hline Exocoetidae & 1 & 30.0 & 1 \\
\hline *Syngnathidae & 3 & 1.0 & 1 \\
\hline *Priacanthidae & 2 & 2.0 & 1 \\
\hline${ }^{*}$ Carangidae & 17 & 2070.0 & 9 \\
\hline Bramidae & 14 & 12.3 & 8 \\
\hline *Lutianidae & 3 & 4.0 & 3 \\
\hline *Chaetodontidae & 7 & 3.5 & 3 \\
\hline *Polynemidae & 1 & 2.0 & 1 \\
\hline Blenniidae & 37 & 27.0 & 10 \\
\hline *Acanthuridae & 524 & 352.2 & 43 \\
\hline Gempylidae & 2 & 5.0 & 2 \\
\hline Scombridae & 3 & 2.0 & 1 \\
\hline *Balistidae & 14 & 11.0 & 12 \\
\hline *Ostraciontidae & 39 & 47.0 & 20 \\
\hline Tetraodontidae & 3 & 202.0 & 3 \\
\hline Molidae & 1 & 520.0 & 1 \\
\hline TOTAL IDENTIFIED & 693 & 3342.2 & \\
\hline
\end{tabular}

$\dagger$ Four small octopods included.

* Families marked with an asterisk are considered to be primarily reef-originating (see text); Tetraodontidae and Blenniidae are not assigned to either the reef-originating or the pelagic category. 